\title{
MARCIO BERNARDO
}

Avaliação comparativa do desempenho térmico de painéis de Light Steel Frame préfabricados para uso em construções modulares

São Paulo 


\section{MARCIO BERNARDO}

Avaliação comparativa do desempenho térmico de painéis de Light Steel Frame préfabricados para uso em construções modulares

Dissertação apresentada à Escola Politécnica da Universidade de São Paulo para a obtenção do título de Mestre em Ciências

Orientadora: $\quad$ Prof. $^{\text {a }}$ Dr $^{\mathrm{a}}$. Brenda Chaves Coelho Leite

São Paulo 


\section{MARCIO BERNARDO}

Avaliação comparativa do desempenho térmico de painéis de Light Steel Frame préfabricados para uso em construções modulares

Dissertação apresentada à Escola Politécnica da Universidade de São Paulo para a obtenção do título de Mestre em Ciências

Área de Concentração: Inovação na Construção Civil

Orientadora: Prof. ${ }^{\mathrm{a}}$. Dra ${ }^{\mathrm{a}}$. Brenda Chaves Coelho Leite

São Paulo 
Este exemplar foi revisado e corrigido em relação à versão original, sob responsabilidade única do autor e com a anuência de seu orientador.

São Paulo, de de

Assinatura do autor:

Assinatura do orientador:

\section{Catalogação-na-publicação}

Bernardo, Marcio

Avaliação comparativa do desempenho térmico de painéis de Light Steel Frame pré-fabricados para uso em construções modulares / M. Bernardo -versão corr. -- São Paulo, 2017.

$$
95 \mathrm{p} \text {. }
$$

Dissertação (Mestrado) - Escola Politécnica da Universidade de São Paulo. Departamento de Engenharia de Construção Civil.

1.Painéis Sandwich 2.Avaliação de Desempenho 3.Desempenho de Materiais de Construção I.Universidade de São Paulo. Escola Politécnica. Departamento de Engenharia de Construção Civil II.t. 
BERNARDO, M.B. Avaliação comparativa do desempenho térmico de painéis de Light Steel Frame pré-fabricados para uso em construções modulares. São Paulo. 2017.

Mestrado. Escola Politécnica, Universidade de São Paulo, São Paulo, 2017. 
Dedico todo esforço empenhado e também todo conhecimento e enriquecimento pessoal e profissional adquirido à minha família, que sempre me fez acreditar na minha capacidade de alcançar tudo aquilo que eu viesse a desejar e sonhar 


\section{AGRADECIMENTOS}

Agradeço à minha família, e em especial meus pais e minha irmã Margareth Cristina Bernardo por sempre me apoiar e acreditar em meu potencial. Também sou muito grato a todos os professores que ao longo desta jornada passaram e deixaram um pouco de si e seus conhecimento em nossas vidas, contribuindo com muito conhecimento; em especial, à minha Orientadora $\mathrm{Dr}^{\mathrm{a}}$ Brenda Chaves Coelho Leite pela oportunidade que me foi concedida e por toda paciência e compreensão disposta ao longo do caminho. Muito obrigado. 
Tenha coragem de seguir seu coração e intuição, de alguma forma eles já sabem o que você realmente quer se tornar.

Cada sonho que você deixa para trás, é um pedaço do seu futuro que deixa de existir.

Steve Jobs 


\section{RESUMO}

As evoluções tecnológicas juntamente com o surgimento de novas necessidades dos usuários resultaram em diversos novos tipos de métodos construtivos. O conceito de industrialização das edificações vem evoluindo com velocidade, e estes novos sistemas construtivos surgiram como alternativa aos sistemas tradicionais buscando entre outros, melhor desempenho térmico, energético, lumínico, acústico e de sustentabilidade. Diante desta crescente demanda por inovação, a ABNT (Associação Brasileira de Normas Técnicas) passou a estudar um conjunto de normas para estabelecer critérios de desempenho ao validar os novos sistemas construtivos de edificações habitacionais. Isto se concretizou com a publicação da Norma de Desempenho (ABNT NBR 15575/2013), que estipula parâmetros para desempenho dessas construções e métodos detalhados de acordo com o desempenho desejado. Simultaneamente, as simulações computacionais evoluíram, permitindo menor custo de experimentação, são capazes de antecipar resultados antes somente possíveis após testes físicos com protótipos e também a encontrar alternativas de soluções também quanto à eficiência energética e ao conforto dos usuários. Entre alguns programas existentes para simulação de desempenho térmico, está o EnergyPlus, o qual foi utilizado para este estudo, tendo como principal objetivo avaliar o desempenho térmico de painéis de light steel frame pré-fabricados utilizados na fachada e nas vedações internas de um sistema construtivo modular composto por estrutura metálica, e piso e a laje de concreto. Para o desenvolvimento do estudo, foi utilizado como modelo base uma residência térrea, configurada por ambientes independentes, que virão a compor uma residência inteira onde serão inseridos os painéis de light steel frame pré-fabricados. As 16 tipologias de painéis foram estudadas em três diferentes cidades do Brasil, sendo elas situadas nas regiões Nordeste, Sudeste e Sul e em dias típicos de verão e inverno, utilizando os recursos de simulação computacional (EnergyPlus) possibilitando a análise comparativa de desempenho térmico de cada tipologia ao serem submetidos a diferentes temperaturas e regime de insolação. A maioria das tipologias de painéis apresentam resultados favoráveis apenas para a cidade de Fortaleza, e desfavoráveis para as cidades de São Paulo e Curitiba, onde somente a última tipologia de painel atendeu os requisitos mínimos de desempenho para todas as cidades. Este estudo não contempla dados experimentais ou ensaios físicos.

Palavras-Chave: Painéis de light steel frame pré-fabricados. Avaliação de desempenho. Desempenho térmico. Energyplus. Simulação computacional. Construção modular. 


\begin{abstract}
Technological developments coupled with the emergence of new user needs resulted in several types of new construction methods. The concept of building industrialization has been evolving with speed, and these new construction systems have emerged as an alternative to traditional systems. These alternative systems seek better thermal performance, energy efficiency, light performance, acoustic and sustainability, among other things. Faced with this growing demand for innovation, ABNT (Brazilian Technical Standards Association) went on to study a set of rules to establish performance criteria to validate the new construction systems of residential buildings. These criteria were established with the publication of Performance Standard (NBR 15575/2013), which provides detailed parameters for performance of these buildings and provides methods according to the desired performance. At the same time, computer simulations have evolved, allowing lower cost of experimentation. These simulations are able to anticipate results which were previously only possible after physical tests of prototypes and also are able to find alternative solutions for energy efficiency and comfort of users. Among some existing programs for simulating thermal performance is the EnergyPlus, which was used for this study, with the primary objective of evaluating the thermal performance of prefabricated light steel frame panels. These panels were used in the facade and the internal seals of a building system composed of modular steel structure and floor and the concrete slab. To develop the study, a one-story residence was used as a base model, set by independent environments, composed entirely of the prefabricated light steel frame panels. The 16 panel types were studied in three different cities in Brazil, located in the Northeast, Southeast and South, and on a typical day of summer and winter. Using the computer simulation resources (EnergyPlus) enabled comparative analysis of thermal performance of each type when subjected to different temperatures and insolation regime. Most panel types have favorable results only in the city of Fortaleza, and unfavorable in the cities of São Paulo and Curitiba, whereas only the last panel type met the minimum performance requirements for all cities. This study does not include experimental data or physical tests.
\end{abstract}

Keywords: Prefabricated light steel frame panels, Evaluation of performance, Thermal performance, Energyplus, Computer simulation, Modular construction. 


\section{LISTA DE ILUSTRAÇÕES}

\begin{tabular}{|c|c|c|c|}
\hline Figura 1 & - & Métodos alternativos de avaliação do desempenho térmico & 22 \\
\hline Figura 2 & - & $\begin{array}{l}\text { Fluxograma esquemático de entendimento por parte do autor do } \\
\text { surgimento, evolução e ligação dos temas }\end{array}$ & 24 \\
\hline Figura 3 & - & $\begin{array}{l}\text { Planta, elevação e detalhe de montagem da estrutura do sistema de } \\
\text { light steel frame }\end{array}$ & 27 \\
\hline Figura 4 & - & $\begin{array}{l}\text { Detalhe genérico das camadas de materiais que normalmente } \\
\text { compõem painéis de light steel frame }\end{array}$ & 28 \\
\hline Tabela 1 & - & Metodologia detalhada da $1^{\mathrm{a}}$ fase & 31 \\
\hline Figura 5 & - & Detalhe ilustrativo do painel 1 & 32 \\
\hline Figura 6 & - & Detalhe ilustrativo do painel 2 & 32 \\
\hline Figura 7 & - & Detalhe ilustrativo do painel 3 & 33 \\
\hline Figura 8 & - & Detalhe ilustrativo do painel 4 & 33 \\
\hline Figura 9 & - & Detalhe ilustrativo do painel 5 & 34 \\
\hline Figura 10 & - & Detalhe ilustrativo do painel 6 & 34 \\
\hline Tabela 2 & - & Metodologia detalhada da $2^{\mathrm{a}}$ fase & 35 \\
\hline Figura 11 & - & Detalhe ilustrativo do painel 7 & 36 \\
\hline Figura 12 & - & Detalhe ilustrativo do painel 8 & 36 \\
\hline Figura 13 & - & Detalhe ilustrativo do painel 9 & 37 \\
\hline Figura 14 & - & Detalhe ilustrativo do painel 10 & 37 \\
\hline Figura 15 & - & Detalhe ilustrativo do painel 11 & 38 \\
\hline Figura 16 & - & Detalhe ilustrativo do painel 12 & 38 \\
\hline Tabela 3 & - & Metodologia detalhada da $3^{\mathrm{a}}$ fase & 39 \\
\hline Figura 17 & - & $\begin{array}{l}\text { Detalhe ilustrativo do painel } 4.1 \text { com uma placa de gesso retirada da } \\
\text { face interna }\end{array}$ & 41 \\
\hline Figura 18 & - & $\begin{array}{l}\text { Detalhe ilustrativo do painel } 4.2 \text { com uma placa cimentícia retirada } \\
\text { da face externa }\end{array}$ & 41 \\
\hline Tabela 4 & - & Metodologia detalhada da $4^{\mathrm{a}}$ fase & 42 \\
\hline Figura 19 & - & $\begin{array}{l}\text { Detalhe ilustrativo do painel } 4.3 \text { com mais uma placa de gesso } \\
\text { adicionada na face interna }\end{array}$ & 44 \\
\hline
\end{tabular}




\begin{tabular}{|c|c|c|c|}
\hline Figura 20 & - & $\begin{array}{l}\text { Detalhe ilustrativo do painel } 4.4 \text { com mais uma placa cimentícia } \\
\text { adicionada na face externa }\end{array}$ & 44 \\
\hline Tabela 5 & - & Metodologia detalhada da $5^{\mathrm{a}}$ fase & 45 \\
\hline Figura 21 & - & $\begin{array}{l}\text { Detalhe ilustrativo do painel } 4 \text { inicial reutilizado na } 5^{\text {a }} \text { fase de } \\
\text { simulação com parâmetros modificados }\end{array}$ & 46 \\
\hline Figura 22 & - & Planta tipo da residência & 48 \\
\hline Figura 23 & - & Corte da residência & 48 \\
\hline Figura 24 & - & Vista da cobertura da residência & 49 \\
\hline Figura 25 & - & Ilustração da cobertura da residência & 49 \\
\hline Figura 26 & - & Ilustração da face frontal da residência voltada ao norte & 50 \\
\hline Figura 27 & - & Ilustração da face sul da residência & 50 \\
\hline Figura 28 & - & Ilustração da face leste da residência & 50 \\
\hline Figura 29 & - & Ilustração da face oeste da residência & 51 \\
\hline Figura 30 & - & Ilustração em perspectiva da residência & 51 \\
\hline Figura 31 & - & Delimitação das zonas térmicas da residência & 52 \\
\hline Figura 32 & - & $\begin{array}{l}\text { Ilustração da residência indicando posicionamento crítico dos } \\
\text { ambientes no verão e no invernos conforme orientações da ABNT } \\
\text { NBR 15575-1/2013 }\end{array}$ & 53 \\
\hline Figura 33 & - & $\begin{array}{l}\text { Ilustração da residência indicando posicionamento e tipos de } \\
\text { acabamentos dos painéis }\end{array}$ & 54 \\
\hline Tabela 6 & - & Propriedades termofísicas dos elementos construtivos da residência & 55 \\
\hline Tabela 7 & - & $\begin{array}{l}\text { Critérios de avaliação do desempenho térmico para condições de } \\
\text { verão }\end{array}$ & 56 \\
\hline Tabela 8 & - & $\begin{array}{l}\text { Critérios de avaliação do desempenho térmico para condições de } \\
\text { inverno }\end{array}$ & 56 \\
\hline Tabela 9 & - & $\begin{array}{l}\text { Critérios de cores utilizadas para análise comparativa dos resultados } \\
\text { e nível de desempenho dos painéis por ambiente }\end{array}$ & 57 \\
\hline Figura 34 & - & $\begin{array}{l}\text { Ilustração ilustrativa das faces norte e oeste às 9:00h do dia 21/12 } \\
\text { utilizado como dia típico de verão em Fortaleza-CE - Fuso horários } \\
\text { (UTC-3) }\end{array}$ & 57 \\
\hline
\end{tabular}




\begin{tabular}{|c|c|c|c|}
\hline Figura 35 & - & $\begin{array}{l}\text { Ilustração das faces sul e leste às 9:00h do dia 21/12 utilizado como } \\
\text { dia típico de verão em Fortaleza-CE - Fuso horário de Brasília } \\
\text { (UTC-3) }\end{array}$ & 58 \\
\hline Figura 36 & - & $\begin{array}{l}\text { Ilustração das faces norte e oeste às 15:00h do dia 21/12 utilizado } \\
\text { como dia típico de verão em Fortaleza-CE - Fuso horário de } \\
\text { Brasília (UTC-3) }\end{array}$ & 58 \\
\hline Figura 37 & - & $\begin{array}{l}\text { Ilustração das faces sul e leste às 15:00h do dia 21/12 utilizado } \\
\text { como dia típico de verão em Fortaleza-CE - Fuso horário de } \\
\text { Brasília (UTC-3) }\end{array}$ & 58 \\
\hline Figura 38 & - & $\begin{array}{l}\text { Ilustração das faces norte e oeste às 09:00h do dia 21/07 utilizado } \\
\text { como dia típico de inverno para as cidades - Fuso horário de } \\
\text { Brasília (UTC-3) }\end{array}$ & 59 \\
\hline Figura 39 & - & $\begin{array}{l}\text { Ilustração das faces sul e leste às 09:00h do dia 21/07 utilizado } \\
\text { como dia típico de inverno para as } 3 \text { cidades - Fuso horário de } \\
\text { Brasília (UTC-3) }\end{array}$ & 59 \\
\hline Figura 40 & - & $\begin{array}{l}\text { Ilustração das faces norte e oeste às 15:00h do dia 21/07 utilizado } \\
\text { como dia típico de inverno para as } 3 \text { cidades - Fuso horário de } \\
\text { Brasília (UTC-3) }\end{array}$ & 59 \\
\hline Figura 41 & - & $\begin{array}{l}\text { Ilustração das faces sul e leste às 15:00h do dia 21/07 utilizado } \\
\text { como dia típico de inverno para as 3cidades - Fuso horário de } \\
\text { Brasília (UTC-3) }\end{array}$ & 60 \\
\hline Figura 42 & - & $\begin{array}{l}\text { Ilustração das faces norte e oeste às 09:00h do dia 21/02 utilizado } \\
\text { como dia típico de verão para as cidades de São Paulo-SP e } \\
\text { Curitiba-PR - Fuso horário de Brasília (UTC-3) }\end{array}$ & 60 \\
\hline Figura 43 & - & $\begin{array}{l}\text { Ilustração das faces sul e leste às 09:00h do dia 21/02 utilizado } \\
\text { como dia típico de verão para as cidades de São Paulo-SP e } \\
\text { Curitiba-PR - Fuso horário de Brasília (UTC-3) }\end{array}$ & 60 \\
\hline Figura 44 & - & $\begin{array}{l}\text { Ilustração das faces norte e oeste às 15:00h do dia 21/02 utilizado } \\
\text { como dia típico de verão para as cidades de São Paulo-SP e } \\
\text { Curitiba-PR - Fuso horário de Brasília (UTC-3) }\end{array}$ & 61 \\
\hline
\end{tabular}




\begin{tabular}{|c|c|c|c|}
\hline Figura 45 & - & $\begin{array}{l}\text { Ilustração das faces sul e leste às 15:00h do dia 21/02 utilizado } \\
\text { como dia típico de verão para as cidades de São Paulo-SP e } \\
\text { Curitiba-PR - Fuso horário de Brasília (UTC-3) }\end{array}$ & 61 \\
\hline Figura 46 & - & $\begin{array}{l}\text { Resultados das simulações dos painéis no ambiente da sala nas } \\
\text { condições e dia típico de verão para a cidade de Fortaleza-CE }\end{array}$ & 63 \\
\hline Figura 47 & - & $\begin{array}{l}\text { Resultados das simulações dos painéis no ambiente do dormitório } 1 \\
\text { nas condições e dia típico de inverno para a cidade de Fortaleza-CE }\end{array}$ & 65 \\
\hline Figura 48 & - & $\begin{array}{l}\text { Resultados das simulações dos painéis no ambiente da sala nas } \\
\text { condições e dia típico de verão para a cidade de São Paulo-SP }\end{array}$ & 67 \\
\hline Figura 49 & - & $\begin{array}{l}\text { Resultados das simulações dos painéis no ambiente do dormitório } 1 \\
\text { nas condições e dia típico de inverno para a cidade de São Paulo-SP }\end{array}$ & 69 \\
\hline Figura 50 & - & $\begin{array}{l}\text { Resultados das simulações dos painéis no ambiente da sala nas } \\
\text { condições e dia típico de verão para a cidade de Curitiba-PR }\end{array}$ & 71 \\
\hline Figura 51 & - & $\begin{array}{l}\text { Resultados das simulações dos painéis no ambiente do dormitório } 1 \\
\text { nas condições e dia típico de inverno para a cidade de Curitiba-PR }\end{array}$ & 73 \\
\hline Tabela 10 & - & $\begin{array}{l}\text { Resultados das temperaturas para análise comparativa e escolha de } \\
\text { uma das tipologias de painéis de } 1 \text { à } 12 \text { a ser utilizada nas demais } \\
\text { simulações }\end{array}$ & 75 \\
\hline Tabela 11 & - & $\begin{array}{l}\text { Resultados de temperaturas para análise comparativa das tipologias } \\
\text { de painéis } 4.1 \text { e } 4.2\end{array}$ & 76 \\
\hline Tabela 12 & - & $\begin{array}{l}\text { Resultados de temperaturas das } 3 \text { cidades para análise comparativa } \\
\text { da tipologia de painel } 4.3\end{array}$ & 77 \\
\hline Tabela 13 & - & $\begin{array}{l}\text { Resultados de temperaturas para análise comparativa do painel } 4.4 \\
\text { com a adição de mais uma placa cimentícia na face externa }\end{array}$ & 78 \\
\hline Figura 52 & - & $\begin{array}{l}\text { Resultados das simulações com novo critério para os dias típicos de } \\
\text { verão utilizando a tipologia de painel } 4 \text { inicial para as } 3 \text { cidades }\end{array}$ & 79 \\
\hline Figura 53 & & $\begin{array}{l}\text { Resultados das simulações com novo critério para os dias típicos de } \\
\text { inverno utilizando a tipologia de painel } 4 \text { inicial para as } 3 \text { cidades }\end{array}$ & 81 \\
\hline Tabela 14 & - & $\begin{array}{l}\text { Status de conclusão dos níveis de desempenhos de todas as } \\
\text { tipologias de painéis estudados nos dias típicos de verão (sala - zona } \\
\text { térmica } 2 \text { ) e inverno (dormitório } 1 \text { - zona térmica 5) nas } 3 \text { cidades }\end{array}$ & 83 \\
\hline
\end{tabular}




\begin{tabular}{l|l|l|l}
\hline Tabela 15 & - & $\begin{array}{l}\text { Status dos níveis de desempenhos de todos as tipologias de painéis } \\
\text { estudados no ambiente da cozinha (zona térmica 1) nas 3 cidades }\end{array}$ & 91 \\
\hline Tabela 16 & - & $\begin{array}{l}\text { Status dos níveis de desempenhos de todos as tipologias de painéis } \\
\text { estudados no ambiente do dormitório 2 (zona térmica 3) nas 3 } \\
\text { cidades }\end{array}$ & 92 \\
\hline Tabela 17 & - & $\begin{array}{l}\text { Status dos níveis de desempenhos de todos as tipologias de painéis } \\
\text { estudados no ambiente do banheiro (zona térmica 4) nas 3 cidades }\end{array}$ & 93 \\
\hline Tabela 18 & - & $\begin{array}{l}\text { Status dos níveis de desempenhos de todos as tipologias de painéis } \\
\text { estudados no ambiente da lavanderia (zona térmica 6) nas 3 cidades }\end{array}$ & 94 \\
\hline Tabela 19 & - & $\begin{array}{l}\text { Resultados de temperaturas mínimas e máximas com todos as } \\
\text { tipologias de painéis estudados na área da cobertura (zona térmica } \\
\text { 7) nas 3 cidades }\end{array}$ & 95 \\
\hline
\end{tabular}


INTRODUÇAO E JUSTIFICATIVA $\ldots \ldots \ldots \ldots \ldots \ldots \ldots \ldots \ldots$

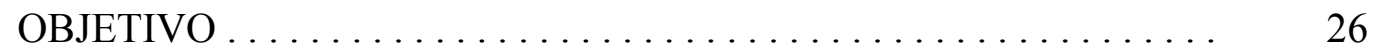

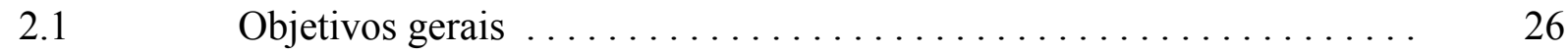

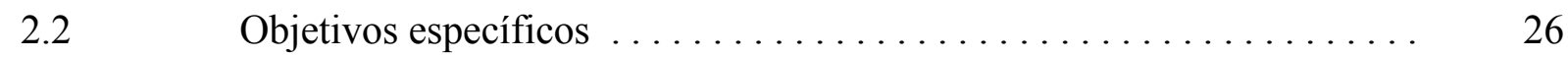

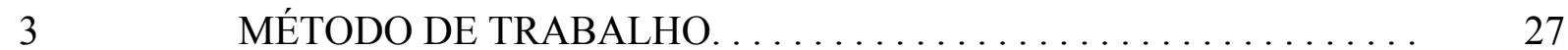

$3.1 \quad$ Descrição do modelo de painel estudado . . . . . . . . . . . 27

3.2 Descrição inicial das metodologias . . . . . . . . . . . . . . . 29

$3.3 \quad$ Metodologia detalhada da $1^{\text {a }}$ fase $\ldots \ldots \ldots \ldots \ldots \ldots \ldots \ldots \ldots$

3.3.1 Tipologias de painéis da $1^{\mathrm{a}}$ fase $\ldots \ldots \ldots \ldots \ldots \ldots \ldots \ldots \ldots \ldots \ldots \ldots \ldots \ldots \ldots$

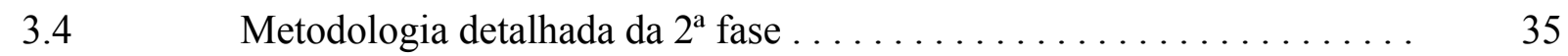

3.4.1 Tipologias de painéis da $2^{\mathrm{a}}$ fase $\ldots \ldots \ldots \ldots \ldots \ldots \ldots \ldots \ldots \ldots \ldots \ldots \ldots \ldots$

$3.5 \quad$ Metodologia detalhada da $3^{\text {a }}$ fase $\ldots \ldots \ldots \ldots \ldots \ldots \ldots \ldots \ldots \ldots \ldots$

3.5.1 Tipologias de painéis da $3^{\text {a }}$ fase $\ldots \ldots \ldots \ldots \ldots \ldots \ldots \ldots \ldots \ldots \ldots \ldots \ldots \ldots \ldots$

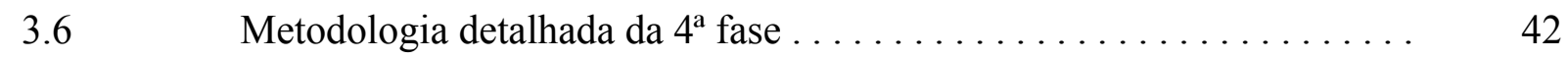

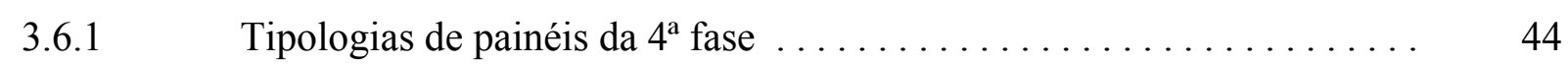

$3.7 \quad$ Metodologia detalhada da $5^{\mathrm{a}}$ fase $\ldots \ldots \ldots \ldots \ldots \ldots \ldots \ldots \ldots$

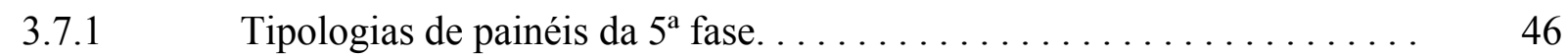

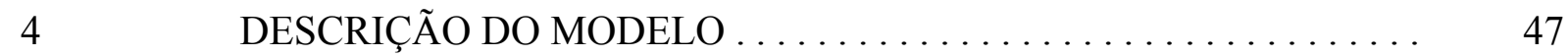

4.1 Características do modelo residencial a ser utilizado nas simulações. . . $\quad 47$

Forma de análise dos resultados $\ldots \ldots \ldots \ldots \ldots \ldots \ldots \ldots \ldots \ldots \ldots$

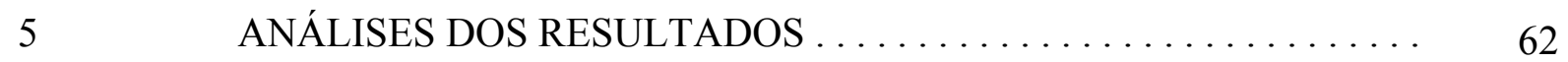

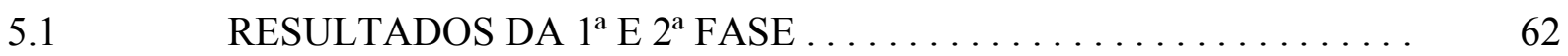

5.1.1 Resultados das simulações para o dia típico de verão em Fortaleza . . . . 63

5.1.2 Resultados das simulações para o dia típico de inverno em Fortaleza . . . 65

5.1.3 Resultados das simulações para o dia típico de verão em São Paulo . . . . 67

5.1.4 Resultados das simulações para o dia típico de inverno em São Paulo . . 69

5.1.5 Resultados das simulações para o dia típico de verão em Curitiba . . . . . 71

5.1.6 Resultados das simulações para o dia típico de inverno em Curitiba . . . 73

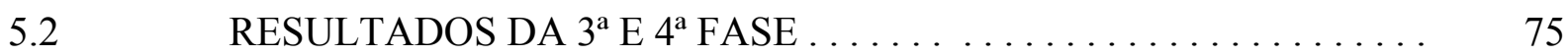

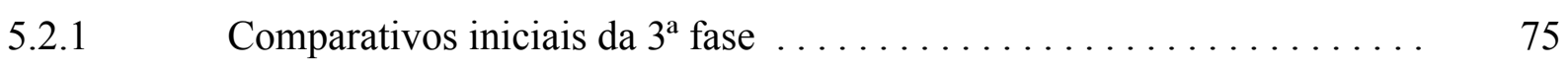


5.2.2 Comparativos dos painéis 4.1 e 4.2 da $3^{\text {a }}$ fase $\ldots \ldots \ldots \ldots \ldots \ldots$

5.2.3 Comparativos do painel 4.3 da $4^{\text {a }}$ fase $\ldots \ldots \ldots \ldots \ldots \ldots \ldots$

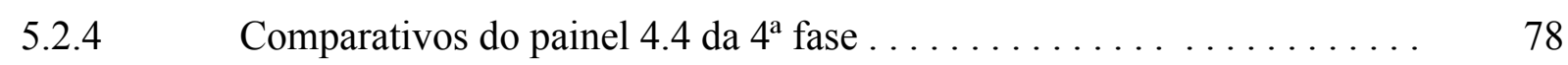

$5.3 \quad$ RESULTADOS DA $5^{\text {a FASE } \ldots \ldots \ldots \ldots \ldots \ldots \ldots \ldots \ldots \ldots \ldots \ldots \ldots \ldots} 79 \ldots \ldots \ldots$

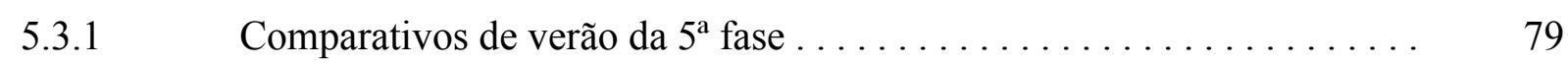

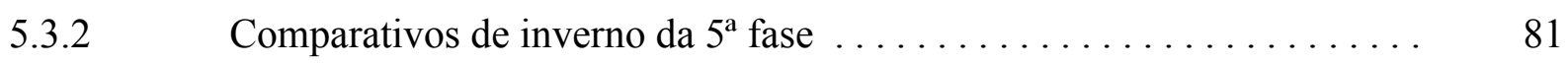

5.3.3 Análise dos resultados com relação às condições de conforto térmico $\quad 82$

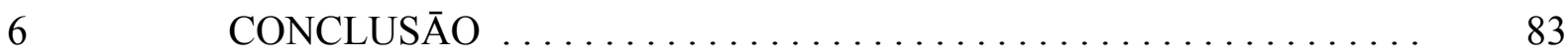

$7 \quad$ SUGESTÕES DE TRABALHOS FUTUROS $\ldots \ldots \ldots \ldots \ldots \ldots \ldots$

REFERÊNCIAS BIBLIOGRÁFICAS .............. 89

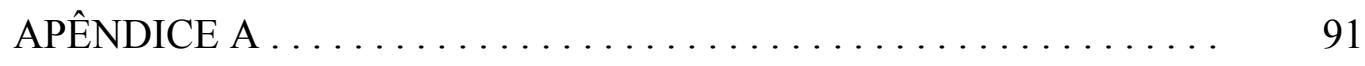




\section{INTRODUÇÃO E JUSTIFICATIVA}

Nos últimos 25 anos, a tecnologia construtiva mudou significativamente, assim como os hábitos e necessidade dos usuários, que se tornaram mais sofisticados, complexos e difíceis de serem atingidos (BORGES, 2008).

Entre estas inovações houve o surgimento de pré-fabricados, porém, segundo VASCONCELLOS (2002), não se pode precisar a data em que começou a pré-moldagem. O próprio nascimento do concreto armado ocorreu com a pré-moldagem de elementos, fora do local de seu uso. Sendo assim, o termo pré-fabricação no campo da construção civil possui o seguinte significado: "fabricação de certo elemento antes do seu posicionamento final na obra" (REVEL, 1973).

Segundo REVEL (1973), a pré-fabricação em seu sentido mais geral se aplica a toda fabricação de elementos de construção civil em indústrias, a partir de matérias primas e semi-produtos cuidadosamente escolhidos e utilizados, sendo em seguida estes elementos transportados à obra onde ocorre a montagem da edificação.

Conforme ORDONÉZ (1974), foi no período pós Segunda Guerra Mundial, principalmente na Europa, que começou, verdadeiramente, a história da pré-fabricação como "manifestação mais significativa da industrialização na construção", e que a utilização intensiva do pré-fabricado se deu em função da necessidade de se construir em grande escala.

A pré-fabricação pode estar presente separadamente em alguns casos, onde somente alguns elementos de uma obra podem ser pré-fabricados e outros não. O conceito de "elementos préfabricados" é definido pela ABNT NBR 15575-1/2013 como parte de um sistema com funções específicas. Geralmente é composto por um conjunto de componentes (exemplo: parede de vedação de alvenaria, painel de vedação pré-fabricado, estrutura de cobertura).

Em outros casos, todo o sistema construtivo pode ser pré-fabricado, onde sistema é definido pela ABNT NBR 15575-1/2013 como a maior parte funcional do edifício, isto é, o conjunto de elementos e componentes destinados a cumprir com um macro que a define (exemplo: fundação, estrutura, vedações verticais, instalações hidro sanitárias, coberturas).

Com a necessidade de reconstrução das cidades, registrada no período pós-guerra, a coordenação modular veio a se consolidar, principalmente na Europa, por consistir em um sistema capaz de racionalizar e ordenar a fabricação de qualquer componente, desde o projeto até o produto final. Entendida como uma ordenadora de espaços, a coordenação modular permite relacionar as medidas de projeto com as medidas da produção industrial, sem abandonar 
as questões da composição geométrica e de proporções. Por meio dela, criam-se critérios para a definição de dimensões e a explicitação da conectividade entre os componentes. A ordenação e a racionalização se efetivam por meio de uma medida de referência denominada módulo, o qual deve ser respeitado em todos os espaços e componentes do projeto (BARBOZA et al., 2008; GREVEN; BALDAUF, 2007).

Segundo a Fundação Getúlio Vargas (2014), a coordenação modular é considerada um dos pilares para a industrialização na construção. Esta relação entre pré-fabricados e coordenação modular, que visa promover a intercambialidade entre os elementos, são as duas principais diretrizes adotadas para o estudo. Em 1950 foi publicada a NB-25R de Coordenação Modular Decimétrica e em 2010, foi disponibilizada a mais recente revisão da norma, a ABNT NBR 15873/2010 de Coordenação Modular das edificações.

Coordenação modular significa "coordenação dimensional mediante o emprego do módulo básico ou de um multimódulo", onde o módulo básico é a menor unidade de medida linear da coordenação modular representado pela letra "M" e seu valor normalizado é $1 \mathrm{M}=100 \mathrm{~mm}$, e o multimódulo é o múltiplo inteiro do módulo básico (ABNT NBR 15873/2010); em outras palavras, a coordenação modular é um instrumento de compatibilização de medidas na construção. O tema foi difundido internacionalmente a partir da década de 1940, cujas primeiras normas da International Organization for Standardization (ISO) datam da década de 1970.

No Brasil publicou-se, em 1950, a primeira norma de coordenação modular, a NB 25-R de Coordenação Modular Decimétrica, sendo sua primeira revisão a NB-25 de Coordenação Modular da Construção, em 1969. Houve um esforço significativo para a normatização detalhada e para a adoção desse instrumento nas décadas de 1960 e 1970.

O Banco Nacional da Habitação (BNH) contratou o Centro Brasileiro da Construção (CBC) em 1969 para o desenvolvimento de uma estratégia de implantação da Coordenação Modular no Brasil. Contudo, as ações não tiveram sistematicidade e recursos suficientes para uma difusão ampla, sendo interrompidas em 1972 (BALDAUF, 2004). Apesar disto, em 1977 a norma passa por uma nova revisão, a ABNT NBR 5706, de Coordenação Modular da Construção e, em 1982 ocorre a publicação de 24 normas sobre o tema, mas, são pouco conhecidas.

Para elaboração do projeto da norma ABNT NBR 15873/2010, foram consideradas seis normas internacionais: a ISO 1791:1983, que define os termos necessários para a concepção e construção de edifícios de acordo com a coordenação modular; ISO 1006:1983, que estabelece o valor do módulo básico para ser usado na coordenação modular de edifícios; ISO 2848:1984, 
princípios e regras da coordenação modular; ISO 6513:1982, séries de medidas multimodulares preferíveis para dimensões modulares; ISO 6514:1982, que determina os valores dos incrementos submodulares; e ISO 1040:1983, que define as medidas dos multimódulos para dimensões coordenadoras horizontais (ABCP, 2015)

A ABNT NBR 15873/2010 fixa um instrumento de compatibilização de elementos e componentes na construção civil por meio da coordenação de dimensões a partir de uma medida padrão: o módulo básico de 100mm. Esse instrumento simplifica as operações da construção e em especial, estimula a fabricação versátil de componentes construtivos por agentes independentes entre si.

Os princípios de coordenação modular não são de caráter obrigatório, cabendo aos responsáveis pelos projetos pela produção de componentes construtivos definirem a amplitude de sua aplicação a cada caso. O escopo da norma é: definir os termos, o valor do módulo básico e os princípios da coordenação modular; a coordenação modular se aplica ao projeto de edificações e de produção de componentes construtivos de todos os tipos, e à construção de edificações.

Os objetivos da coordenação modular visam promover a compatibilidade dimensional entre elementos construtivos (definidos nos projetos das edificações e definidos pelos respectivos fabricantes). Isto significa ampliar a cooperação entre os agentes da cadeia produtiva da construção civil, racionalizar a variedade de medidas de coordenação empregadas na fabricação de componentes construtivos, simplificar o processo de marcação no canteiro de obras para posicionamento e instalação de componentes construtivos, aumentar a intercambialidade de componentes, tanto na construção inicial quanto em reformas, e melhorias ao longo da vida útil projetada da edificação (KAAP, 2005)

Apesar de o Brasil ser um dos primeiros países do mundo a aprovar uma norma sobre coordenação modular, poucos objetivos foram alcançados, apesar de toda a promoção para a racionalização da construção (BALDAUF, 2004).

A implementação da coordenação modular depende de pelo menos três fatores (KAAP, 2005): prática de projetistas e construtores, legislação urbana, exigências de programas de financiamento, normas técnicas e oferta de componentes construtivos, elementos e produtos disponíveis no mercado, cujas características e padrões sejam coerentes com as demandas do mercado, em termo de custos e qualidade.

No cenário mundial, em países desenvolvidos não se fala mais de coordenação modular, pois já está automaticamente incorporada aos elementos construtivos. A coordenação modular 
permite alcançar patamares muito mais elevados de racionalização, mas é imprescindível industrializar. A industrialização exige uma coordenação modular rigorosa para compatibilizar componentes. Uma linha de fabricação de qualquer componente que seja não pode ser mudada onde as máquinas trabalham de forma seriada para que seja barato. (GREVEN, H.A., 2008). A coordenação modular é imprescindível para qualquer Sistema industrializado, inclusive para a tecnologia de light steel frame, porém, a mesma não impõe o uso da coordenação modular. $\mathrm{O}$ steel frame se utiliza de perfis de aço galvanizado formado a frio que proporciona uma construção a seco e industrializada, tornando-se uma opção em paralelo aos sistemas mais convencionais. Embora seja utilizado em países como Estados Unidos, Inglaterra, Japão e Austrália há mais de 40 anos, teve seu uso intensificado no Brasil a partir da década de 1990, com o desenvolvimento da cadeia produtiva (TREBILOCK, 1994).

Com o surgimento destes novos sistemas, elementos e componentes construtivos, surgiu também a necessidade se avaliar seu desempenho. O conceito de desempenho de edifícios vem sendo estudado e discutido há mais de 30 anos no Brasil. Há a necessidade de se avaliar tecnicamente as novas soluções construtivas, de modo que possa ser previsto o comportamento dessas edificações durante a sua vida útil esperada (GONÇALVES, et al, 2003).

No Brasil, o conceito de desempenho ganhou forças no fim da década de 1990 quando a Caixa Econômica Federal, sucessora do Banco Nacional da Habitação, identificou a necessidade desses estudos se transformarem em normas técnicas para a avaliação dos novos sistemas construtivos em habitação (BORGES, 2008). Com a implementação de políticas públicas em programas habitacionais para moradia popular do governo, a Associação Brasileira de Normas Técnicas (ABNT) passou a desenvolver um conjunto de normas que visam o conceito de desempenho de edificações com até 5 pavimentos.

Houve então a publicação da norma de desempenho para edificações habitacionais de até 5 pavimentos, a norma ABNT NBR 15575/2013 - Edificações habitacionais - Desempenho, publicada em julho de 2013. De acordo com CBIC (2013), a norma segue uma sequência de exigências dos usuários em relação à segurança e habitabilidade. São contextualizados conceitos de vida útil, prazo de garantia, manutenibilidade, incumbência de cada agente envolvido, durabilidade e estabelecidos níveis de desempenho: mínimo (M), intermediário (I) e superior (S), sendo o atendimento ao desempenho mínimo obrigatório.

Conforme ABNT NBR 15575-1/2013, os requisitos de desempenho são "as condições que expressam qualitativamente os atributos que o edifício habitacional e seus sistemas devem 
possuir, a fim de que possam satisfazer às exigências dos usuários", e que os critérios de desempenho são "as especificações quantitativas dos requisitos de desempenho, expressos em termos de quantidades mensuráveis, a fim de que possam ser objetivamente determinados". A norma ABNT NBR 15575/2013 está dividida em 6 partes: A parte 1, de requisitos gerais, apresenta os objetivos, premissas e conceitos referentes às outras partes específicas e são especificados índices de referência para parâmetros de desempenho. As demais partes estão divididas em assuntos específicos de sistemas de estrutura, pisos, vedações e esquadrias, cobertura e hidro sanitários (ABNT NBR 15575/2013).

A procura por métodos construtivos modulares, com grande parte de seus componentes préfabricados e/ou pré-construídos com a finalidade de diminuir custos, racionalizar o uso da mão de obra e evitar retrabalhos, aliados às necessidades de atender às normas de desempenho, e o surgimento de novos materiais, estimulou o surgimento e uso de simulações computacionais como poderosos processos de ajuda à inovação na construção civil. Esse recurso representa uma força auxiliar na redução do tempo de desenvolvimento das fases de projeto e aprovações legais prévias à construção de uma edificação (HAJJAR, 2002).

Para avaliação do desempenho térmico, segundo a CBIC (2013), a norma ABNT NBR $15575 / 2013$ propõe primeiramente um procedimento simplificado de análise. Nas partes 4 e 5 da norma constam os índices que devem ser atendidos de forma prescritiva e os requisitos e critérios dos materiais de paredes, de fachada e das coberturas. Para a avaliação do desempenho térmico por meio de um programa de simulação computacional, deve-se seguir critérios e métodos detalhados na norma.

Os critérios para determinação do desempenho térmico da norma ABNT NBR 15575-1/2013, pelo método de simulação computacional, são calculados para um dia típico de verão e um dia típico de inverno. No verão, o valor máximo diário da temperatura do ar interno de cada recinto dever ser menor ou igual ao valor máximo diário da temperatura do ar externo; e no inverno, o valor mínimo diário da temperatura do ar interno de cada recinto deve ser sempre $3^{\circ} \mathrm{C}$ superior ao valor mínimo diário da temperatura do ar externo.

A figura 1 a seguir apresenta os métodos de avaliação do desempenho térmico, sendo a forma prescritiva como procedimento $1 \mathrm{~A}$ e o método de simulação computacional como procedimento 
1B; o fluxograma é baseado na determinação da transmitância térmica - U e na capacidade térmica - CT das paredes de fachada e das coberturas.

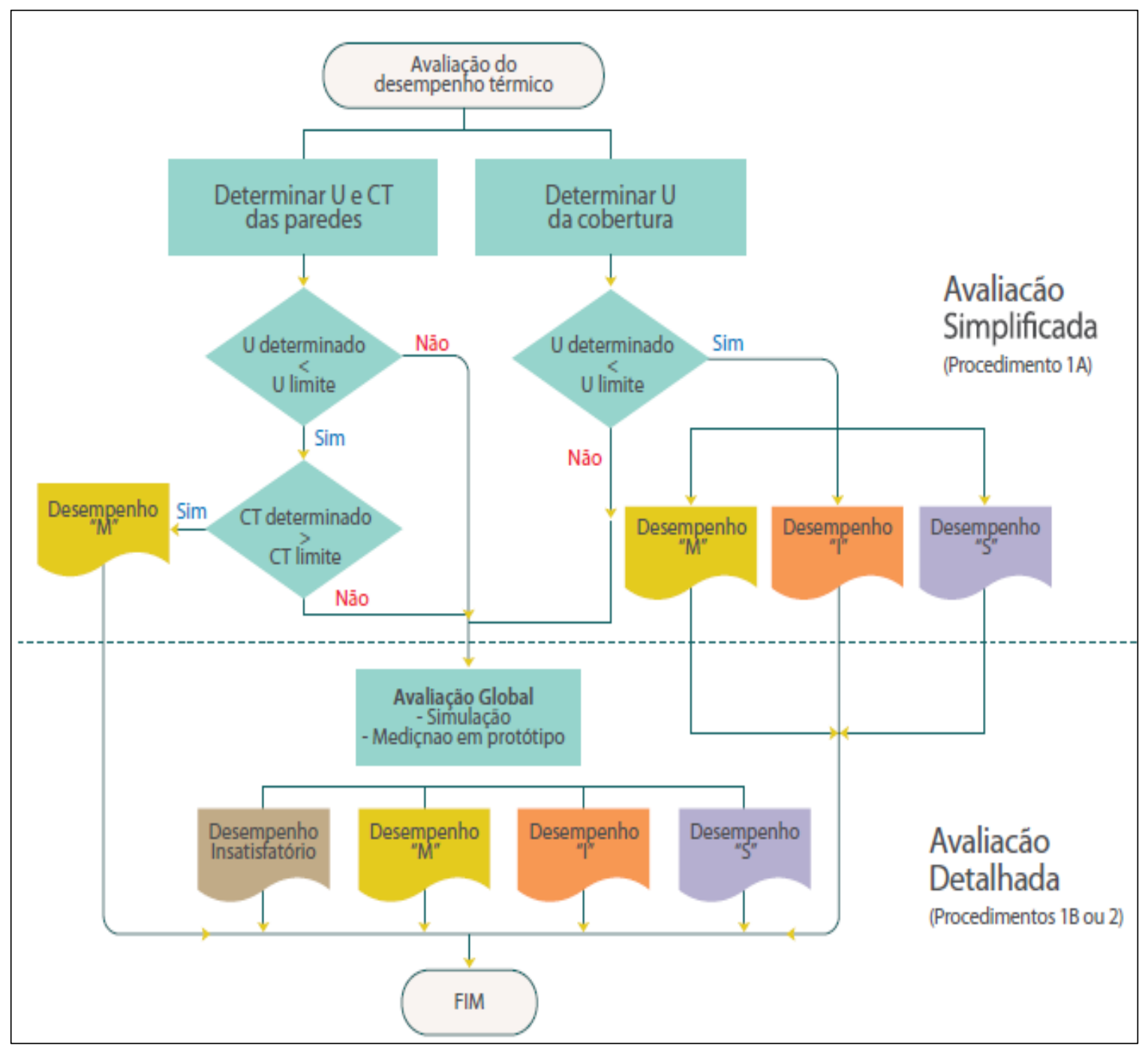

Figura 1 - Métodos alternativos de avaliação do desempenho térmico. Fonte: IPT, 2013.

Conforme a ABNT NBR 15575-1/2013, o adequado desempenho térmico repercute no conforto das pessoas e em condições adequadas para o sono e atividades normais em uma habitação. Requisitos como o desempenho lumínico e térmico tendem a cada vez mais a serem definidos não apenas para atender às exigências de conforto humano, mas também à necessidade premente de economia de energia ao longo do tempo (BORGES, 2008).

A mensuração e definição do desempenho desejado dos usuários de uma construção requerem um grande conhecimento e especialidade de diversas áreas envolvidas na construção civil. $\mathrm{O}$ conceito de desempenho de edificações é um grande desafio quando se trata das necessidades 
de habitabilidade segundo critérios que possam ser atendidos economicamente, tecnicamente e socialmente.

Portanto é muito importante que o desempenho seja avaliado antes da construção do edifício, ainda na fase de projeto para que não haja a desaprovação por parte do usuário, o que poderia afetar o desempenho da vida útil esperado.

Os recursos da simulação computacional auxiliam na concepção do projeto com inclusão de estratégias passivas e ajuda a encontrar soluções otimizadas para as edificações e retrofit; além disso, pode-se avaliar o desempenho de uma edificação construída. Porém, no Brasil, a complexidade das ferramentas de simulação e o entendimento multidisciplinar das variáveis que envolvem o comportamento térmico, influenciam na pouca utilização dessas ferramentas na rotina dos profissionais da construção civil (SORGATO, 2009).

Atualmente, para as simulações de desempenho da edificação, o programa mais utilizado é o EnergyPlus, que tem suas raízes nos programas BLAST e DOE-2, que foram desenvolvidos pelo Department of Energy (Departamento de Energia), órgão governamental dos Estados Unidos e lançados no final de 1970 e início de 1980 como ferramentas de energia e simulação de carga. A versão mais atualizada disponível é a 8.6.0 (janeiro de 2017). O EnergyPlus possui como principais recursos de simulação os índices de refrigeração, ventilação e iluminação natural, sistema fotovoltaico, aquecimento, dentre outros (US. DEPARTMENT OF ENERY, 2015).

Baseado em uma metodologia de cálculos dinâmico, o software permite a aproximação de resultados a uma situação real na avaliação do comportamento térmico do edifício. Além disso, o programa tem a possibilidade de manipular, com qualidade, um elevado número de parâmetros para garantir um bom resultado da simulação; é capaz de simular 8760 horas por ano com variações horárias de ocupação, cargas internas e modela efeitos de inércia térmica (SORGATO et al, 2012).

Com a atual difusão dos métodos de projeto em BIM (Building Information Modeling) a simulação multimétodo está sendo cada vez mais utilizado desde para planos de massa da edificação até o planejamento de sua operação durante toda a sua vida útil. Esquematicamente este processo pode ser representado pela Figura 2 abaixo, onde o autor demonstra seu entendimento através de um simples fluxograma. 
O fluxograma da Figura 2 abaixo apresenta o entendimento do autor a ligação dos temas tratados.

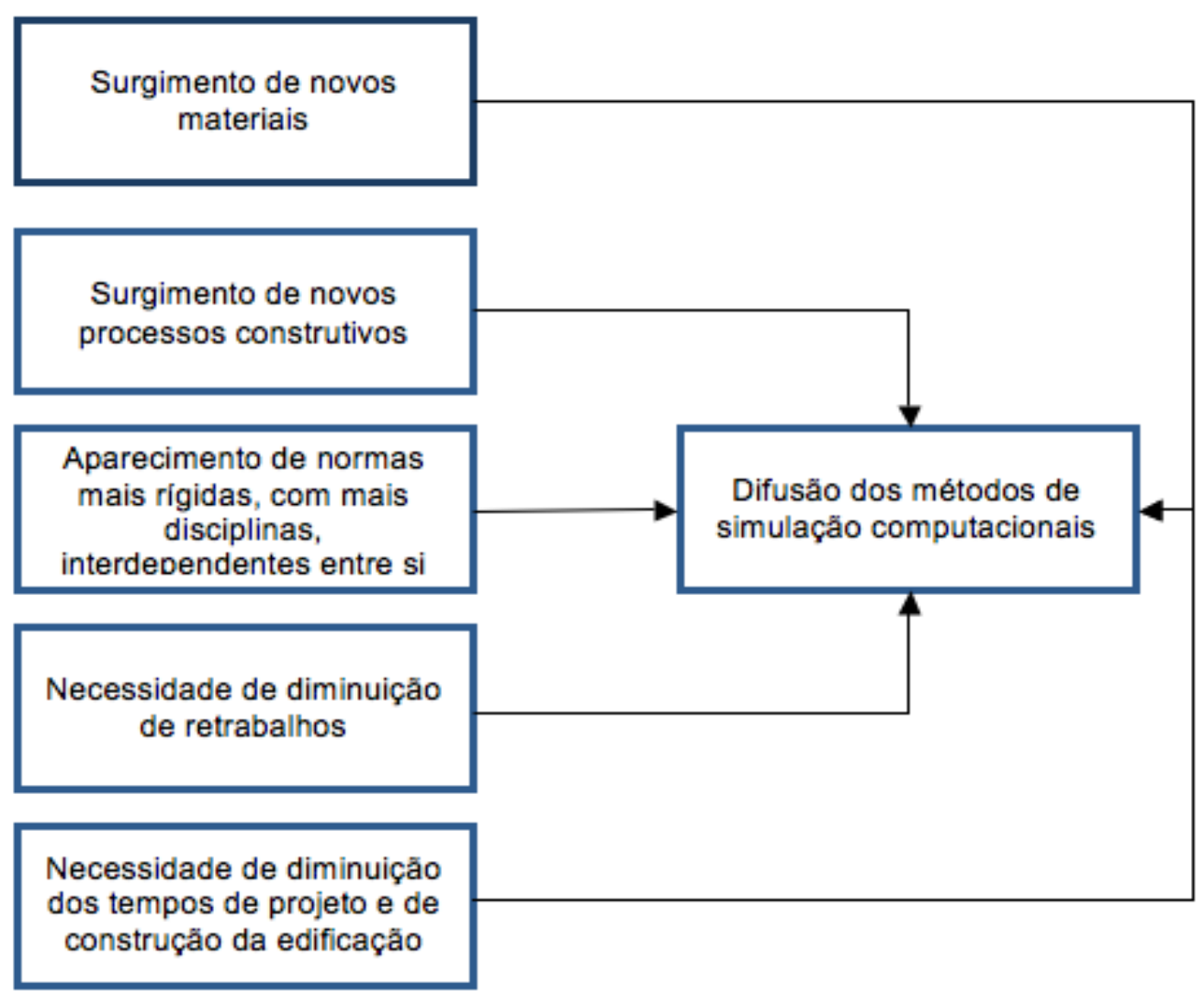

Figura 2 - Fluxograma esquemático de entendimento por parte do autor quanto ao surgimento, evolução e ligação dos temas tratados.

Fonte: Arquivo pessoal, 2015.

Desta forma, os métodos de simulação computacional têm um importante papel de avaliar previamente a soma de diversos atributos de um novo projeto, material ou sistema que, na maioria das vezes, antes somente era possível através de testes físicos. Sendo assim, este estudo objetiva utilizar a simulação computacional para avaliar comparativamente o desempenho térmico de painéis pré-fabricados, do tipo light steel frame que serão utilizados em um sistema construtivo coordenado modularmente proposto por uma Startup; sistema este, do qual será executado protótipo em escala real, em parceria com SESI/SENAI-PR e SESI/SENAI-SC, com previsão de conclusão para maio de 2017.

A simulação prévia comparativa, ainda na fase de projeto pode ser mais segura se as informações sobre o desempenho (térmico, acústico, dentre outros) das tipologias de painéis de light steel frame pré-fabricados que virão a ser inseridos no protótipo forem conhecidas. Fornecer essas informações, estudar o comportamento térmico destas tipologias de painéis pré- 
fabricados, sob diversas condições climáticas é uma necessidade, pois, os resultados podem auxiliar nas tomadas de decisão em projeto e beneficiar o atendimento de futuros testes físicos, aos quais o protótipo será submetido. Atualmente, esses estudos podem ser feitos de forma satisfatória e com baixo custo, dada a disponibilidade de boas ferramentas de simulação computacional.

Quanto aos painéis pré-fabricados, existe uma gama de tipos disponíveis no mercado e que podem ser utilizados em construções modulares. A escolha da tecnologia do painel a ser utilizado tanto nas simulações quanto no futuro protótipo está relacionada com uma parceria comercial firmada entre a Startup e uma empresa de painéis de light steel frame. Esses painéis são compostos por perfis leves de aço galvanizado no seu interior, com uma camada de manta isolante de lã de vidro e, placas cimentícias em ambas as faces (podendo ou não ser adicionado placas de gesso na face interna de algumas tipologias de painéis).

Além da parceria comercial já firmada, outro ponto que influenciou na escolha desta tecnologia de painel foi o fato de ser este um dos mais conhecidos pelo setor da construção civil tanto para vedações verticais internas quanto externas sendo inclusive, similar ao drywall. Trata-se, portanto, de uma técnica que se tornou commodity, ou seja, amplamente difundida no mercado nacional. As informações das propriedades termofísicas de cada material que compõe a tecnologia de painel utilizado neste estudo, estão disponíveis na ABNT NBR 15220-2/2005. 


\section{OBJETIVO}

\subsection{Objetivo Geral}

O objetivo deste trabalho é avaliar comparativamente o comportamento térmico de diferentes tipologias de painéis de light steel frame pré-fabricados com variações das espessuras das camadas isolantes e das placas de fechamentos internos e externos. Os painéis serão simulados em uma residência coordenada modularmente e sujeita às condições climáticas típicas de três cidades do Brasil: região Nordeste, na cidade de Fortaleza-CE; região Sudeste, na cidade de São Paulo e região Sul, na cidade de Curitiba. O intuito é gerar insumos prévios que auxiliem na decisão do projeto executivo e apresentem melhor custo benefício, tanto referente ao protótipo, como para futuros projetos do sistema modular reversível.

\subsection{Objetivos específicos}

a. Identificar uma tecnologia de painel pré-fabricado para vedação vertical que possibilite ser padronizado, porém, versátil para possibilitar alterar as espessuras dos materiais que o compõe, e que seja difundido no mercado nacional;

b. Quantificar comparativamente o desempenho térmico de cada variação proposta nas espessuras e nas camadas internas e externas dos materiais que compõem as tipologias de painéis avaliados, utilizando o programa EnergyPlus para as simulações computacionais;

c. Comparar os resultados das simulações e identificar quais das tipologias de painéis atendem satisfatoriamente os requisitos da Norma de Desempenho ABNT NBR 15575-1/2013;

d. Verificar entre as tipologias que apresentem resultados favoráveis, se é possível reduzir as espessuras ou camadas de um ou mais materiais com o objetivo de utilizar menor quantidade de material;

e. Classificar cada tipologia de painel avaliado de acordo com seu status de desempenho apresentado para cada cidade. 


\section{MÉTODO DE TRABALHO}

\subsection{Descrição do modelo de painel estudado}

As tipologias de painéis pré-fabricados internos e externos, serão da tecnologia de light steel frame, conforme destacado anteriormente. É um sistema industrializado a seco, que se tornou, ao longo dos anos uma opção no setor brasileiro de construção civil, assim como o drywall. O steel frame é formado por perfis guias e montantes de aço galvanizado que são encaixados e parafusados entre si e formando uma malha estrutural. Normalmente o steel frame é independente de outra estrutura, pois possibilita através de seus perfis, ter função estrutural. Mas no presente sistema modular reversível, a função estrutural está destinada à superestrutura formada de tubos de aço pesado de seção quadrada; portanto, os painéis em steel frame são utilizados apenas para os fechamentos, não exercendo função estrutural. A Figura 3 abaixo apresenta as características estruturais do steel frame.

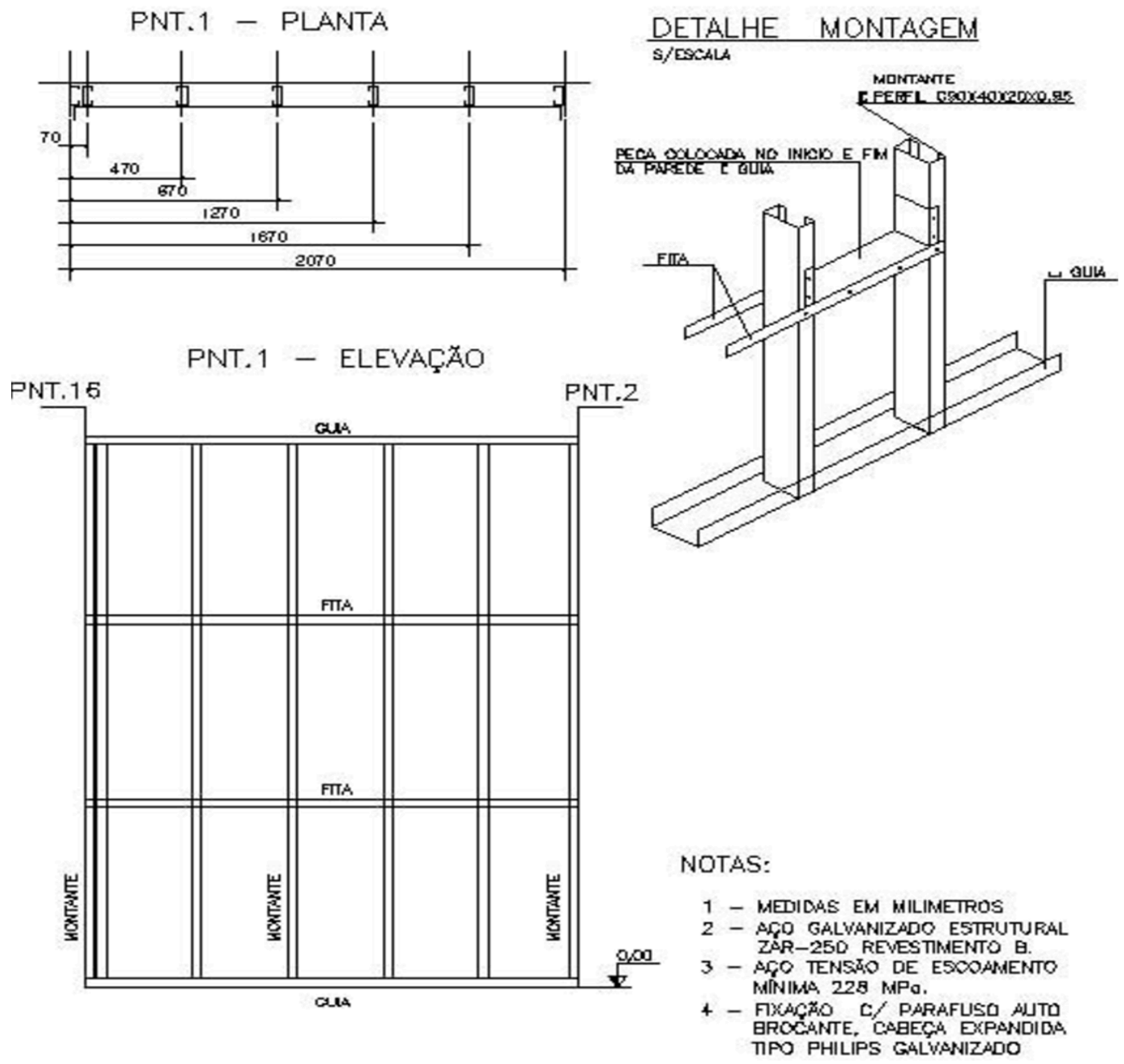

Figura 3 - Planta, elevação e detalhe de montagem da estrutura do sistema de light steel frame Fonte: Portal metálica, 2016. 
Na Figura 4 abaixo, é exemplificado os demais materiais que normalmente compõem os painéis da tecnologia de light steel frame, sendo estes, fixados nos perfis guias e montantes de aço galvanizado mostrados na Figura 3 acima.

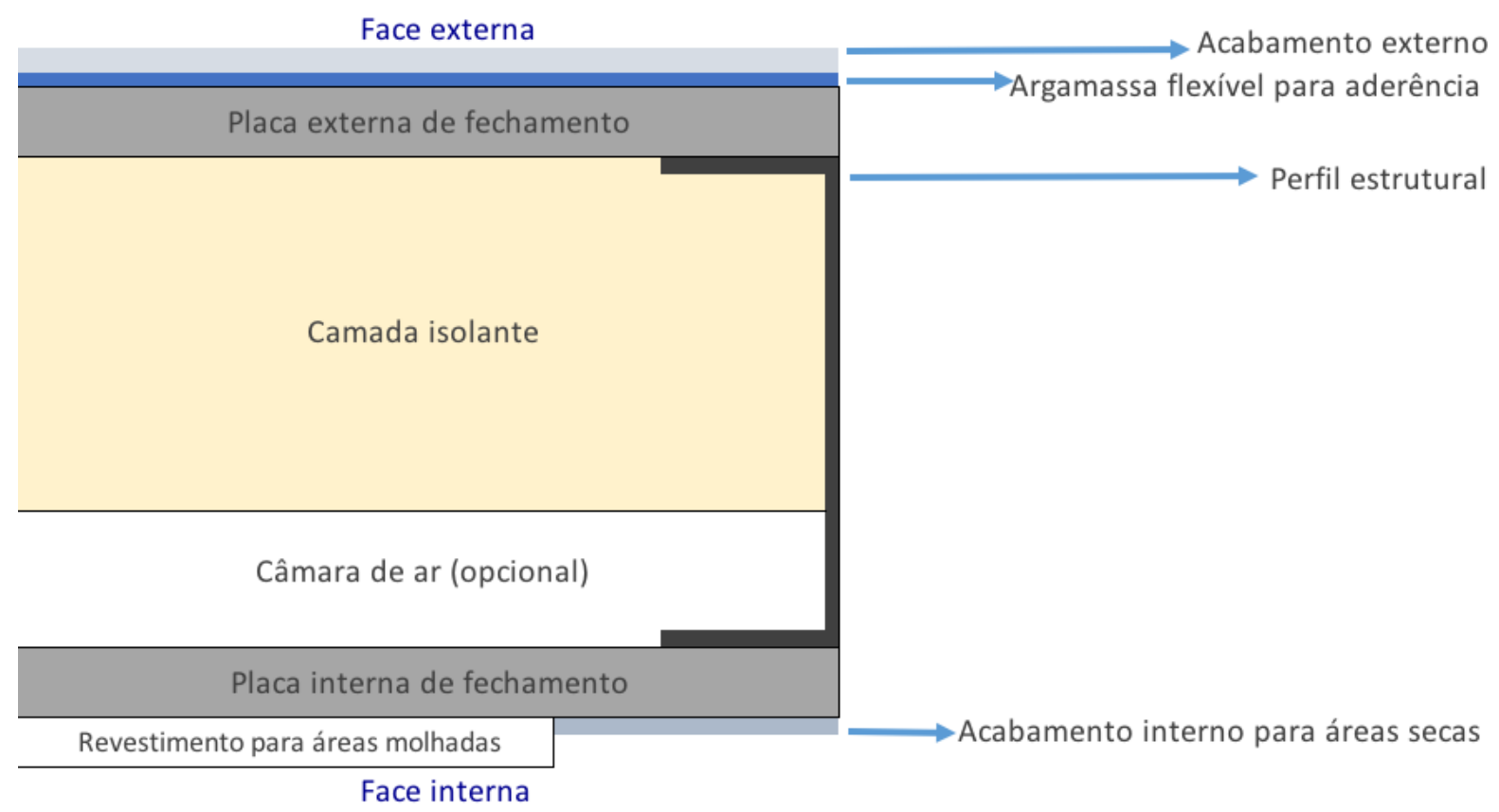

Figura 4 - Detalhe genérico das camadas de materiais que normalmente compõem painéis de light steel frame Fonte: Portal metálica, 2016.

O material da camada isolante interna dos painéis foi considerado o mesmo (lã de vidro) para todas as tipologias alterando-se apenas as espessuras. Já as placas de fechamentos internas e externos variaram-se entre placas simples, duplas e triplas sendo todas placas cimentícia para a face externa e dependendo da tipologia, mista com placas de gesso na face interna.

Todas as simulações utilizaram um modelo simplificado, sendo o foco do trabalho verificar a influência das tipologias de painéis que compõem os módulos da residência como um todo, e a influência dos materiais de um cômodo para o outro, e não de sua estrutura. E ainda, conter os perfis estruturais no interior dos painéis dificultaria a simulação e não geraria uma resposta útil. Sendo assim, não contribuiria com a pesquisa e ficaria com modelo complexo e dificultaria a execução da simulação.

Os painéis da tecnologia de light steel frame, foram escolhidos pois, além da parceria comercial, atendem aos requisitos deste estudo e as premissas projetuais. É tecnologia conhecida no mercado, industrializada e possibilita versatilidade nas camadas de materiais de seus materiais. Trata-se, portanto, de uma tecnologia commodity, difundida no setor 


\subsection{Descrição inicial das metodologias}

Após a escolha da tecnologia, determinou-se composições de materiais de inicialmente, 12 tipologias de painéis. Posteriormente, foi escolhido uma única tipologia e simulado 4 variações da mesma, resultando em um total de 16 tipologias de painéis, os quais foram submetidos à diversas simulações utilizando parâmetros críticos. E ainda, esta tipologia de painel escolhido foi simulado novamente com mudanças nos parâmetros Todas os resultados foram analisados comparativamente, na tentativa de identificar uma ou mais composições mínimas necessárias para cada cidade estudada.

Posteriormente, os painéis foram dimensionados com as medidas padrões do sistema construtivo modular reversível, o qual possui ambientes independentes entre si, que ao se unir, formam uma residência completa, que neste caso terá apenas o pavimento térreo.

O estudo esta dividido em 5 fases, sendo a $1^{\text {a }}$ fase com 6 tipologias de painéis com larguras internas de 70mm (esta largura padrão é resultante dos perfis estruturais) onde inicialmente variou-se as espessuras das camadas da lã de vidro e posteriormente, a quantidade de placas de fechamentos. $\mathrm{Na} 2^{\mathrm{a}}$ fase, utilizou-se mais 6 painéis, com maior largura interna de $90 \mathrm{~mm}$. Também com variações das espessuras da camada isolante e das quantidades de placas.

$\mathrm{Na} 3^{\mathrm{a}}$ fase, inicialmente foi realizado uma análise prévia com as 12 opções de tipologias de painéis iniciais, a qual possibilitou uma comparação geral dos níveis de desempenho. A tipologia que apresentou os melhores resultados foi escolhida para ser utilizada nas fases seguintes. Ainda na $3^{\mathrm{a}}$ fase, foi necessário a realização de estudos para entender o desempenho isolado das placas que compõem o painel, resultando em 2 novas variações da tipologia de painel escolhido.

Já a $4^{\text {a }}$ fase foi uma tentativa de atender o desempenho apresentado ao serem adicionadas 1 placa da face interna e outra na face externa da tipologia de painel escolhido, portanto, resultando em mais outras novas 2 tipologias de painéis.

Até a fase anterior todas as simulações utilizavam os mesmos parâmetros, que necessitaram ser modificados devido ao fato de não possibilitarem resultados favoráveis de nenhuma tipologia de painel para os dias típicos de inverno. Portanto, a $5^{\text {a }}$ fase serviu para reutilizar a tipologia de painel que foi escolhido na $3^{\text {a }}$ fase, e testá-lo diante aos novos parâmetros estipulados.

Para definição do dias típicos de verão e de inverno foi necessária uma análise das temperaturas de diversos dias de acordo com os dados climáticos fornecidos pelo diretório do Laboratório de Eficiência Energética em Edificações da Universidade Federal de Santa Catarina, (LABEEE, 
2014), onde, optou-se pela escolha dos dias típicos que apresentam temperaturas mais extremas, ou seja, dias típicos de verão que apresentavam temperaturas mais altas em cada cidade e dias típicos de inverno que apresentavam temperaturas mais baixas. Os dias típicos de inverno e verão escolhidos para cada cidade foi:

- Zona 8 Cidade de Fortaleza-CE - Região Nordeste: em 21/12 - dia típico de verão e em 21/07 - dia típico de inverno;

- Zona 3 Cidade de São Paulo-SP - Região Sudeste: em 21/02 - dia típico de verão e em 21/07 - dia típico de inverno;

- Zona 1 Cidade de Curitiba-PR - Região Sul: em 21/02 - dia típico de verão e em 21/07 dia típico de inverno.

Nas tabelas 1, 2, 3, 4 e 5 a seguir, são apresentadas as metodologias detalhadas de cada fase. E abaixo (Figuras Figuras 5, 6, 7, 8, 9, 10, 11, 12, 13, 14, 15, 16, 17, 18, 19, 20 e 21), são apresentados detalhes ilustrativos das composições das tipologias de painéis de cada fase. 


\subsection{Metodologia detalhada da $1^{\text {a }}$ fase}

A metodologia adotada para a composição das 6 tipologias de painéis da $1^{\text {a }}$ fase com perfis montantes de $70 \mathrm{~mm}$ de largura, esta descrita na tabela 1 abaixo.

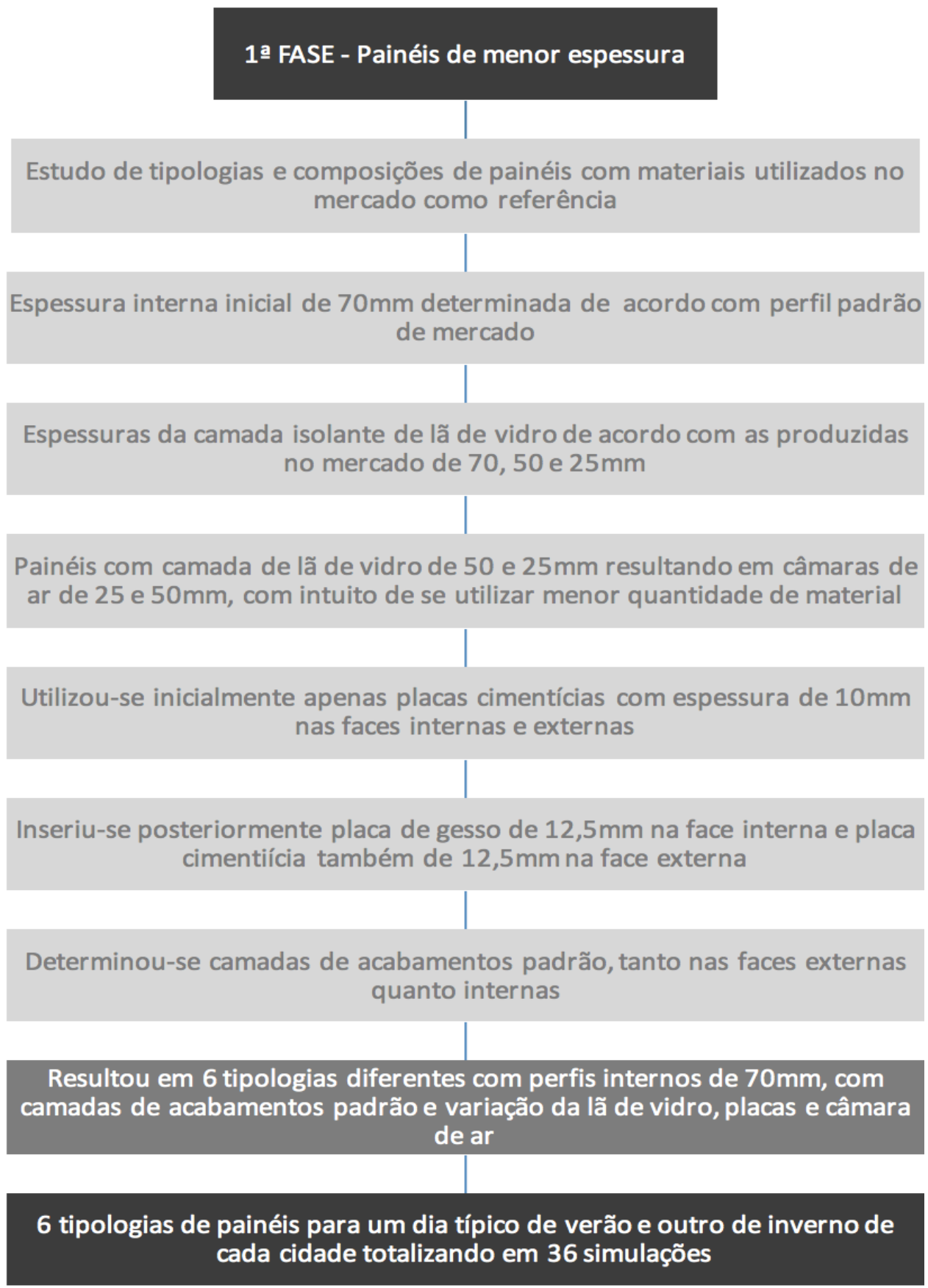

Tabela 1 - Metodologia detalhada da $1^{\mathrm{a}}$. Fase.

Fonte: Arquivo pessoal, 2016 


\subsubsection{Tipologias de painéis da $1^{\text {a }}$ Fase.}

A seguir são apresentadas nas Figuras 5, 6, 7, 8, 9 e 10 as espessuras e camadas de materiais que compõem cada uma das 6 tipologias de painéis internos e externos da $1^{\text {a }}$ fase.

\section{Painel 1:}

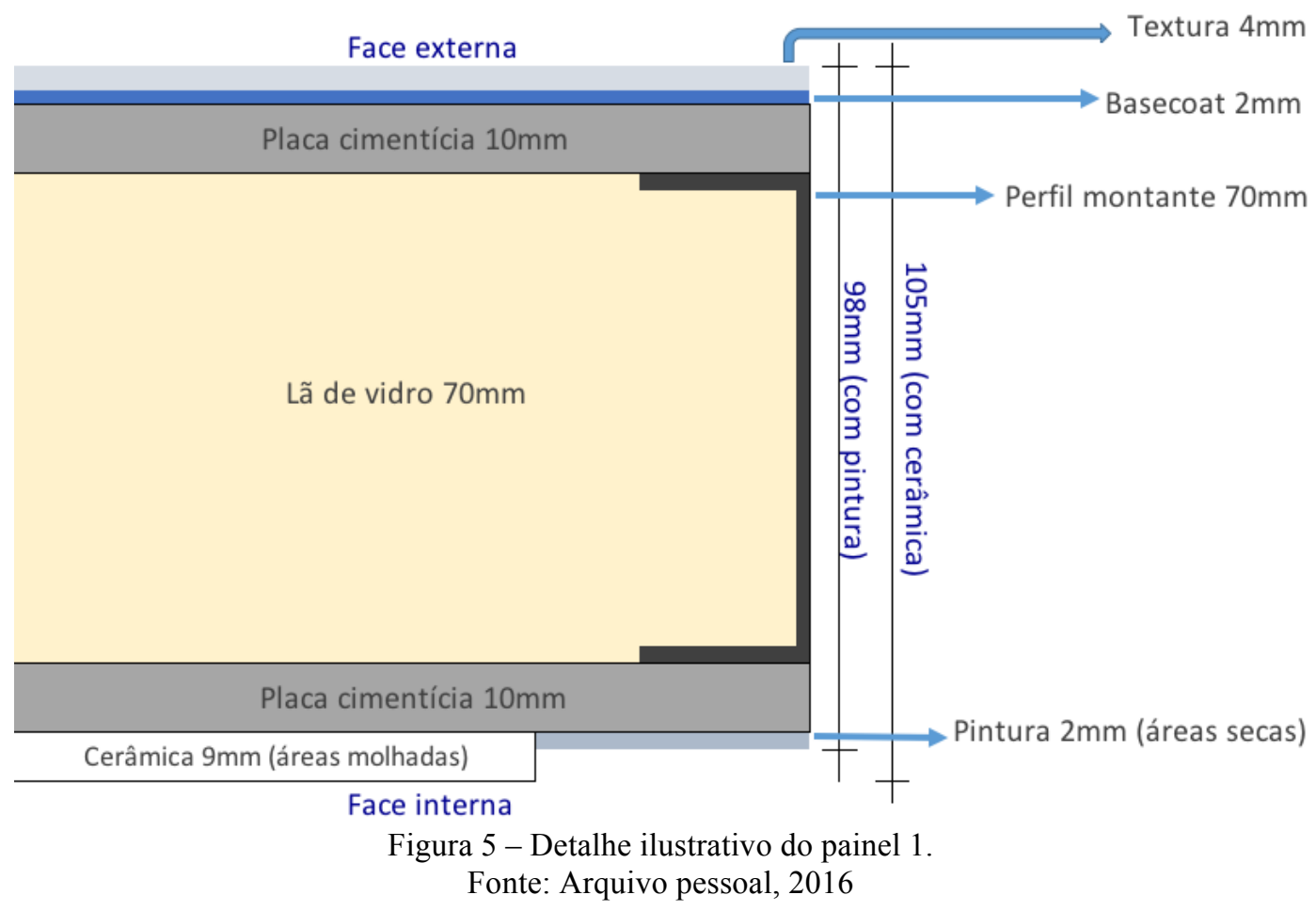

Painel 2:

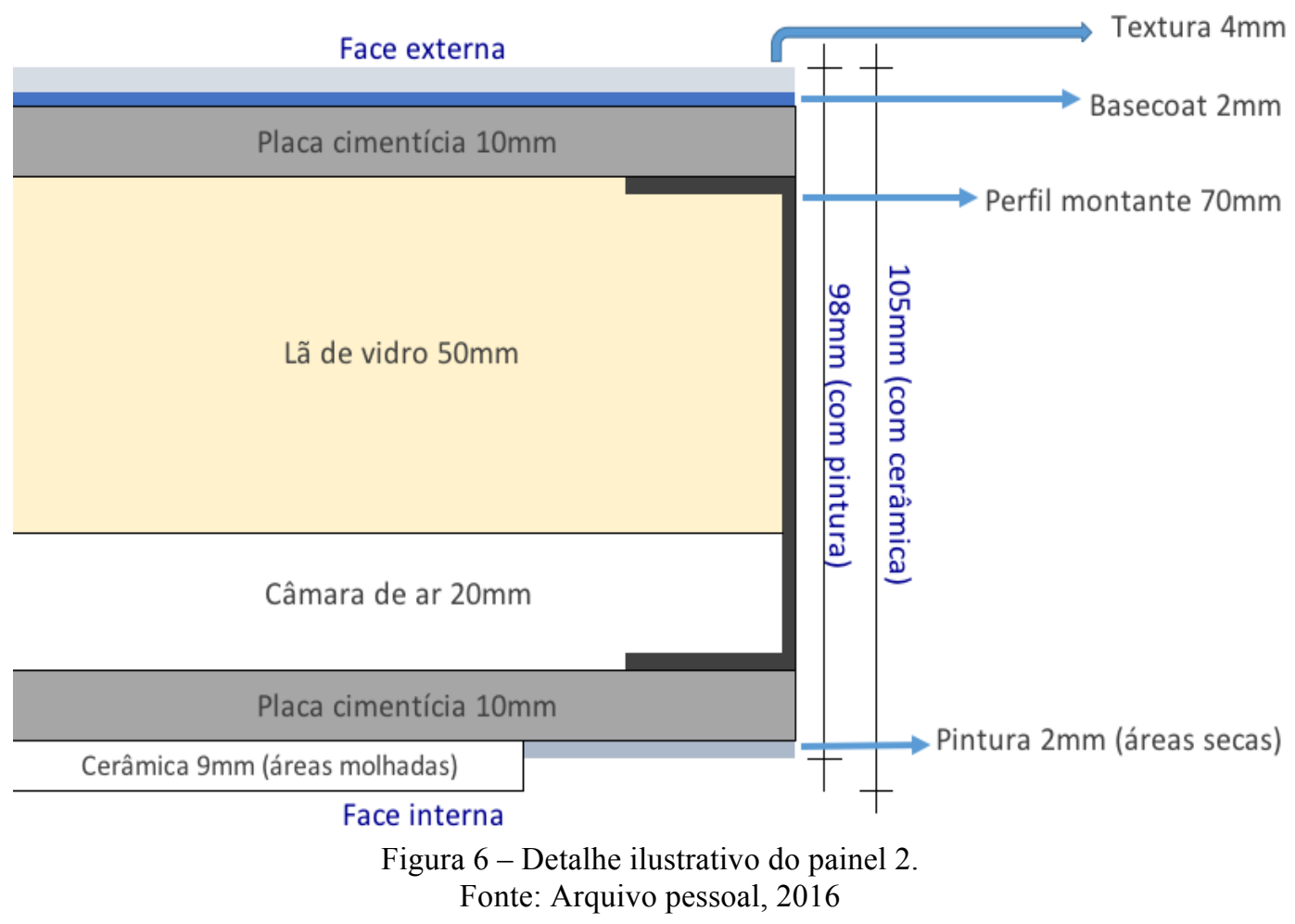




\section{Painel 3:}

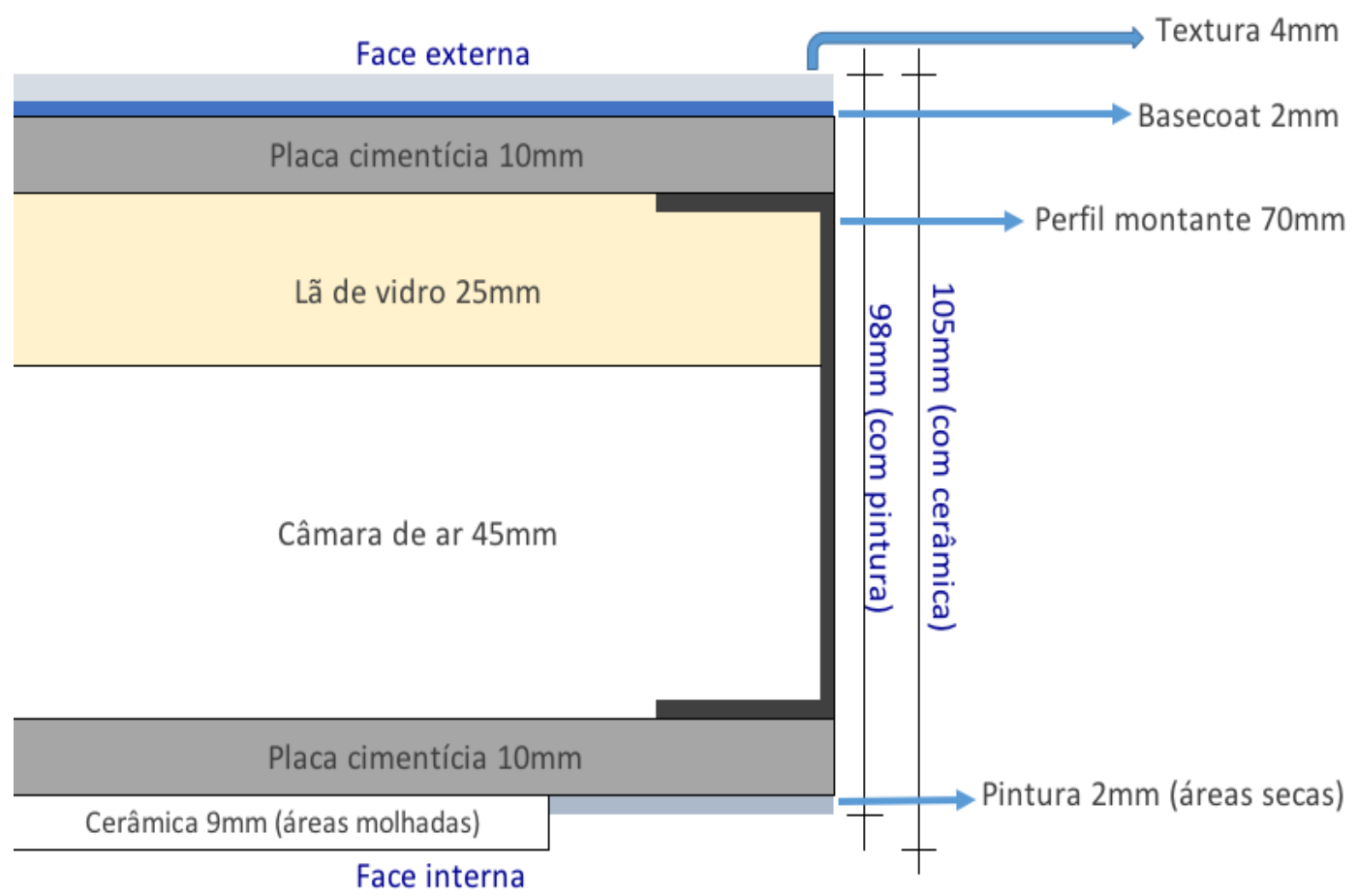

Figura 7 - Detalhe ilustrativo do painel 3.

Fonte: Arquivo pessoal, 2016

\section{Painel 4:}

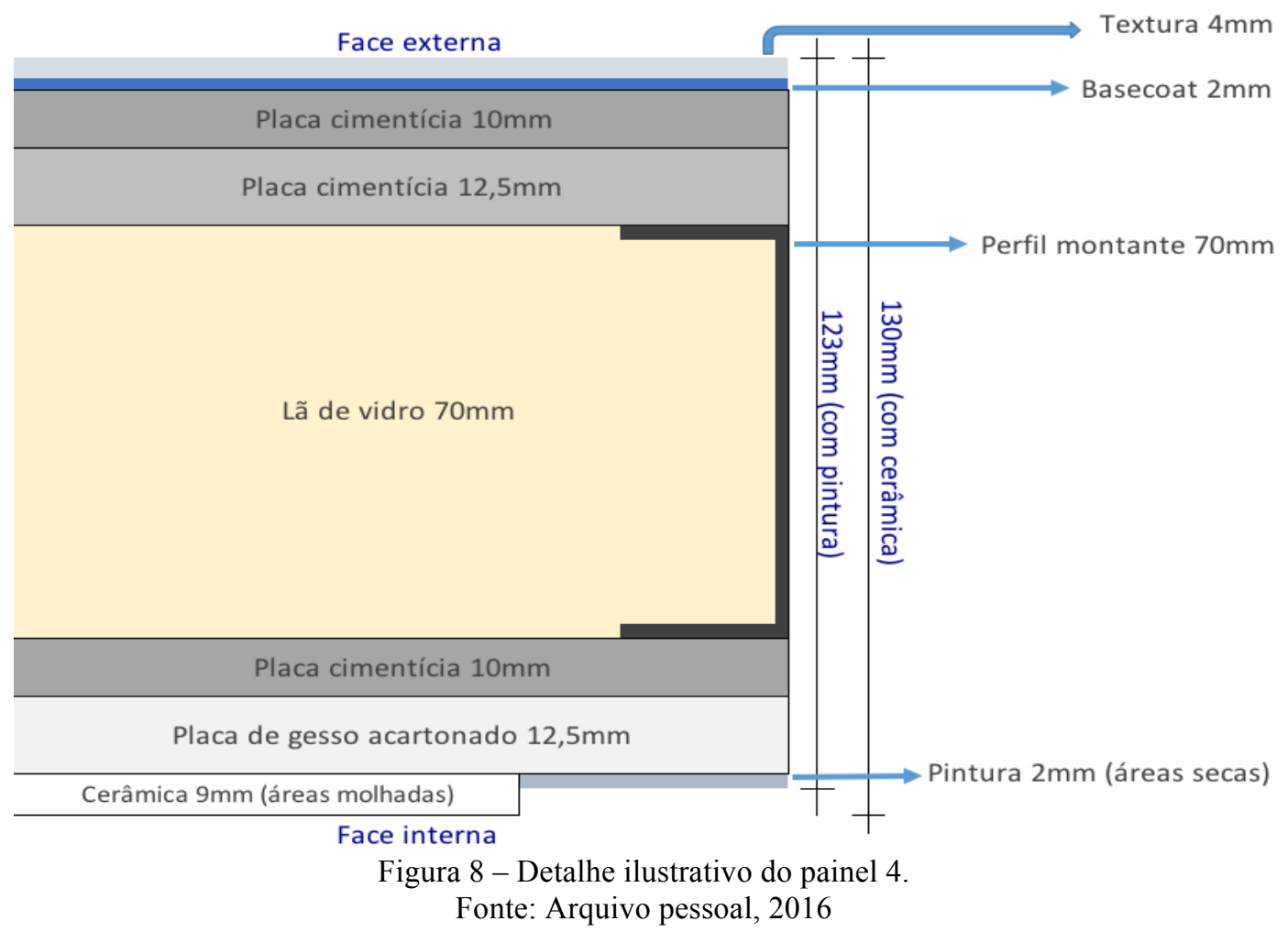




\section{Painel 5:}

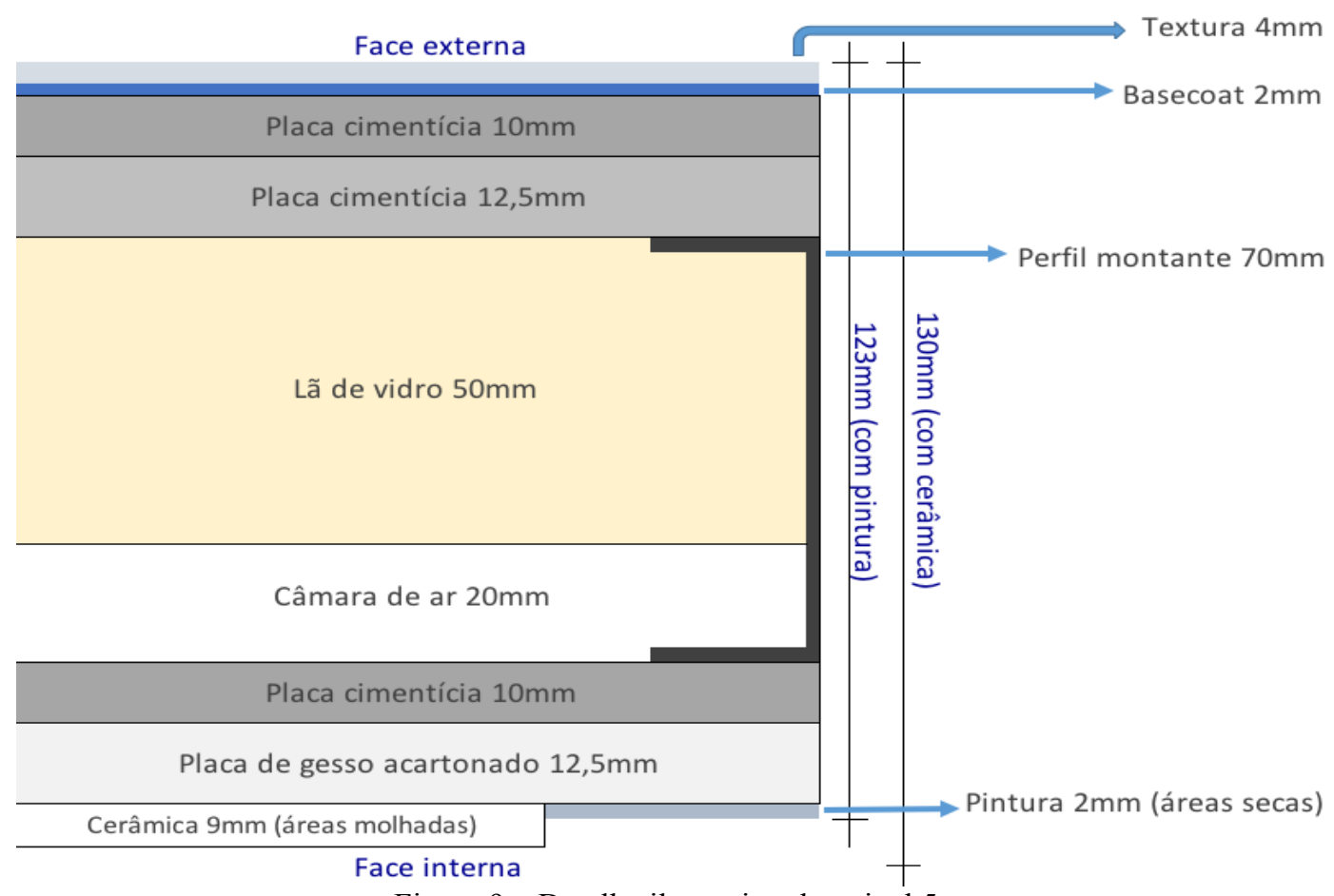

Figura 9 - Detalhe ilustrativo do painel 5.

Fonte: Arquivo pessoal, 2016

\section{Painel 6:}

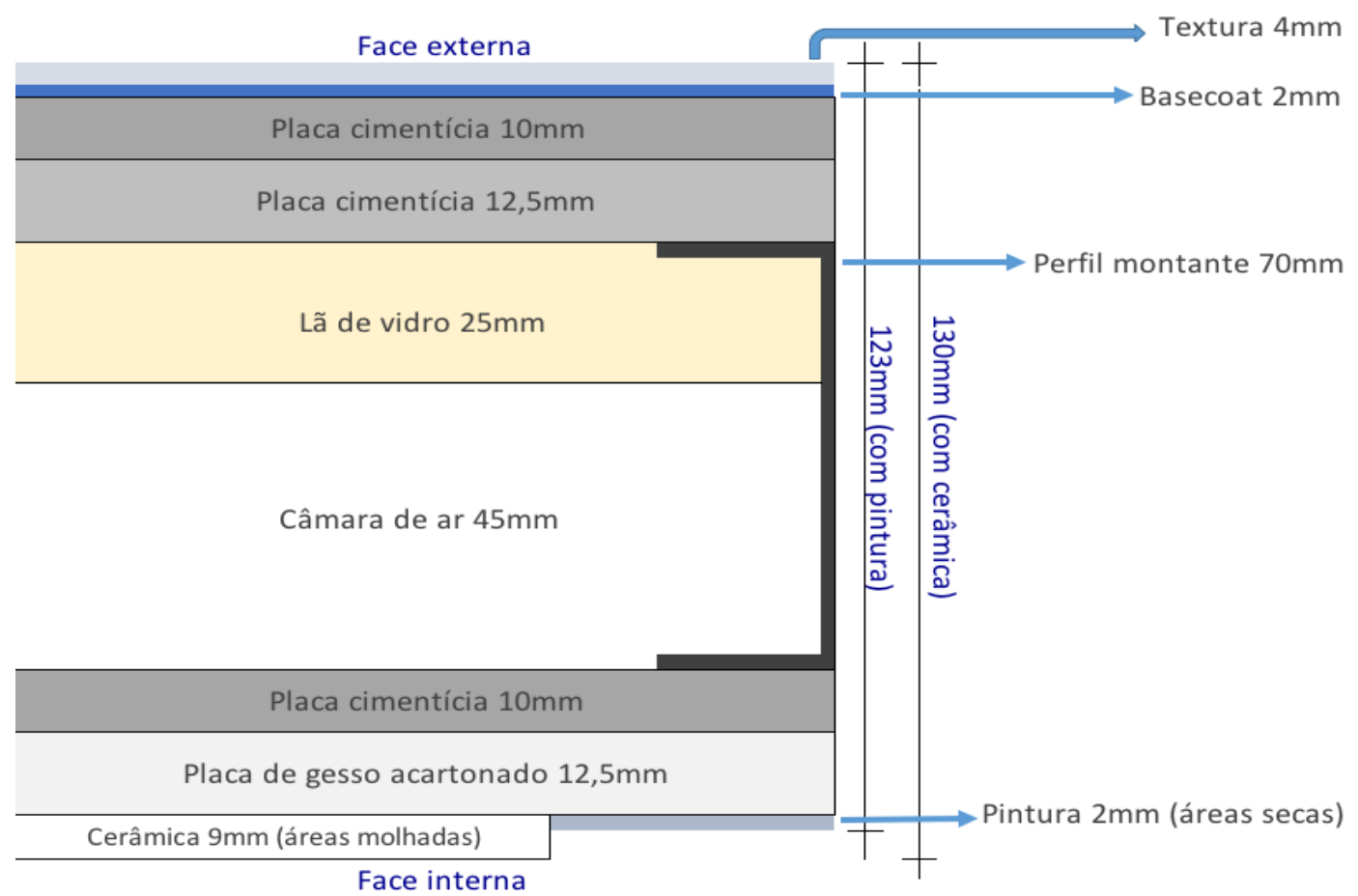

Figura 10 - Detalhe ilustrativo do painel 6.

Fonte: Arquivo pessoal, 2016 


\subsection{Metodologia detalhada da $2^{\mathrm{a}}$ fase}

As larguras internas dos painéis da $2^{\mathrm{a}}$ fase passaram de $70 \mathrm{~mm}$ para $90 \mathrm{~mm}$ tornando o painel mais robusto (com maior espessura). Este ganho de $20 \mathrm{~mm}$, foi utilizado para aumento da espessura da lã de vidro ou da a câmara de ar. Os parâmetros são os mesmos da $1^{\mathrm{a}}$ fase. A metodologia adotada para a composição das 6 tipologias de painéis da $2^{\mathrm{a}}$ fase com perfis montantes de $90 \mathrm{~mm}$ de largura, esta descrita na tabela 2 abaixo.

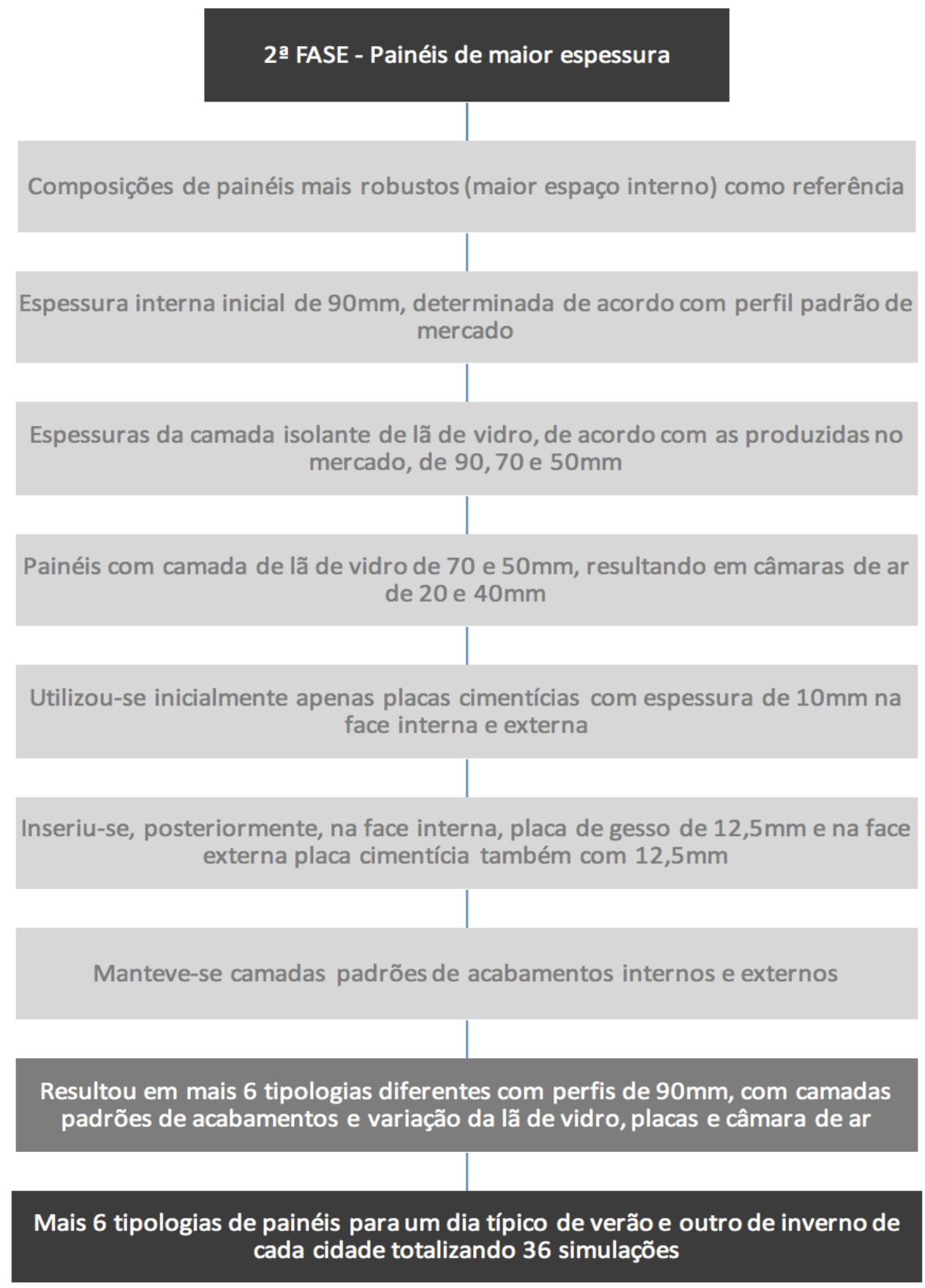

Tabela 2 - Metodologia detalhada da $2^{\mathrm{a}}$. Fase.

Fonte: Arquivo pessoal, 2016 


\subsubsection{Tipologias de painéis da $2^{\mathrm{a}}$ Fase}

Em seguida são apresentadas nas Figuras 11, 12, 13, 14, 15 e 16 as espessuras e camadas de materiais que compõem cada uma das 6 tipologias de painéis internos e externos da $2^{\mathrm{a}}$ fase.

Painel 7:

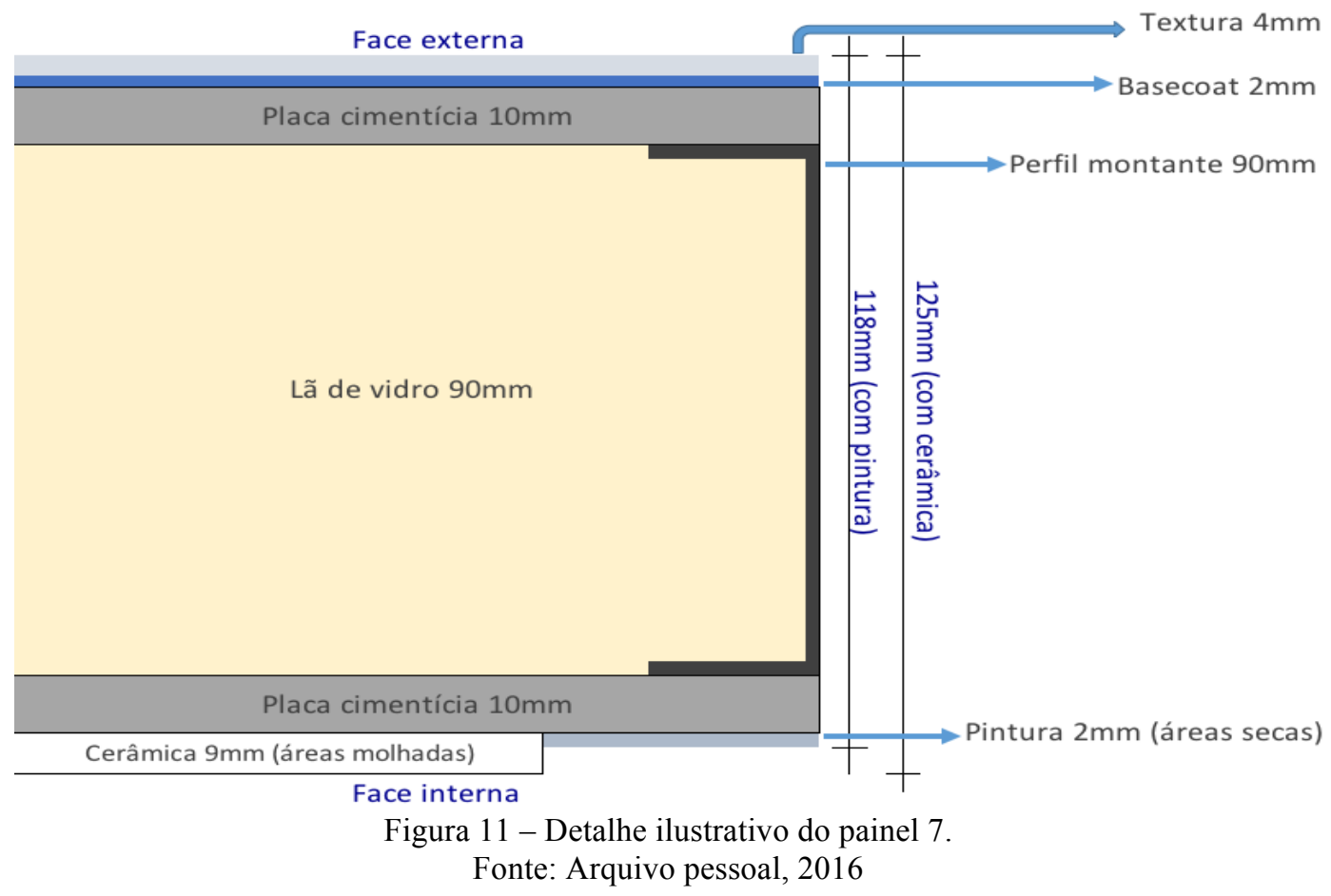

Painel 8:

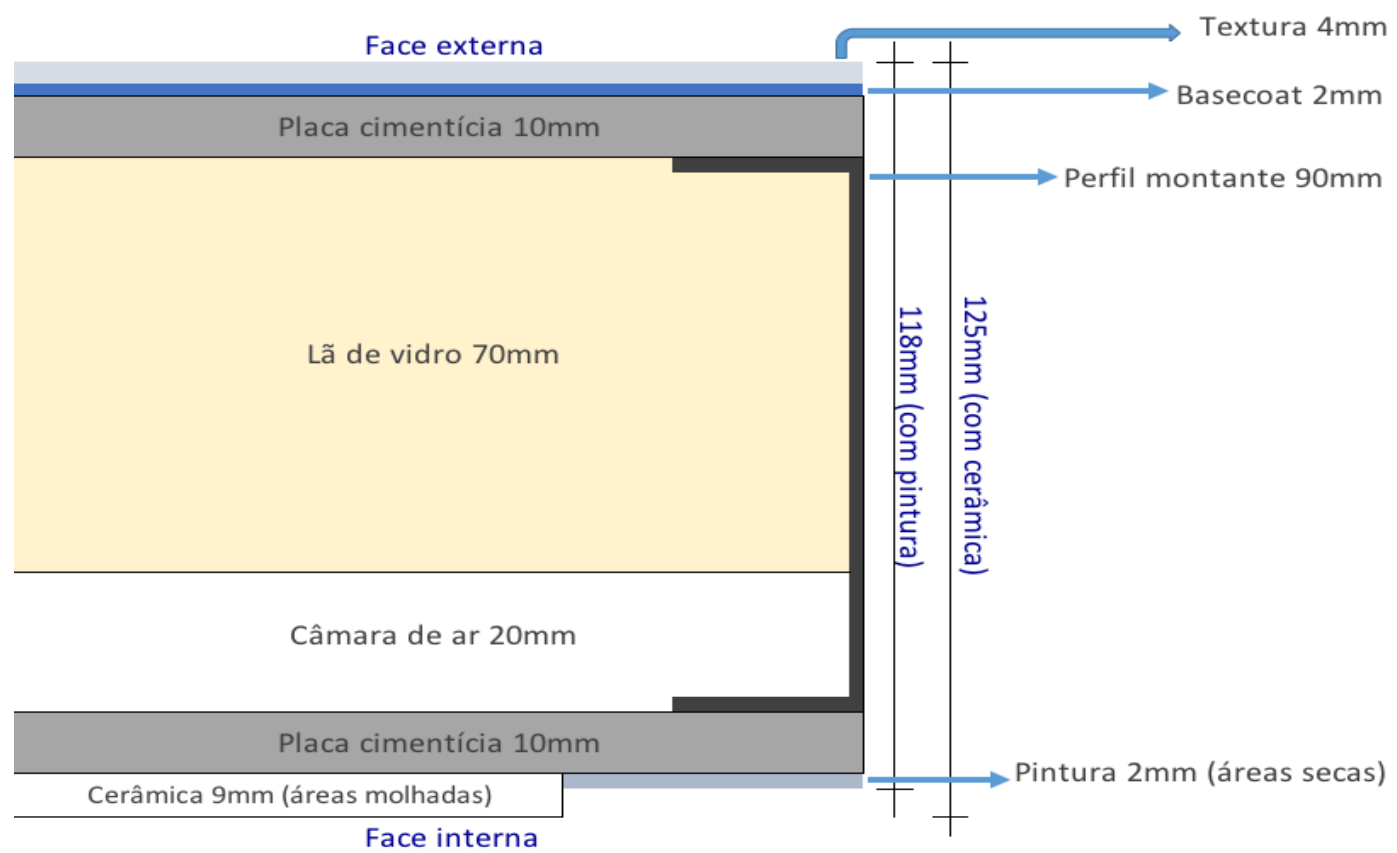

Figura 12 - Detalhe ilustrativo do painel 8.

Fonte: Arquivo pessoal, 2016 
Painel 9:

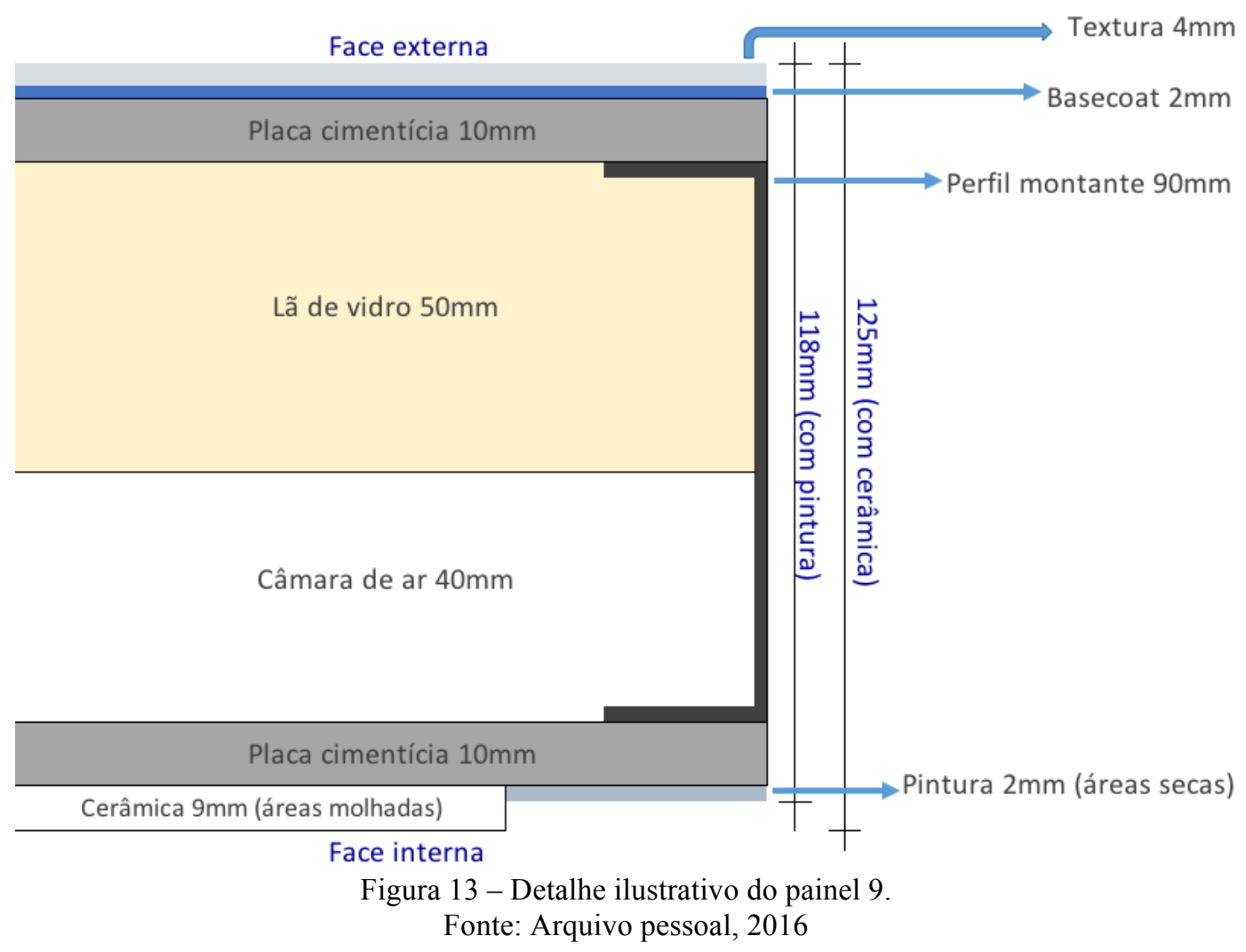

Painel 10:

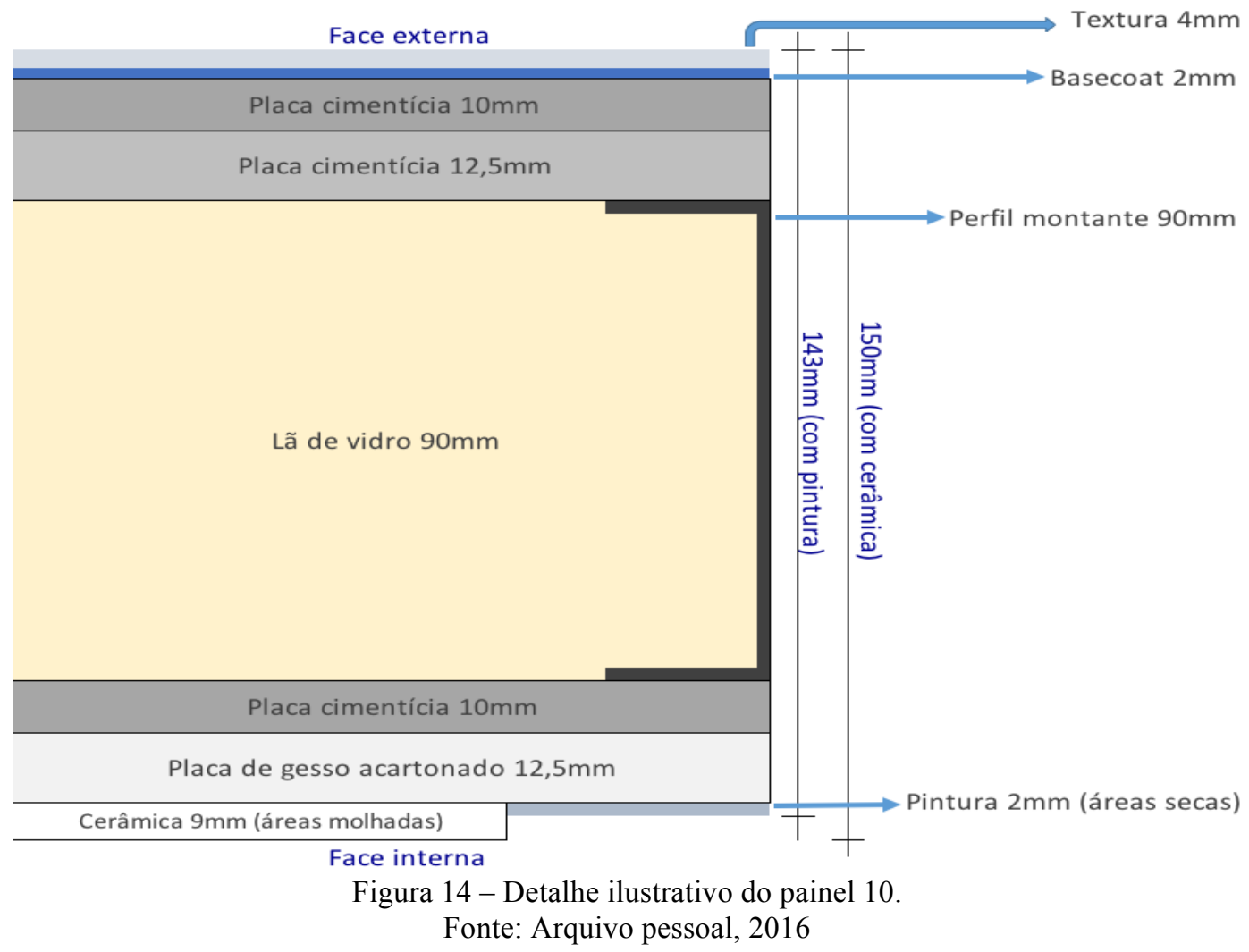


Tipologia de Painel 11:

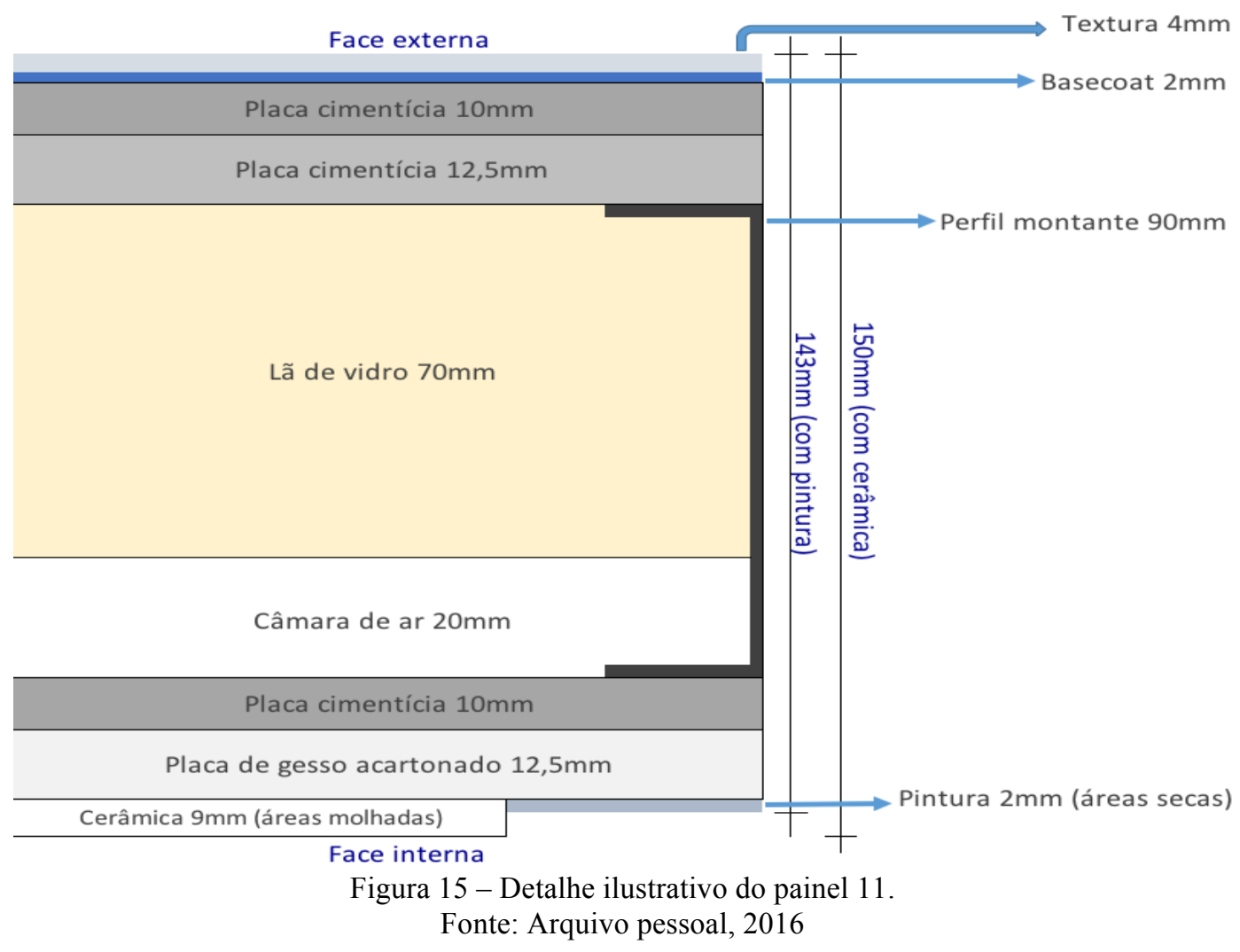

Painel 12:

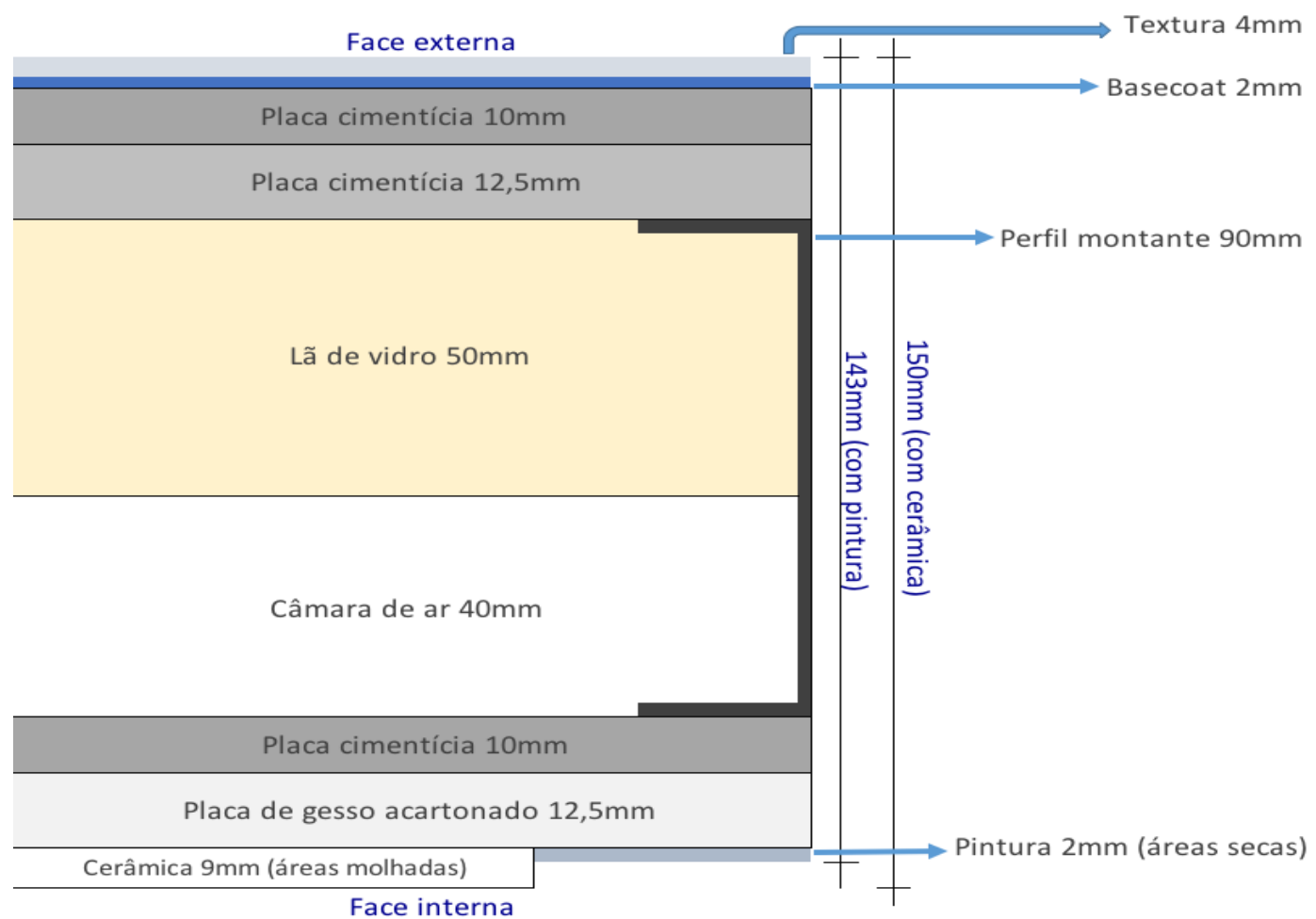

Figura 16 - Detalhe ilustrativo do painel 12.

Fonte: Arquivo pessoal, 2016 


\subsection{Metodologia detalhada da $3^{a}$ fase}

A metodologia adotada para a composição das 2 tipologias de painéis da $3^{\text {a }}$ fase esta descrita na tabela 3 abaixo. As premissas dos dias típicos de verão e inverno, nas condições mais restritivas foram mantidas.

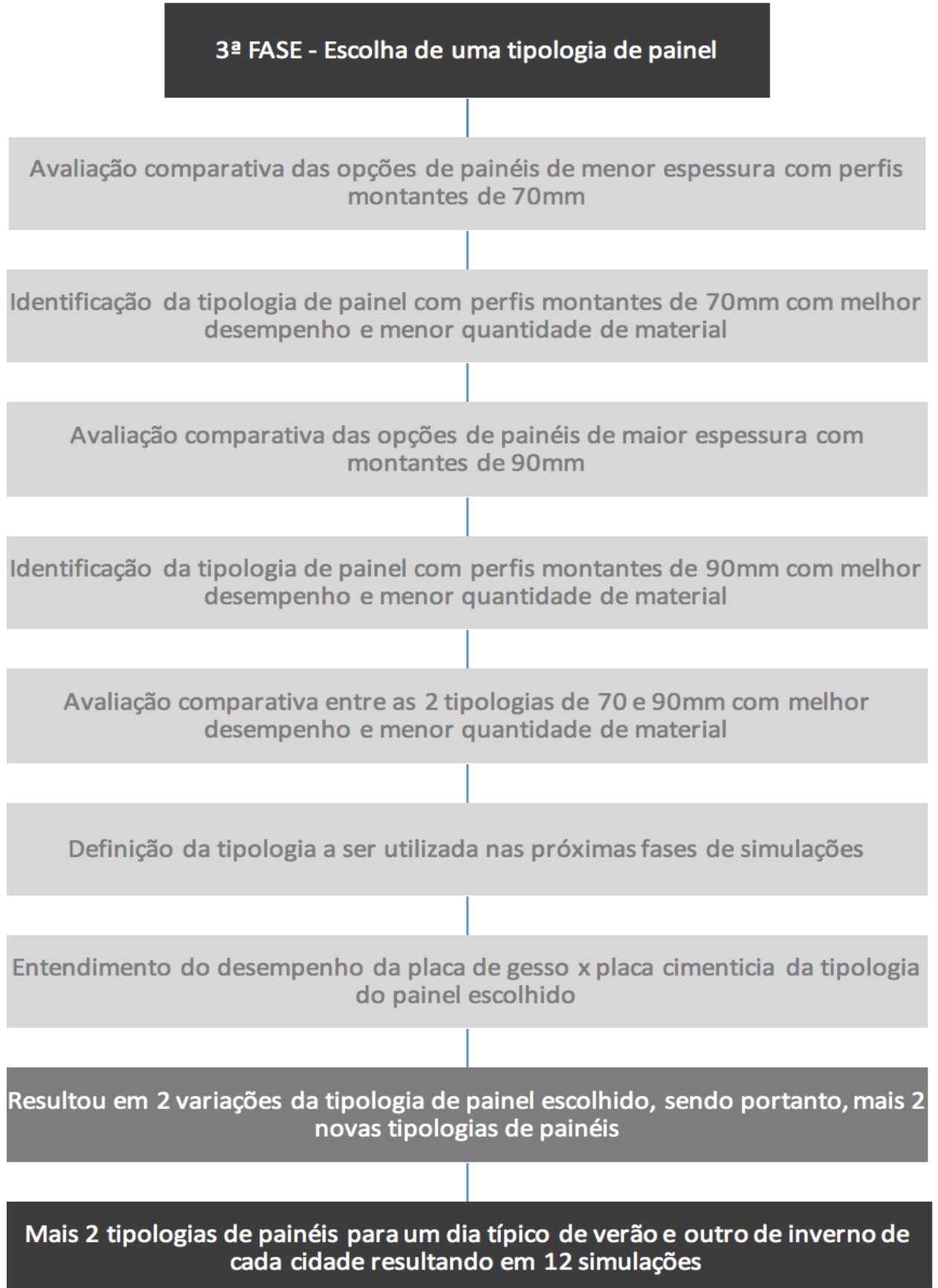

Tabela 3 - Metodologia detalhada da $3^{\text {a }}$. Fase.

Fonte: Arquivo pessoal, 2016 
O intuito na $3^{\text {a }}$ fase não foi o de simular mais outras diversas tipologias de painéis, e sim de fazer uma avaliação prévia e escolher uma única para ser utilizada desta fase em diante. $\mathrm{Na} 1^{\mathrm{a}}$ e $2^{\mathrm{a}}$ fase, foram simuladas 12 tipologias diferentes de painéis entre as opções de menor espessura $(70 \mathrm{~mm})$ e as opções de maior espessura $(90 \mathrm{~mm})$, resultando em um total de 72 simulações. Através destas, no início da $3^{\mathrm{a}}$ fase foi possível realizar uma avaliação comparativa dos níveis de desempenho. Aquela tipologia de painel que apresentou melhores resultados utilizando menores espessuras ou quantidades de materiais foi a escolhida.

Após a definição da tipologia de painel a ser utilizado, foi realizado um estudo para mensurar o desempenho térmico individual das últimas camadas de placas internas e externas. Para isto foi necessário simular 2 novas ramificações da tipologia de painel escolhida, sendo uma sem a última camada de placa de gesso da face interna, denominada tipologia de painel 4.1. E a outra, sem a última camada de placa cimentícia da face externa, denominada tipologia 4.2.

Esta etapa se fez necessária devido a ambas as camadas terem sido adicionadas ao mesmo tempo nas simulações iniciais, motivo pelo qual não foi possível de ser verifícado anteriormente. Os detalhes ilustrativos destas tipologias são apresentados nas Figuras 17 e 18 a abaixo. 


\subsubsection{Tipologias de painéis da $3^{\mathrm{a}}$ Fase}

Em seguida são apresentadas nas Figuras 17 e 18 as espessuras e camadas de materiais que compõem cada uma das 2 tipologias de painéis internos e externos da $3^{\mathrm{a}}$ fase.

Painel 4.1:

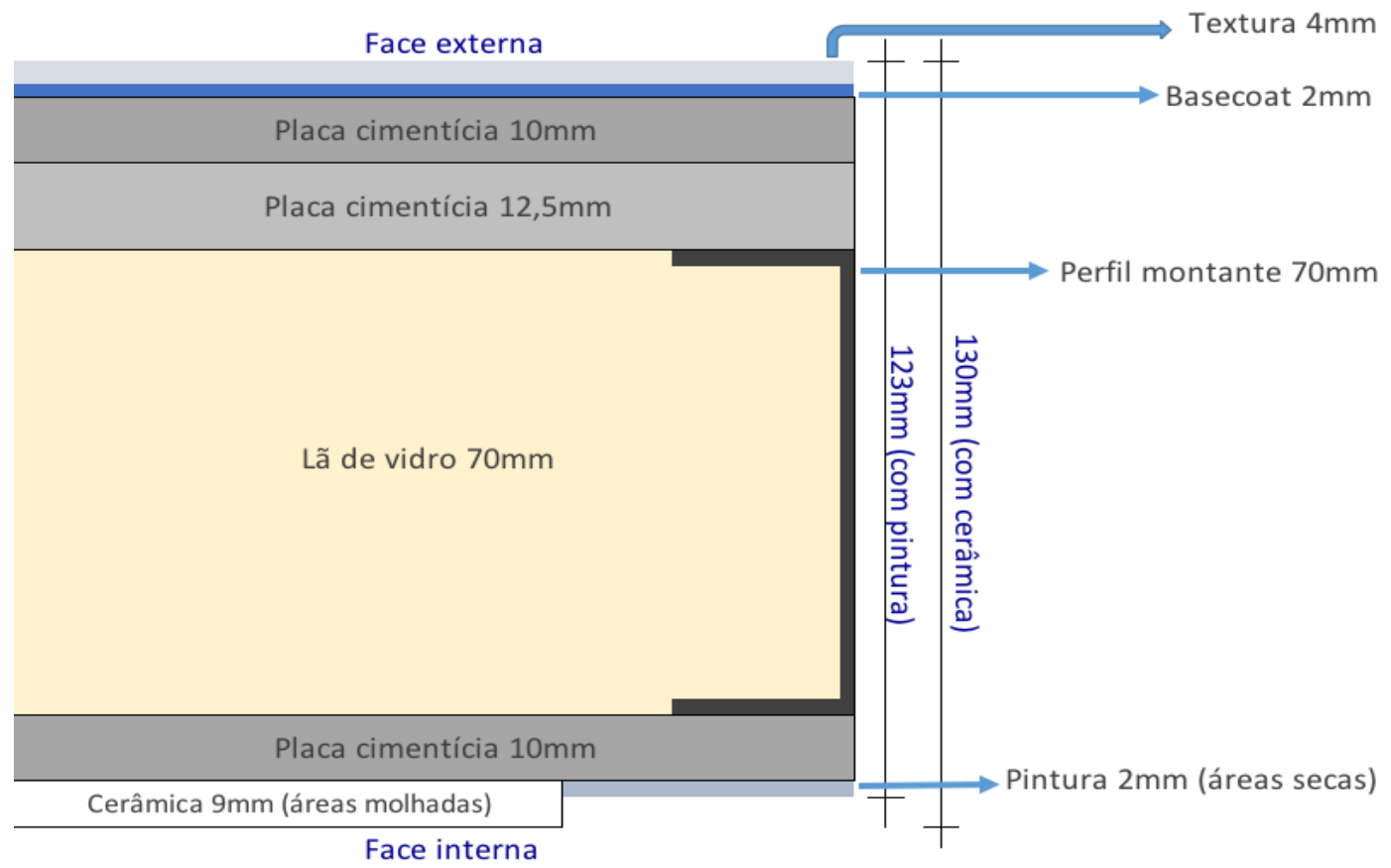

Figura 17 - Detalhe ilustrativo do painel 4.1 com uma placa de gesso retirada da face interna. Fonte: Arquivo pessoal, 2016

Painel 4.2:

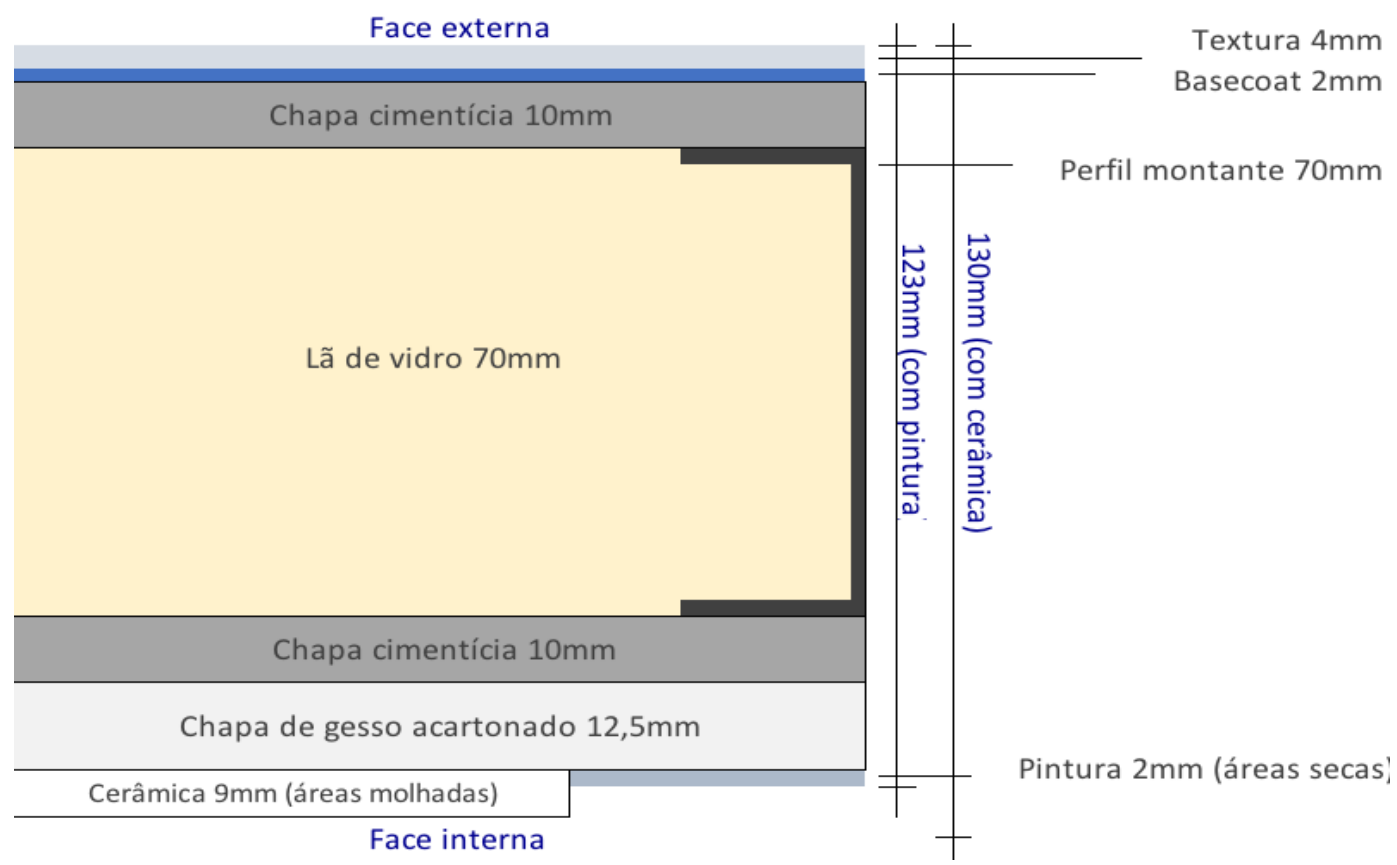

Figura 18 - Detalhe ilustrativo do painel 4.2 com uma placa cimentícia retirada da face externa. Fonte: Arquivo pessoal, 2016 


\subsection{Metodologia detalhada da $4^{\text {a }}$ fase}

Após as simulações de diversas tipologias de painéis da $1^{\mathrm{a}}$ e $2^{\mathrm{a}}$ fase e da escolha de uma destas tipologias na $3^{\mathrm{a}}$ fase, na $4^{\mathrm{a}}$ fase, foram adicionadas camadas de placas tanto na face interna quanto na externa desta tipologia de painel selecionada. A metodologia detalhada da $4^{\mathrm{a}}$ fase esta descrita na tabela 4 abaixo.

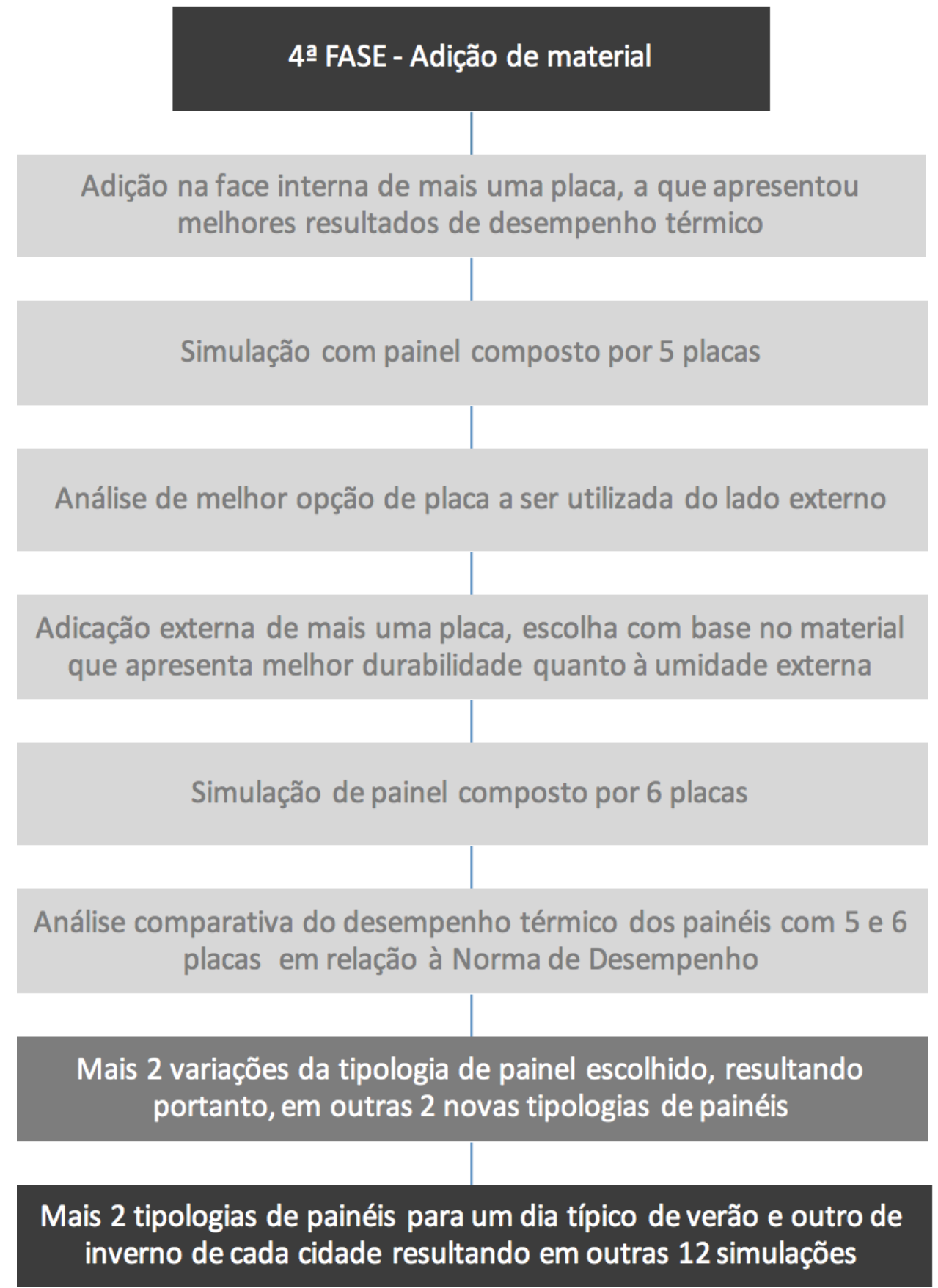

Tabela 4 - Metodologia detalhada da $4^{\text {a }}$. Fase.

Fonte: Arquivo pessoal, 2016 
A $4^{\mathrm{a}}$ fase resultou em duas novas tipologias de painel, uma com 5 placas o qual foi denominado 4.3 , e a tipologia de painel 4.4, tendo esta o total de 6 placas. As placas de gesso não podem ficar expostas a umidade em área externa, devido a isto, foi escolhida a placa cimentícia para ser adicionada na face externa da tipologia 4.4, ao invés de placas gesso.

Com o total de 72 simulações iniciais da $1^{\mathrm{a}}$ e $2^{\mathrm{a}}$ fase, somados a mais 24 simulações da $3^{\mathrm{a}}$ e $4^{\mathrm{a}}$ fase, chegou-se em um total de 96 simulações. As simulações até a $4^{\text {a }}$ fase, seguiam-se na tentativa de que uma ou mais tipologias de painéis pudessem atender aos requisitos de desempenho mínimo, estando expostos à parâmetros mais exigentes, inclusive acima dos estipulados na Norma de Desempenho. O intuito era encontrar tipologias de painéis que pudessem atender a tais cenários, pois então, todos os outros com menor exigência, teoricamente, apresentariam resultados favoráveis e com níveis mais elevados de conforto para o usuário.

Porém, após as tipologias apresentarem resultados consideravelmente desfavoráveis para os dias típicos de inverno perante a estes parâmetros mais exigentes, optou-se por modifica-los. A redução nos níveis de exigências dos parâmetros, tem como intuito atender o principal objetivo do presente estudo que é, fornecer insumos para uma tomada de decisão de uma tipologia de painel e com bom custo beneficio (sem excesso de material) que apresente resultados favoráveis para as 3 cidades. Utilizando os parâmetros anteriores, pode-se concluir que isto não seria possível. As mudanças de parâmetros são apresentadas e utilizadas a partir da $5^{\mathrm{a}}$ fase. 


\subsubsection{Tipologias de painéis da $4^{\mathrm{a}}$ Fase}

Em seguida são apresentadas nas Figuras 19 e 20 as espessuras e camadas de materiais que compõem cada uma das 2 tipologias de painéis internos e externos da $4^{\mathrm{a}}$ fase.

\section{Painel 4.3}

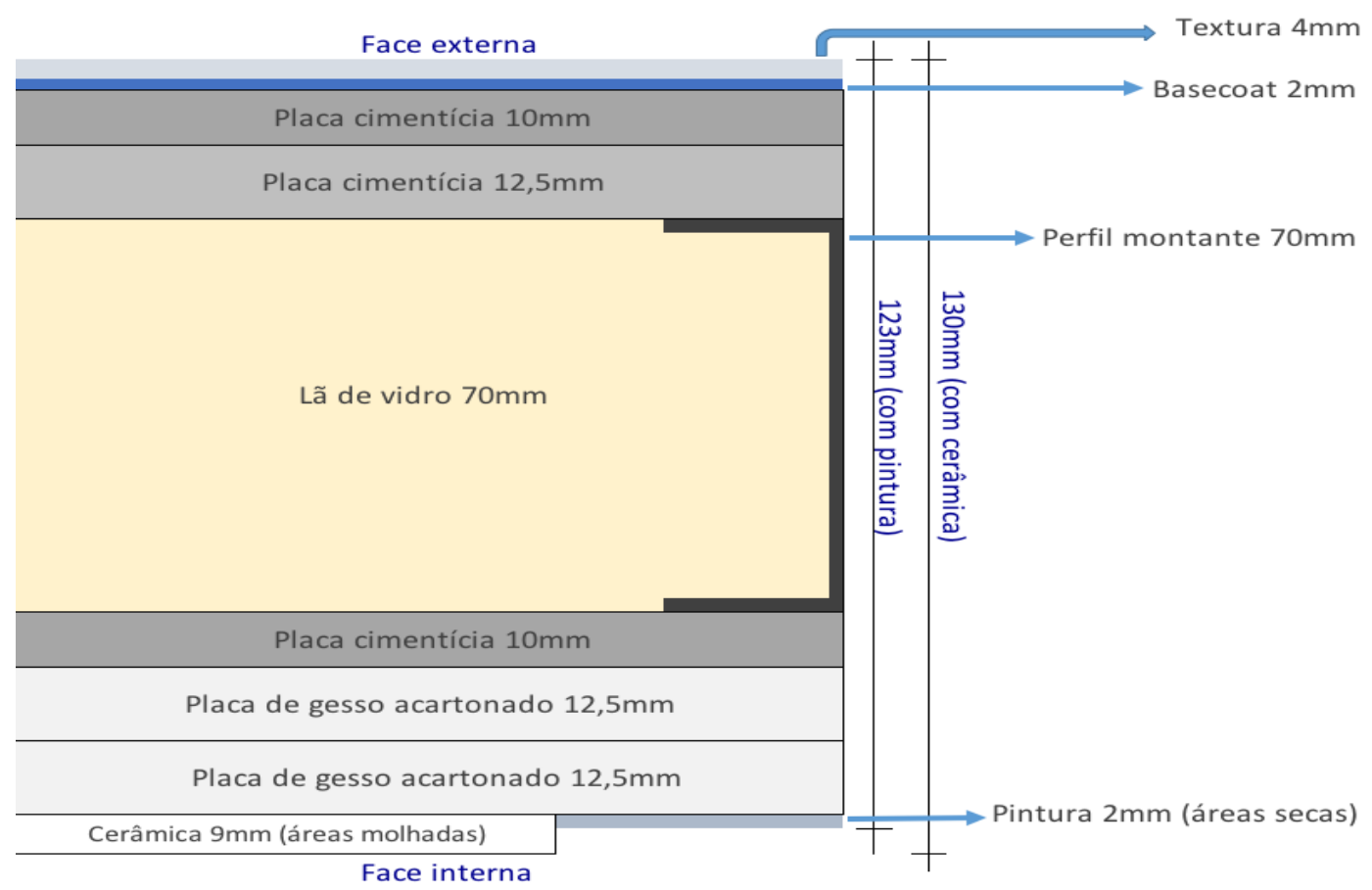

Figura 19 - Detalhe ilustrativo do painel 4.3 com mais uma placa de gesso adicionada na face interna. Fonte: Arquivo pessoal, 2016

Painel 4.4:

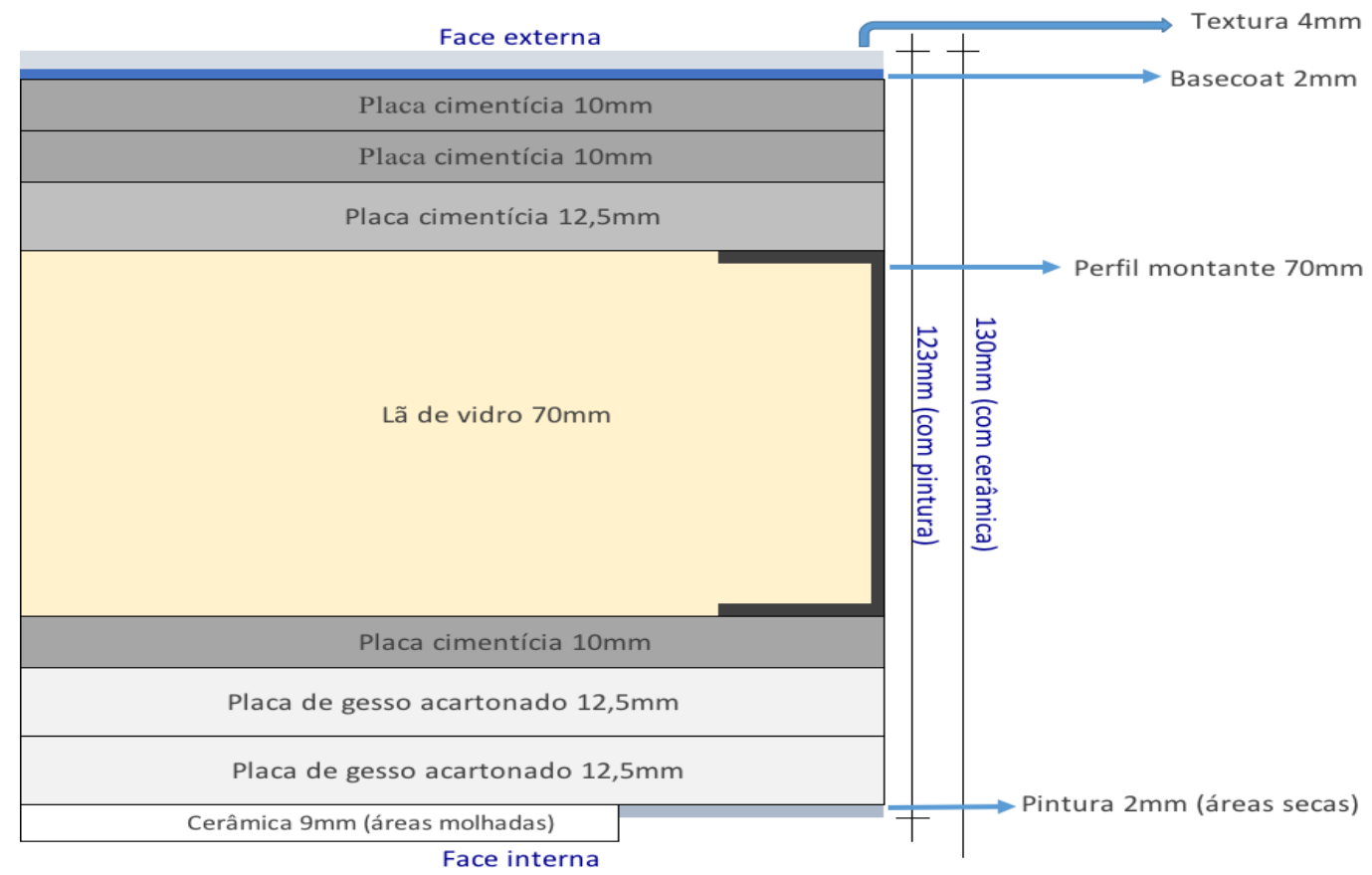

Figura 20 - Detalhe ilustrativo do painel 4.4 com mais uma placa cimentícia adicionada na face externa. Fonte: Arquivo pessoal, 2016 


\subsection{Metodologia detalhada da $5^{\text {a }}$ fase}

$\mathrm{Na} 5^{\mathrm{a}}$ fase, reutilizou-se a mesma tipologia de painel que foi escolhida anteriormente, em sua versão inicial sem variações (exclusões ou adições de materiais). Portanto, o que muda nesta fase, são os parâmetros, conforme permite a ABNT NBR 15575-1/2013.

A mudança de parâmetro para os dias típicos de inverno poderia ter sido menos restritivo (mais fácil de ser atendido), se tivesse sido adotado a taxa de renovação de somente 1 vez por hora. Optou-se pela taxa de renovação de 5 vezes por hora exatamente por ser um cenário mais restritivo entre as opções, e estar mais próximo dos objetivos inicias do estudo.

A metodologia adotada para a $5^{\text {a }}$ fase esta descrita na tabela 5 abaixo.

\section{5a FASE - Mudanças de Parâmetros}

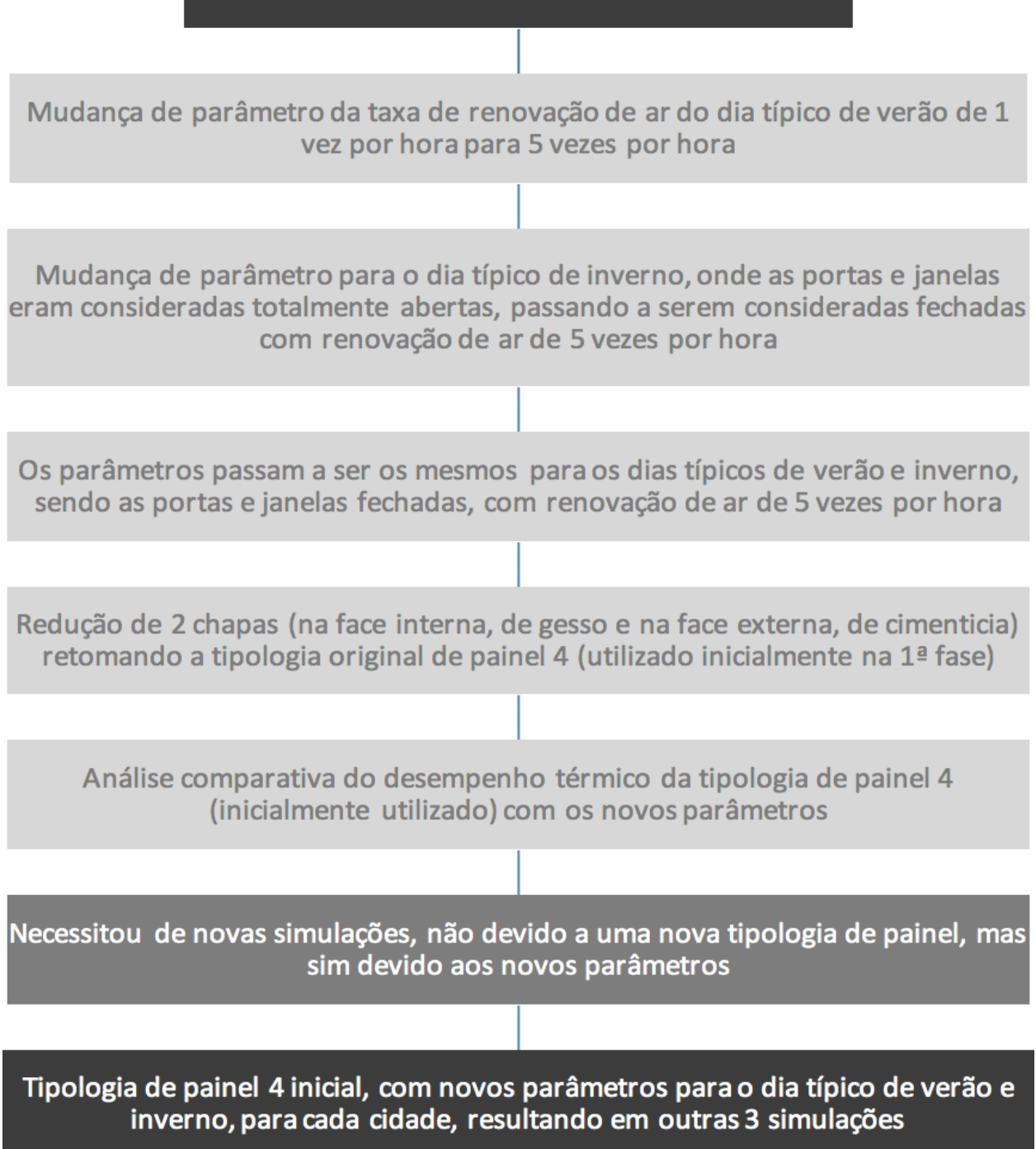

Tabela 5 - Metodologia detalhada da $5^{\text {a }}$. Fase.

Fonte: Arquivo pessoal, 2016 


\subsubsection{Tipologia de painel da $5^{\text {a }}$ Fase}

A seguir, é apresentado novamente na Figura 21 as espessuras individuais de cada material e as espessuras totais que compõem a tipologia de painel 4 inicial, o qual foi reutilizado na $5^{\text {a }}$ fase com parâmetros modificados.

Painel 4 inicial:

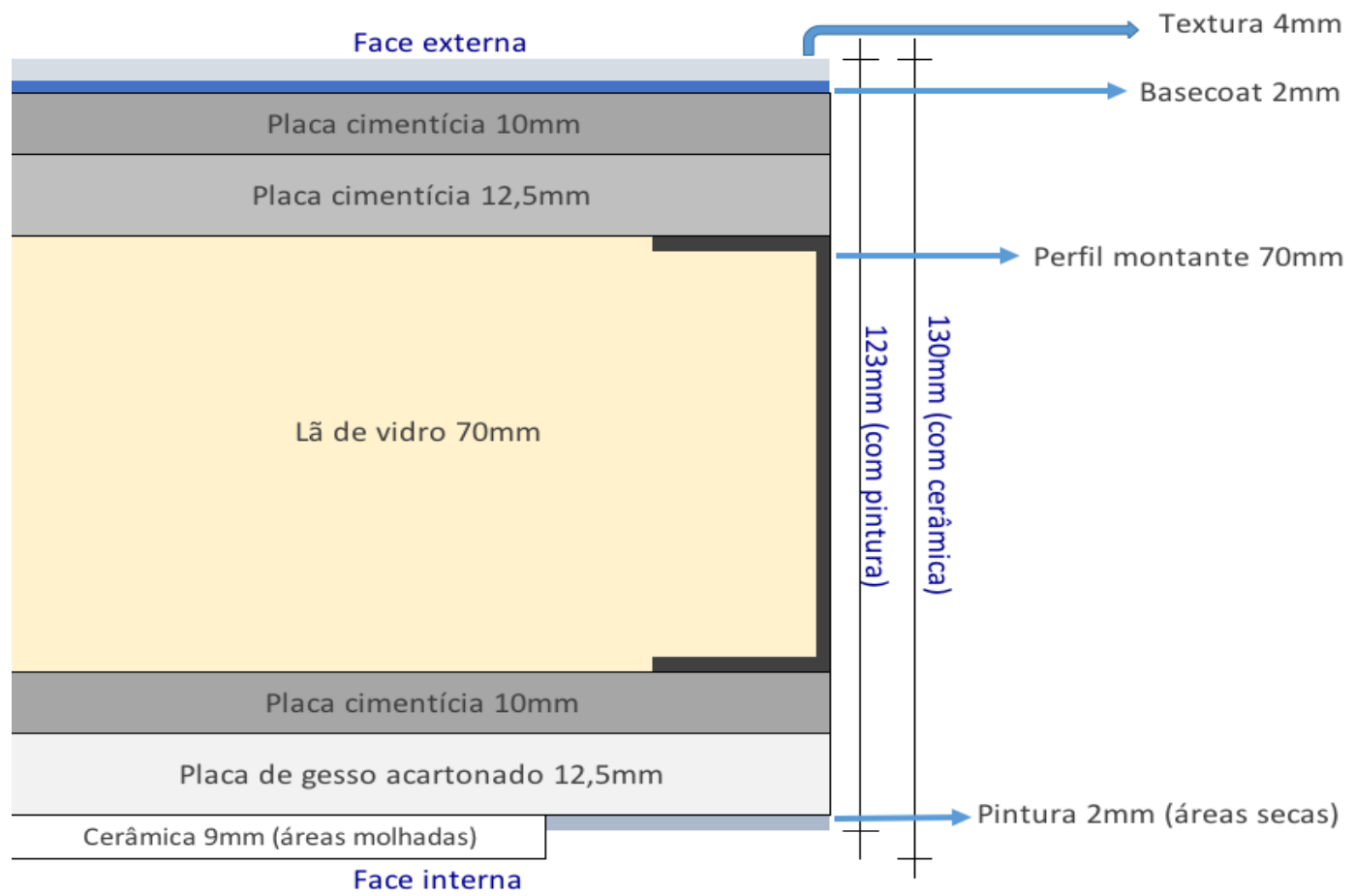

Figura 21 - Detalhe ilustrativo do painel 4 inicial reutilizado na $5^{\text {a }}$ fase de simulação com parâmetros modificados.

Fonte: Arquivo pessoal, 2016 


\section{DESCRIÇÃO DO MODELO}

São apresentadas a seguir, as características do modelo residencial térreo a ser utilizado para as simulações e posteriormente, a forma de análise dos resultados.

\subsection{Características do modelo residencial a ser utilizado nas simulações:}

O modelo para as simulações é uma residência modular térrea de $49,92 \mathrm{~m}^{2}$. A tipologia construtiva é: piso e laje de concreto, cobertura em duas águas, com telha de fibrocimento; os perfis e as vigas são de aço sendo estas as premissas inalteráveis.

As tipologias de painéis pré-fabricados foram inseridas nas fachadas e nas vedações internas. Foram utilizados os dados meteorológicos da cidade de Fortaleza-CE (Região Nordeste), São Paulo-SP (Região Sudeste) e Curitiba-PR (Região Sul) do Brasil para avaliar o modela da planta (Fig. 22) abaixo

Todos os ambientes possuem medidas coordenadas modularmente de multimódulos de $10 \mathrm{~cm}$ sendo as medidas de comprimento dos ambientes variáveis entre 1,60m e 3,20m, larguras variáveis de 1,30m e 2,60m e altura interna bruta do pé direito de 2,80. As Figuras 22, 23 e 24 a seguir ilustram a planta, corte e cobertura da residência objeto deste estudo.

É importante ressaltar que a $1^{\text {a }}$ fase de prototipação a ser realizada, não será a a residência modular completa com todos os ambientes, conforme ilustrado na Figura 22 abaixo, sendo esta a configuração utilizada nas simulações para este estudo. A $1^{\mathrm{a}}$ fase de prototipação prevê a execução apenas dos ambientes de sala, de banheiro e o de cozinha devido ao teto máximo de valor disponível para a categoria de Startup do Edital SENAI SESI de Inovação 2016 na qual o projeto foi selecionado juntamente com outras 11 empresas.

Os demais ambientes, são objetos a serem comtemplados em uma $2^{\mathrm{a}}$ fase de prototipação, através de uma nova aprovação deste mesmo edital, que disponibilizará o restante da verba necessária para o protótipo da casa completa.

E como o prazo de término de execução do protótipo em escala real está previsto para maio de 2017, bem como o início da realização dos testes, não será possível a realização de nenhuma medição real in loco ou verificação física anterior a esta data; portanto, não será possível, para este trabalho a realização de comparação ou conferência dos resultados. 


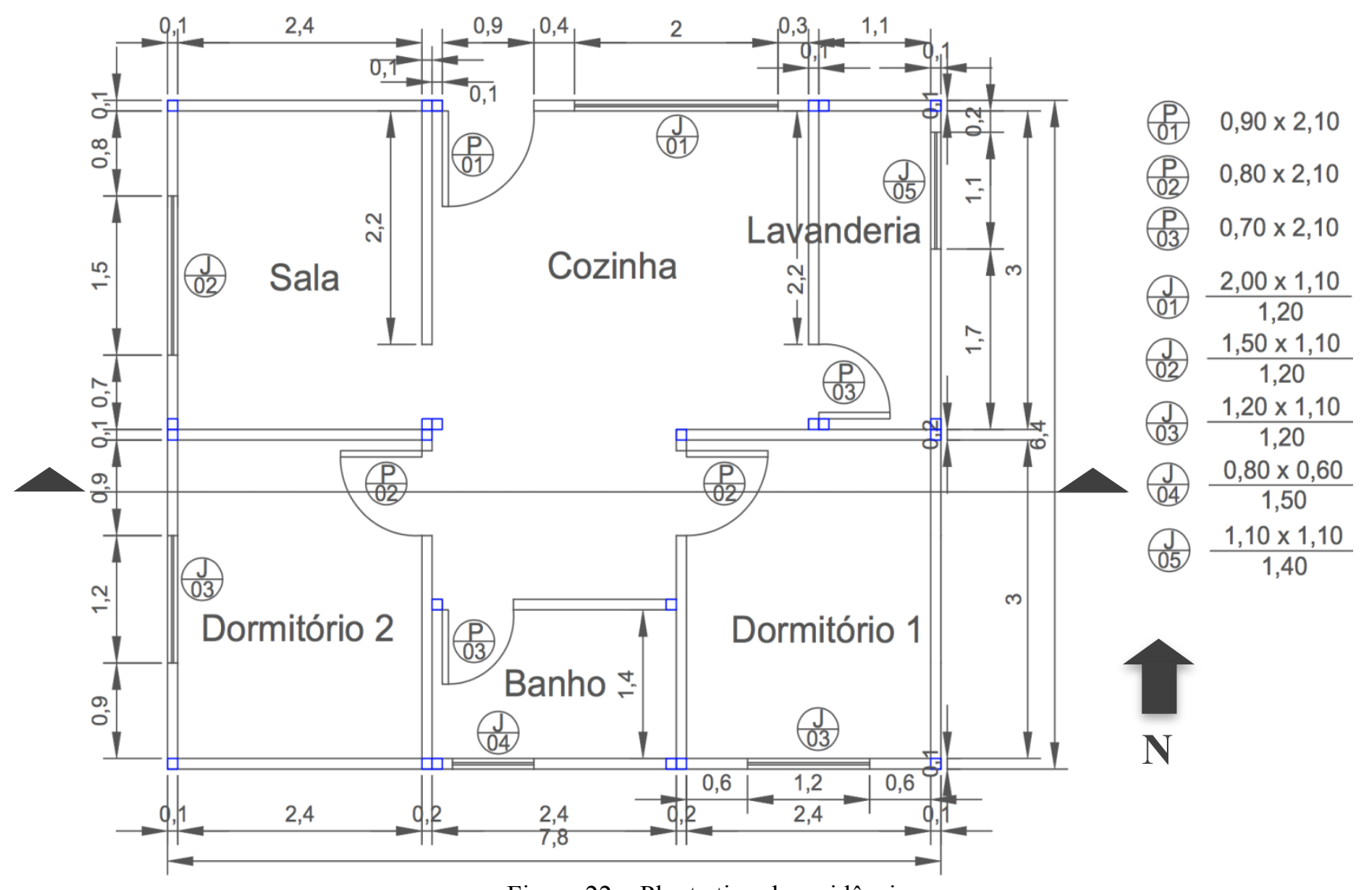

Figura 22 - Planta tipo da residência.

Fonte: Arquivo pessoal, 2015.

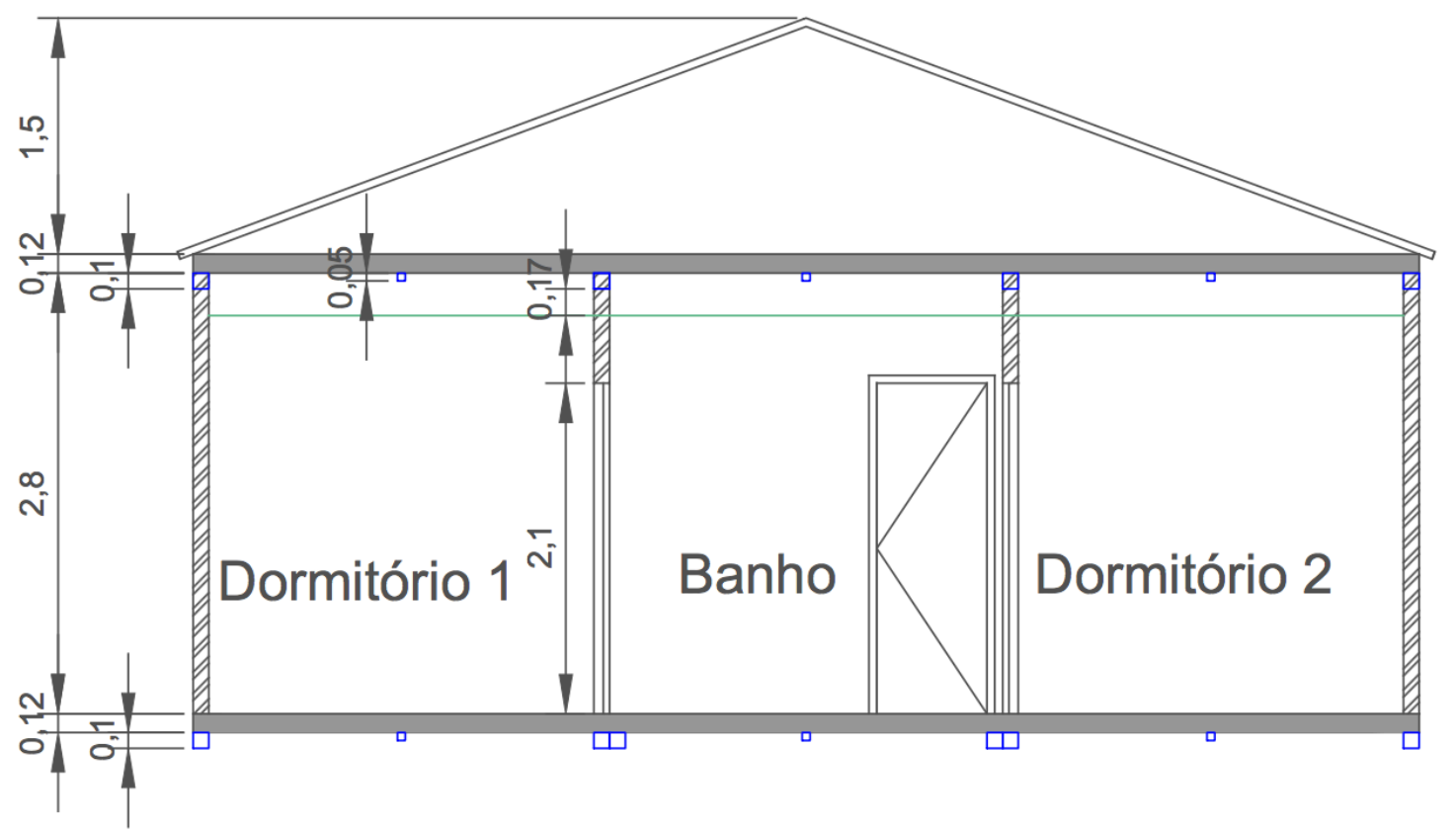

Figura 23 - Corte da residência. Fonte: Arquivo pessoal, 2015. 


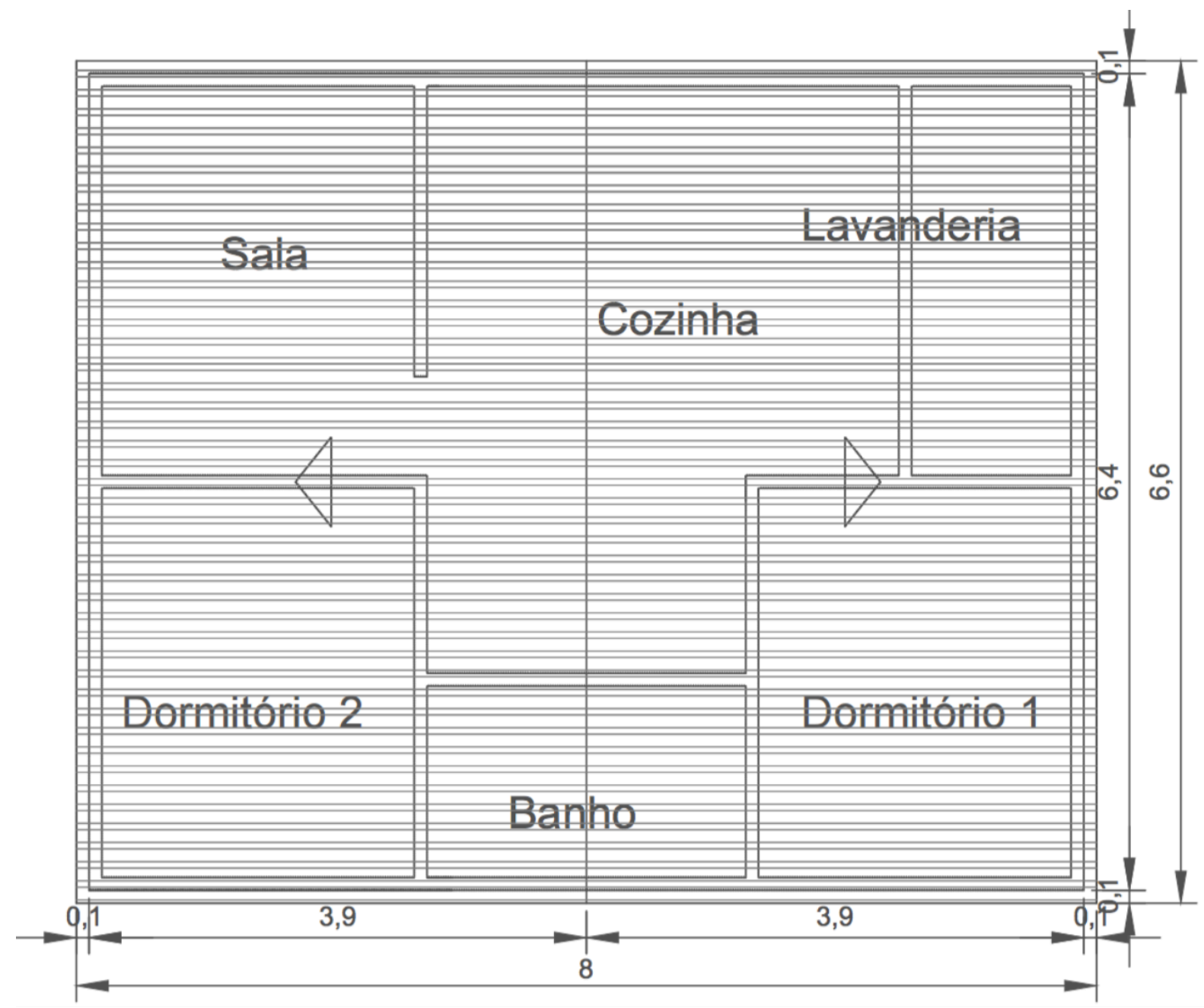

Figura 24 - Vista da cobertura da residência.

Fonte: Arquivo pessoal, 2015.

As Figuras 25, 26, 27, 28, 29 e 30 abaixo apresentam a residência completa com modelagem no software Sketchup 2015.

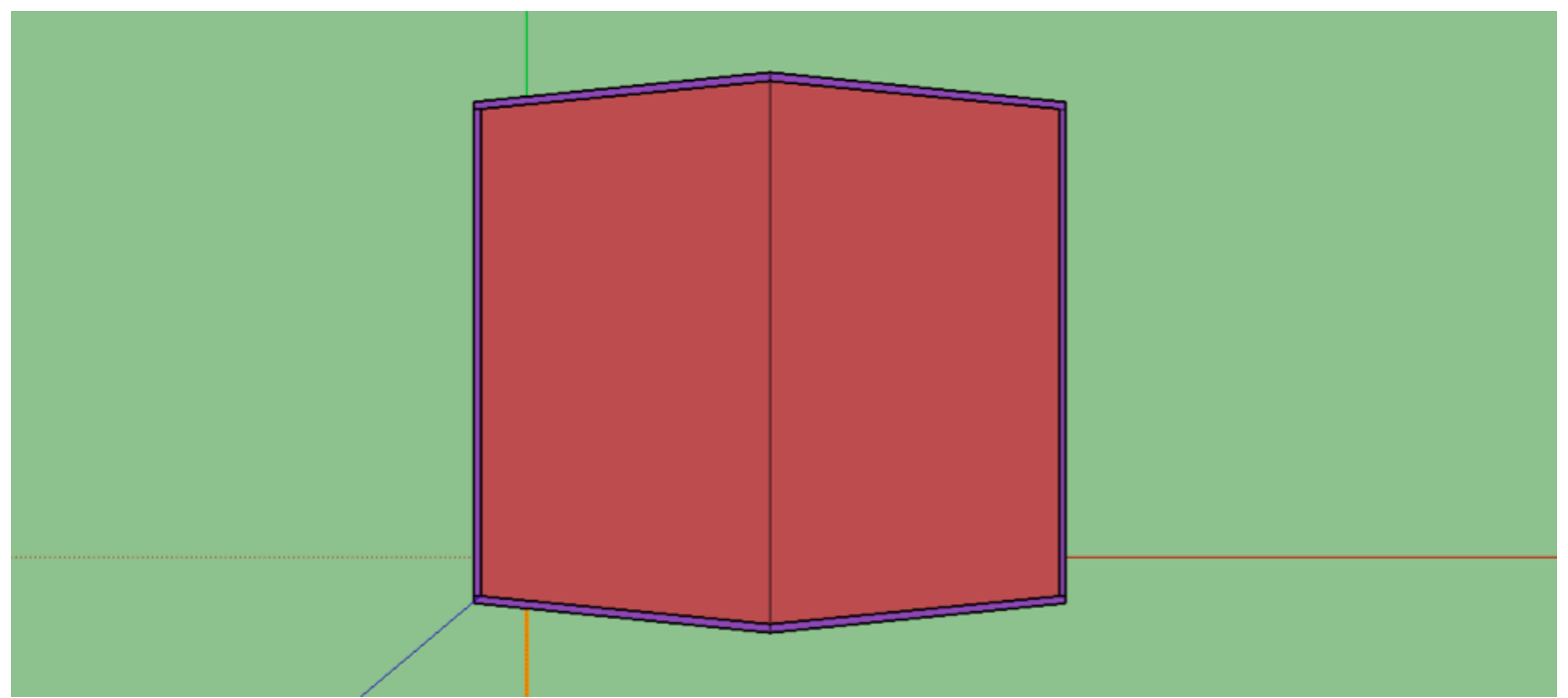

Figura 25 - Ilustração da cobertura da residência. Fonte: Arquivo pessoal, 2015. 


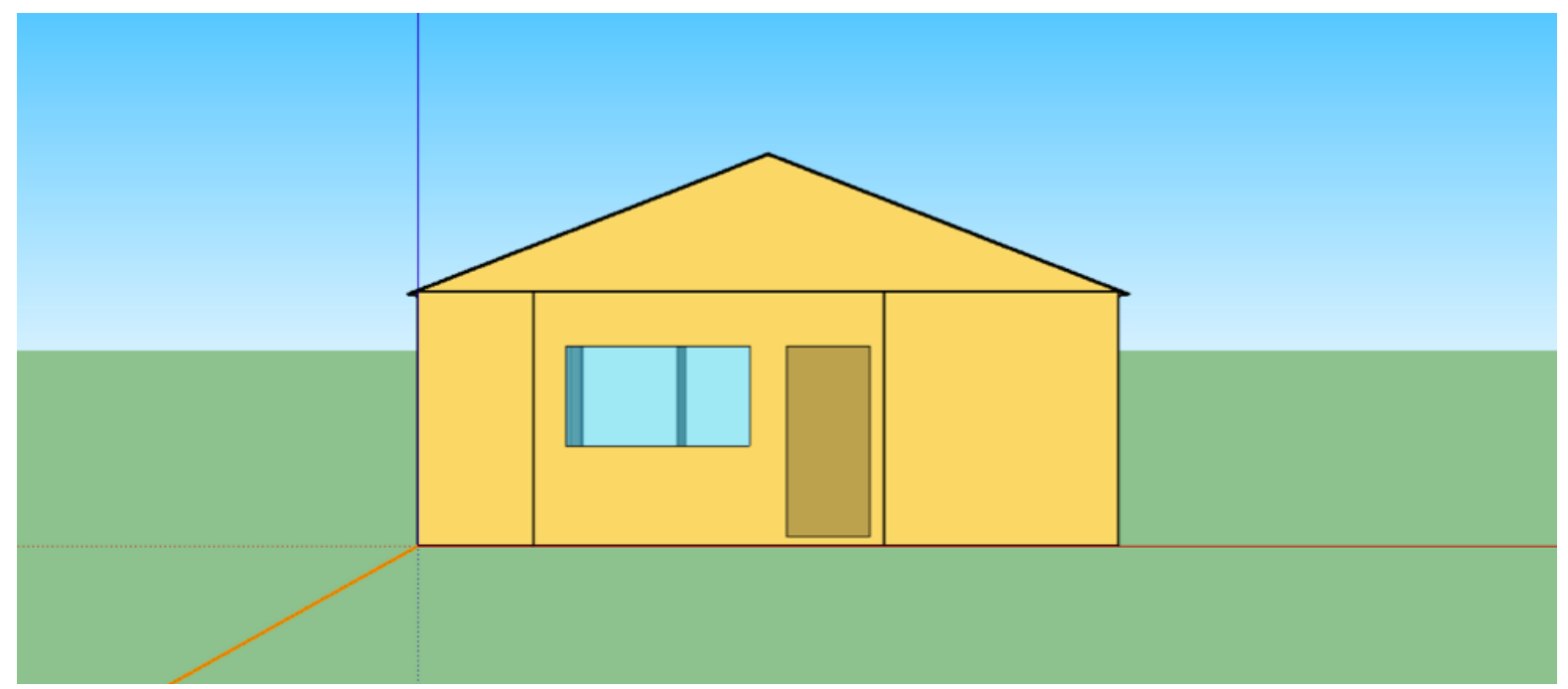

Figura 26 - Ilustração da face frontal da residência voltada ao norte. Fonte: Arquivo pessoal, 2015.

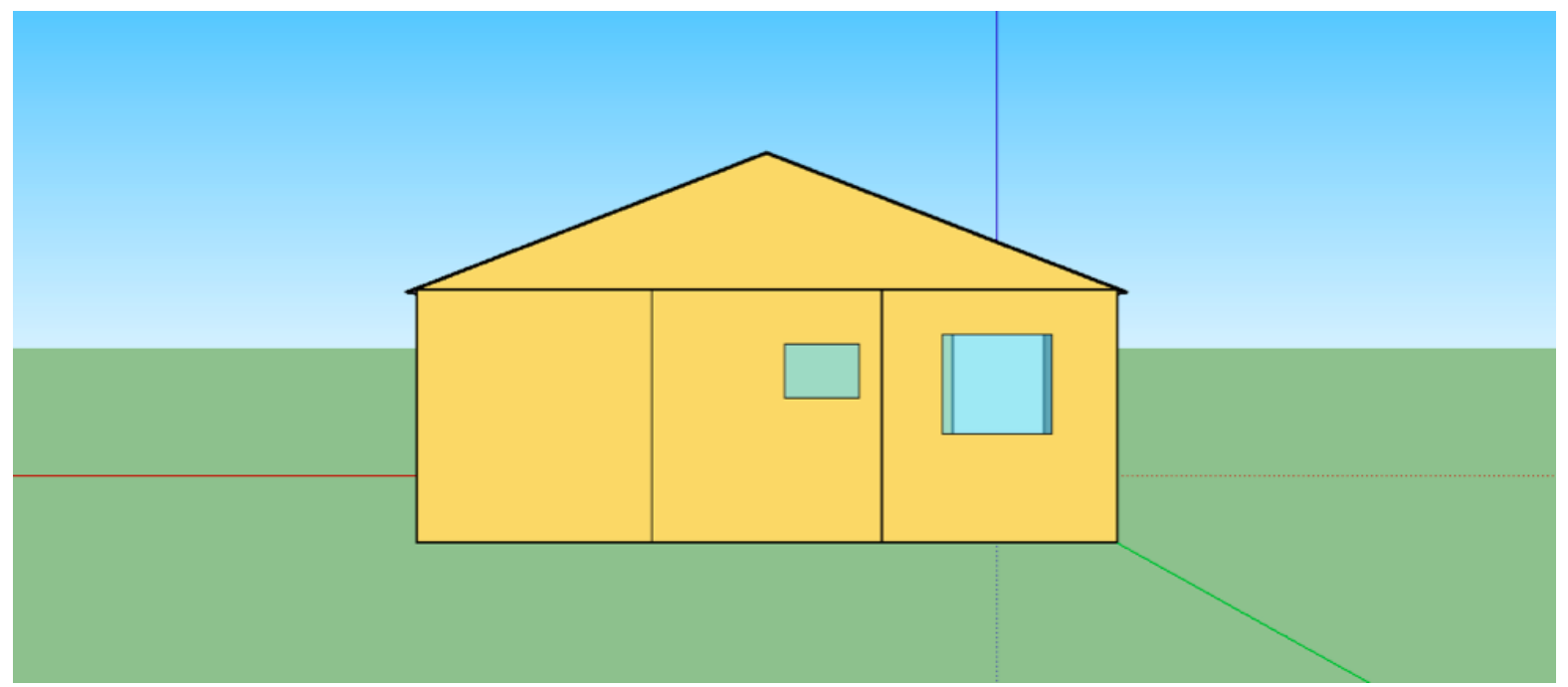

Figura 27 - Ilustração da face sul da residência.

Fonte: Arquivo pessoal, 2015.

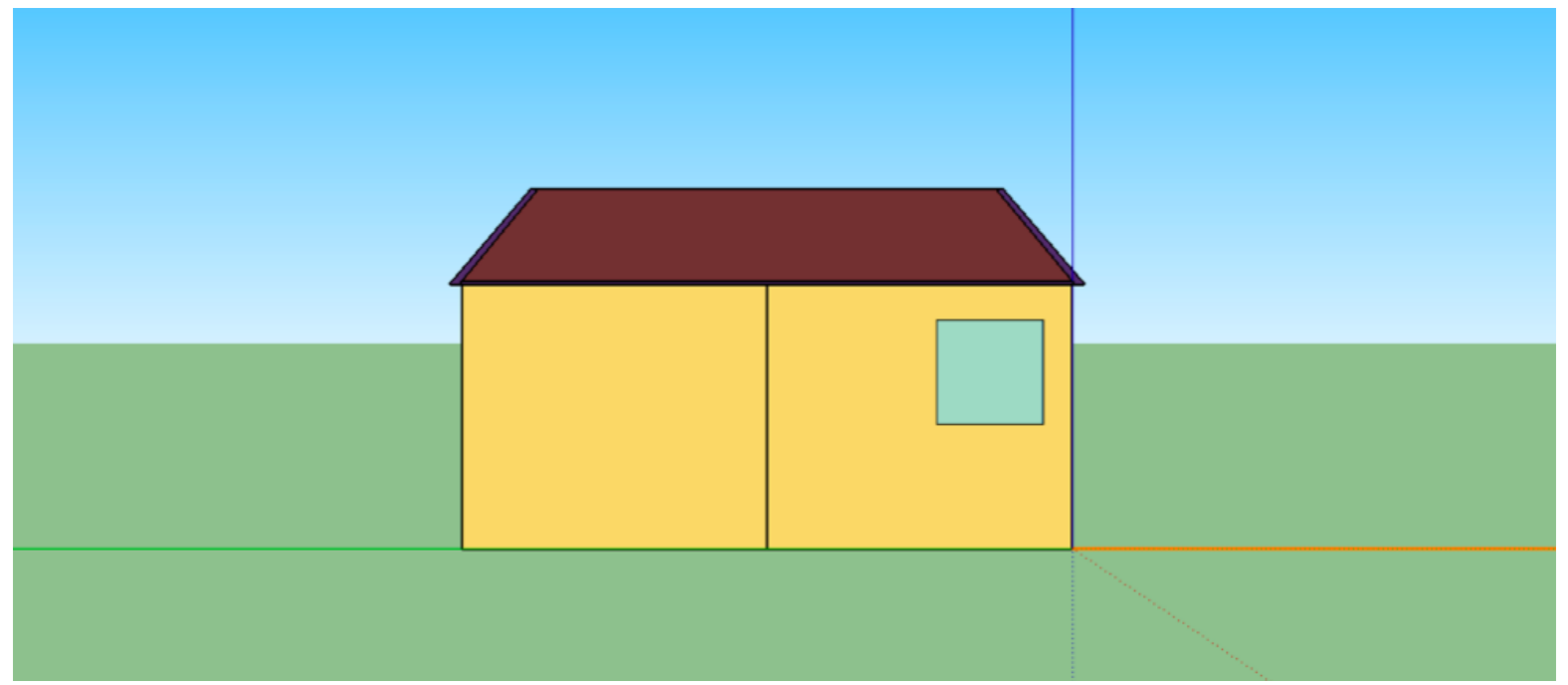

Figura 28 - Ilustração da face leste da residência.

Fonte: Arquivo pessoal, 2015. 


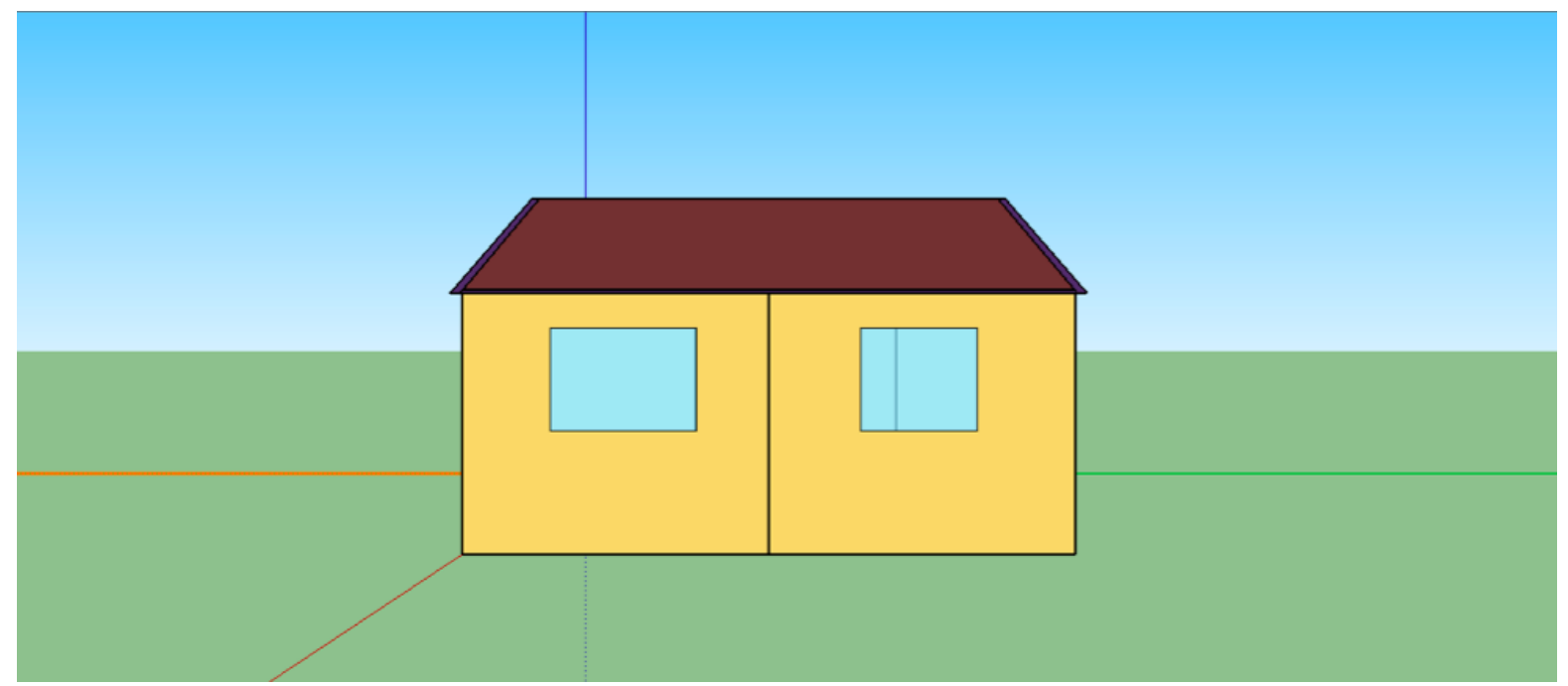

Figura 29 - Ilustração da face oeste da residência. Fonte: Arquivo pessoal, 2015.

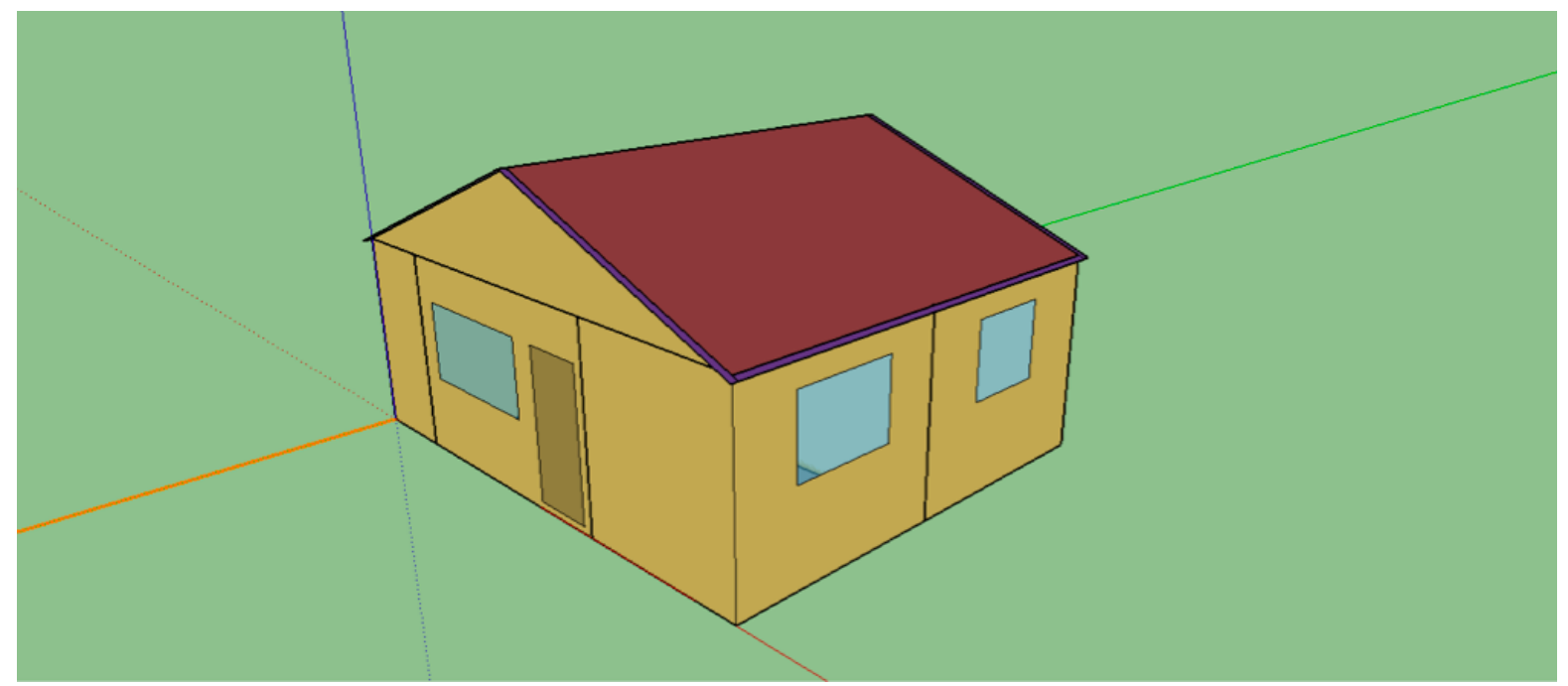

Figura 30 - Ilustração em perspectiva da residência. Fonte: Arquivo pessoal, 2015.

A residência possui um total de 7 zonas térmicas. Sendo elas:

- Zona térmica 1 - cozinha: $3,20 \mathrm{~m} \times 3,90 \mathrm{~m}=12,48 \mathrm{~m}^{2}$ com altura interna bruta do pé direito de $2,80 \mathrm{~m}$, resultando aproximadamente em $35 \mathrm{~m}^{3}$ e hall dos quartos e banheiro: $1,60 \mathrm{mx} 2,60 \mathrm{~m}=4,16 \mathrm{~m}^{2}$ com altura interna bruta do pé direito de $2,80 \mathrm{~m}$, resultando aproximadamente em $11,7 \mathrm{~m}^{3}$.

- Zona térmica 2 - sala: $3,20 \mathrm{mx} 2,60 \mathrm{~m}=8,32 \mathrm{~m}^{2}$ com altura interna bruta do pé direito de $2,80 \mathrm{~m}$, resultando aproximadamente em $23,3 \mathrm{~m}^{3}$.

- Zona térmica 3 - dormitório 2: 3,20mx2,60m =8,32 $\mathrm{m}^{2}$ com altura interna bruta do pé direito de $2,80 \mathrm{~m}$, resultando aproximadamente em $23,3 \mathrm{~m}^{3}$. 
- Zona térmica 4 - banheiro: $1,60 \mathrm{mx} 2,60 \mathrm{~m}=4,16 \mathrm{~m}^{2}$ com altura interna bruta do pé direito de $2,80 \mathrm{~m}$, resultando aproximadamente em $11,7 \mathrm{~m}^{3}$.

- Zona térmica 5 - dormitório 1:3,20mx2,60m =8,32 $\mathrm{m}^{2}$ com altura interna bruta do pé direito de 2,80m, resultando aproximadamente em $23,3 \mathrm{~m}^{3}$.

- Zona térmica 6 - área de serviço: $3,20 \mathrm{mx} 1,30 \mathrm{~m}=4,16 \mathrm{~m}^{2}$ com altura interna bruta do pé direito de 2,80m, resultando aproximadamente em $11,7 \mathrm{~m}^{3}$.

- Zona térmica 7 - área que não aparece na planta por estar entre laje e telhado formando um colchão de ar de 49,92m². Esta área não será avaliada por não se tratar de uma zona de permanência prolongada.

A zonas térmicas estão representadas na Figura 31 abaixo.

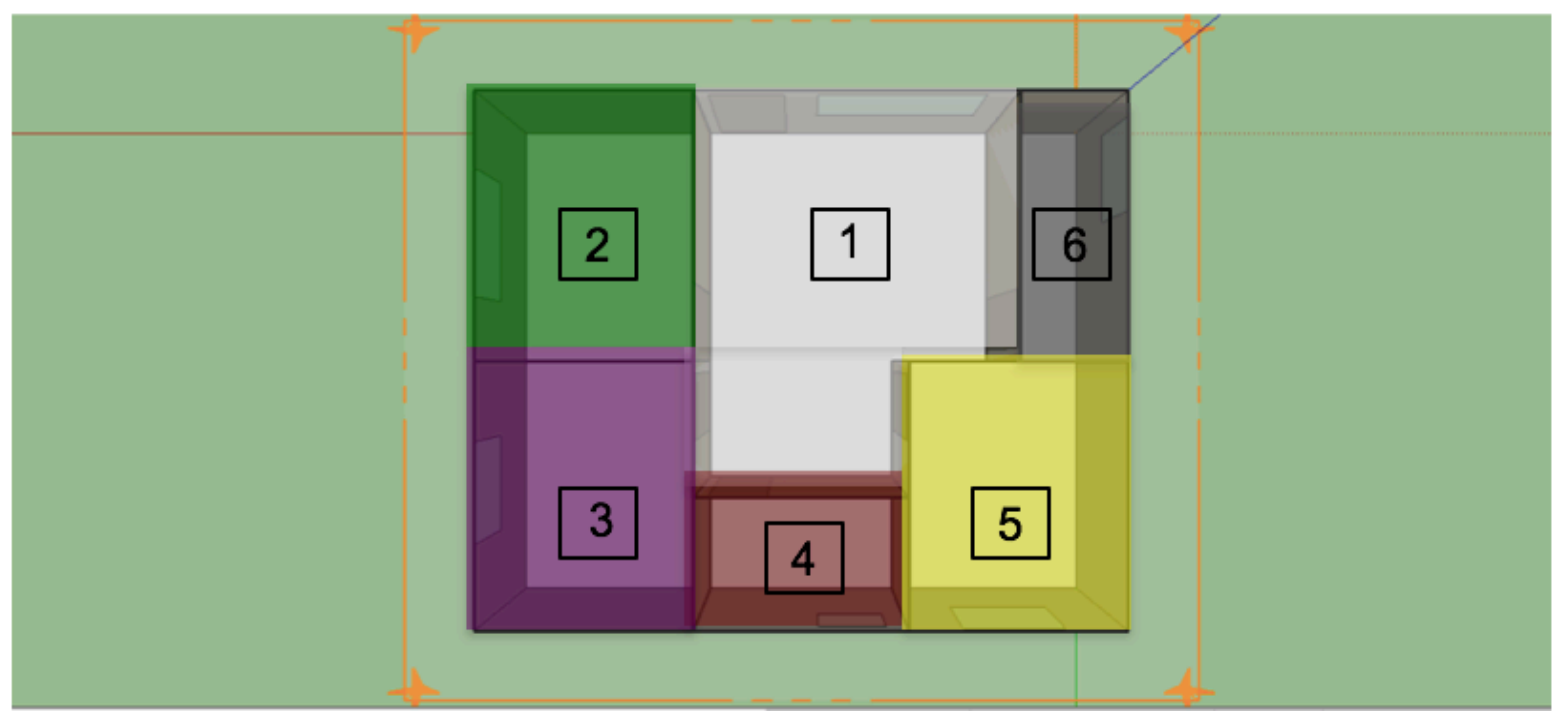

Figura 31 - Delimitação das zonas térmicas da residência.

Fonte: Arquivo pessoal, 2015.

Os ambientes considerados como referência para as análises (zonas térmicas 2 e 5 da Figura 31 acima), estão posicionados de acordo com as orientações da ABNT NBR 15575-1/2013, assumindo-se orientações geográficas mais críticas de ambientes de permanência prolongada (quartos e salas) posicionados nas extremidades da habitação. Sendo:

- Verão: janela do cômodo voltada para oeste e a outra parede exposta do mesmo cômodo voltada para norte. Conforme destacado em laranja na Figura 32 abaixo.

- Inverno: janela do cômodo voltada para sul e a outra parede exposta do mesmo cômodo voltada para leste. Conforme destacado em azul na Figura 32 abaixo. 
O posicionamento geográfico dos ambientes mais críticos de acordo com a Norma de Desempenho está representado na Figura 32 abaixo.

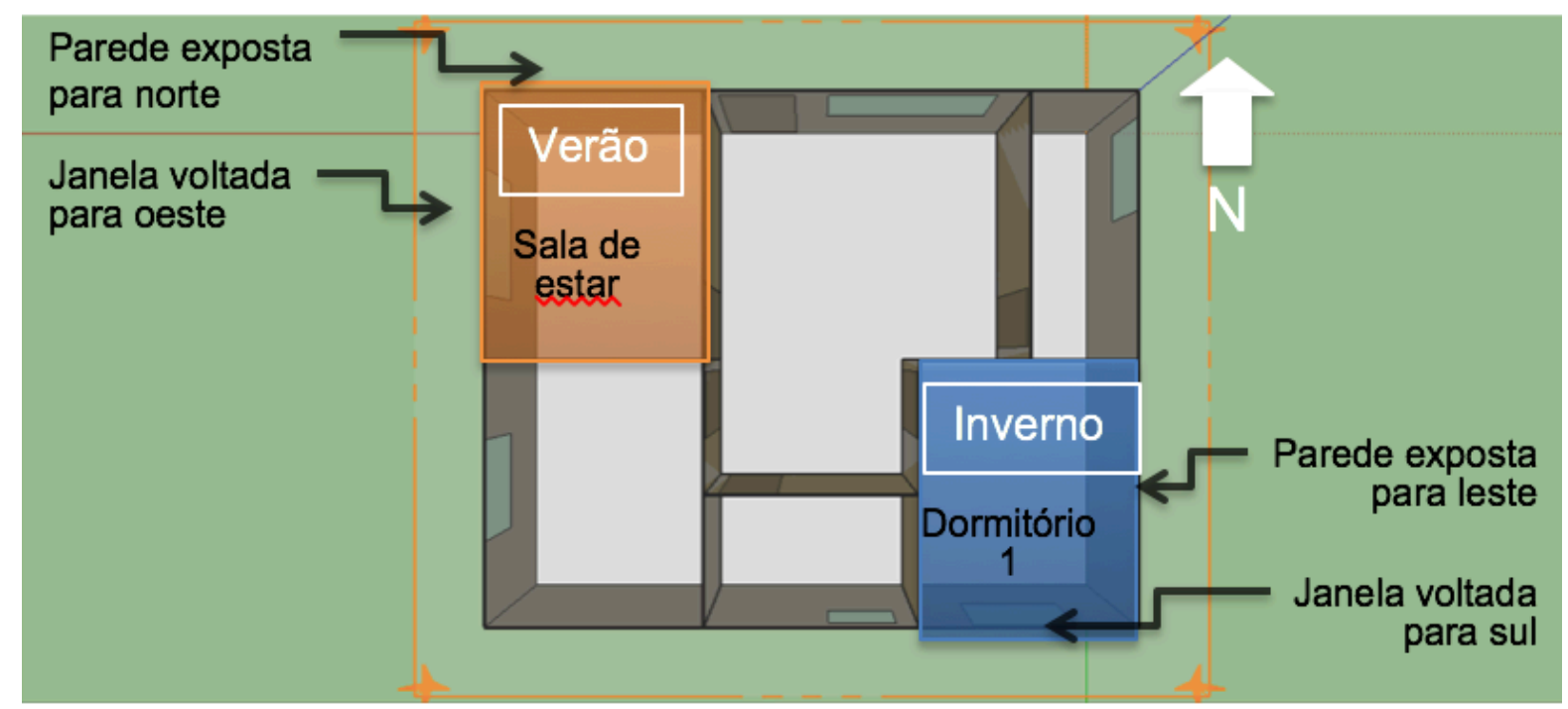

Figura 32 - Ilustração da residência indicando posicionamento crítico dos ambientes no verão e no inverno conforme orientações da ABNT NBR 15575-1/2013.

Fonte: Arquivo pessoal, 2015.

Para facilitar a industrialização do sistema, tanto a superestrutura, quanto os painéis em steel frame são coordenados modularmente As tipologias de painéis em steel frame têm premissas de materiais de acabamentos internos e externos inalteráveis, ou seja, as camadas de acabamentos (textura, basecoat, gesso liso, pintura, argamassa colante e cerâmica) mantêm-se padrão e são posicionadas igualmente na residência, independente das variações nas camadas internas (placas, câmara de ar e camada isolante, estas sim, alteráveis).

São considerados 5 tipos de camadas de acabamentos, a depender da necessidade de cada ambiente, podendo os painéis externos ter dois tipos de camadas de acabamentos internos:

- (1) face externa com camadas de acabamento em textura e basecoat e a face interna com camadas voltada para ambiente seco, em gesso liso e pintura;

- (2) face externa com camadas de acabamento em textura e basecoat e a face interna com camadas voltada para ambiente molhado, em argamassa colante e cerâmica;

Já os painéis internos, podem ter três tipos de camadas de acabamentos, dependendo também da necessidade do ambiente ou face para qual estiver voltado.

- (3) ambas as faces com camadas voltadas para ambientes secos, em gesso liso e pintura;

- (4) uma face com camadas voltada para ambientes secos, em gesso liso e pintura e a outra com camadas voltada para ambientes molhados, em argamassa colante e cerâmica; 
- (5) ambas faces de camadas voltadas para ambientes molhados ou molháveis compostas de argamassa colante e cerâmica.

Os posicionamentos destes painéis podem ser vistos na Figura 33 abaixo:

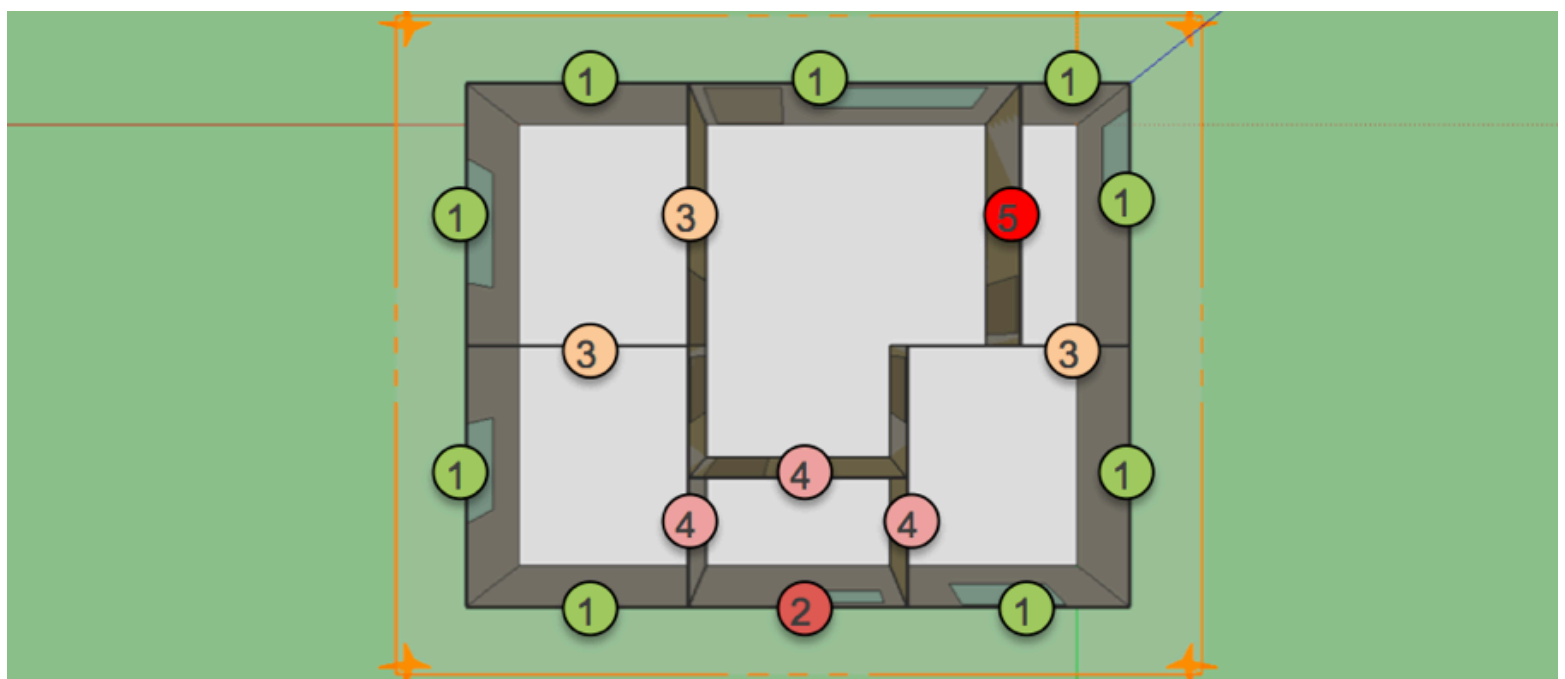

Figura 33 - Ilustração da residência indicando posicionamento e tipos de acabamentos dos painéis.

Fonte: Arquivo pessoal, 2015.

Já as camadas internas de cada painel (placas, câmara de ar e camada isolante), conforme mencionado anteriormente, estas são premissas alteráveis, podendo tanto estar ou não cada uma delas presentes nas composições internas das tipologias de painéis, quanto também podem ter suas espessuras variadas.

É importante destacar que as simulações não levaram em conta as cargas internas da residência ou schedules de ocupação; ou seja, ocupantes, iluminação e uso de equipamentos elétricos (ABNT NBR 15575-1/2013). Como condição de contorno, admitiu-se que as janelas e paredes externas estão desobstruídas, portanto, sem a presença de edificações ou vegetação nas proximidades e ainda, o beiral do telhado foi deixado com uma dimensão mínima de $10 \mathrm{~cm}$ para que não venha a exercer sombreamento nas faces da residência.

Quanto às janelas, adotou-se o sistema de abertura de folhas de correr. Quando consideradas abertas, significa 50\% de abertura e quando consideradas fechadas, $0 \%$ de abertura. Já as portas, estas quando consideradas abertas significa $100 \%$ da abertura e quando consideradas fechadas, também $0 \%$ de abertura. As aberturas dos vãos das janelas estão de acordo com o estipulado na ABNT NBR 15575-4/2013. 
A tabela 6 abaixo, apresenta as informações das propriedades termofísicas dos materiais que compõem os elementos construtivos da residência:

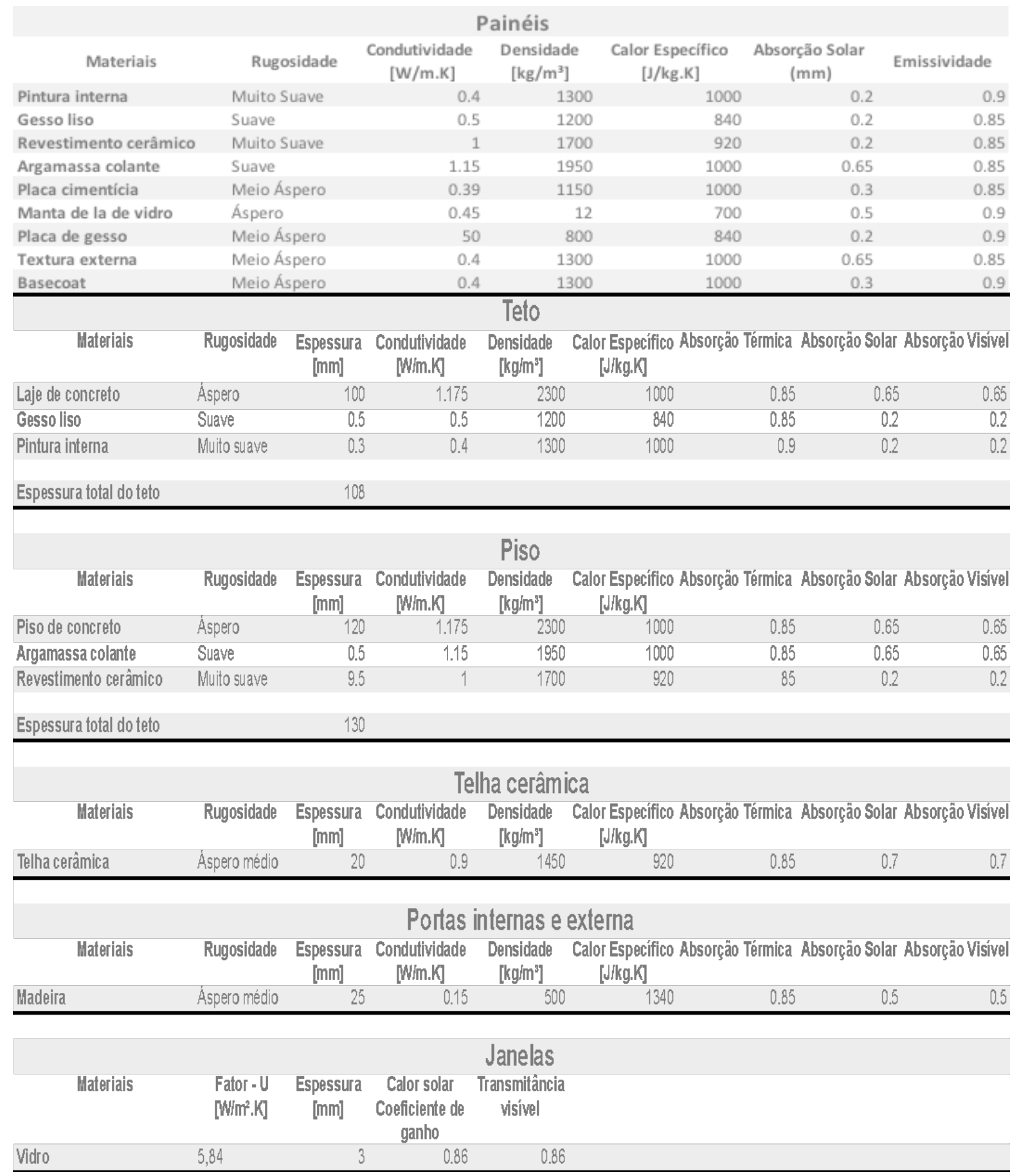

Tabela 6 - Propriedades termofísicas dos elementos construtivos da residência.

Fonte: ABNT NBR 15220-2/2005, 2005 


\subsection{Forma de Análise dos Resultados}

Os resultados das simulações das tipologias de painéis, em termos de temperatura do ar interno foram comparados entre si, bem como os índices comparativos de conforto térmico obtidos foram verificados quanto ao atendimento àqueles estipulados pela ABNT NBR 15575-1/2013. Desta forma, foi possível verificar quais tipologias de painéis pré-fabricados obtiveram resultados satisfatórios aos requisitos mínimos da Norma de Desempenho.

Os níveis mínimos, intermediários e superiores de desempenho são estipulados tanto para temperaturas de verão quanto de inverno. Os critérios de desempenho térmico para as condições de verão são apresentados na tabela 7 abaixo.

\begin{tabular}{|c|c|c|}
\hline \multirow{2}{*}{ Nível de desempenho } & \multicolumn{2}{|c|}{ Critério } \\
\hline & Zonas 1 a 7 & Zona 8 \\
\hline M & Ti,máx. $\leq$ Te,máx. & Ti,máx. $\leq$ Te,máx. \\
\hline I & Ti,máx. $\leq$ (Te,máx. $\left.-2^{\circ} \mathrm{C}\right)$ & Ti,máx. $\leq\left(\right.$ Te,máx. $\left.-1{ }^{\circ} \mathrm{C}\right)$ \\
\hline$S$ & Ti,máx. $\leq$ (Te,máx. $\left.-4^{\circ} \mathrm{C}\right)$ & $\begin{array}{c}\text { Ti,máx. } \leq\left(\text { Te,máx. }-2^{\circ} \mathrm{C}\right) \text { e } \\
\text { Ti,mín. } \leq\left(\text { Te,mín. }+1^{\circ} \mathrm{C}\right)\end{array}$ \\
\hline \multicolumn{3}{|c|}{$\begin{array}{l}\text { Ti,máx. É o valor máximo diário da temperatura do ar no interior da edificação, em graus Celsius. } \\
\text { Te,máx. É o valor máximo diário da temperatura do ar exterior à edificação, em graus Celsius. } \\
\text { Ti,mín. É o valor mínimo diário da temperatura do ar no interior da edificação, em graus Celsius. } \\
\text { Te,mín. É o valor mínimo diário da temperatura do ar exterior à edificação, em graus Celsius. } \\
\text { Nota Zonas bioclimáticas de acordo com a NBR 15220-3, Figura } 16 \text { do presente guia. }\end{array}$} \\
\hline
\end{tabular}

Tabela 7 - Critério de avaliação do desempenho térmico para condições de verão.

Fonte Tabela E1.-Anexo E da norma ABNT NBR 15575 - Parte 1, página 62.

Conforme mencionado anteriormente, nas as simulações dos dias típicos de verão, considerouse o cenário mais crítico para dias quentes que seria com todas as janelas e portas fechadas durante as 24 horas do dia; a renovação de ar foi considerada a "padrão" (renovação por frestas) de $1 \mathrm{ren} / \mathrm{h}$, ou seja, uma renovação de ar por hora no ambiente (ABNT NBR 15575-1/2013). Estes parâmetros foram usados na $1^{\mathrm{a}}, 2^{\mathrm{a}}, 3^{\mathrm{a}} \mathrm{e} 4^{\mathrm{a}}$ fase, sendo modificado para 5 ren/h na $5^{\mathrm{a}}$ fase. Os critérios de desempenho para as condições de inverno são apresentados na tabela 8 abaixo.

\begin{tabular}{|c|c|c|}
\hline \multirow{2}{*}{ Nível de desempenho } & \multicolumn{2}{|c|}{ Critério } \\
\cline { 2 - 3 } & Zonas bioclimáticas 1 a 5 & Zonas bioclimáticas 6, 7 e 8 \\
\hline M & Ti,mín. $\geq\left(\right.$ Te,mín. $\left.+3^{\circ} \mathrm{C}\right)$ & $\begin{array}{c}\text { Nestas zonas, este critério } \\
\text { não precisa ser verificado }\end{array}$ \\
\hline $\mathrm{S}$ & Ti,mín. $\geq\left(\right.$ Te,mín. $\left.+5^{\circ} \mathrm{C}\right)$ & \\
\hline $\begin{array}{l}\text { Ti,mín. É o valor mínimo diário da temperatura do ar no interior da edificação, em graus Celsius. } \\
\text { Te,mín. É o valor mínimo diário da temperatura do ar exterior à edificação, em graus Celsius. } \\
\text { Nota Zonas bioclimáticas de acordo com a ABNT NBR 15220-3, Figura 16 do presente guia. }\end{array}$ \\
\hline
\end{tabular}

Tabela 8 - Critério de avaliação do desempenho térmico para condições de inverno. Fonte Tabela E2.-Anexo E da norma ABNT NBR 15575 - Parte 1, página 63. 
Para as simulações de inverno, considerou-se todas as janelas e portas abertas 24 horas, também com o objetivo de analisar comparativamente o cenário mais crítico. Este foi o parâmetro utilizado na $1^{\mathrm{a}}, 2^{\mathrm{a}}, 3^{\mathrm{a}}$ e $4^{\mathrm{a}}$ fase, o qual foi modificado na $5^{\mathrm{a}}$ fase, passando a ser considerado portas e janelas fechadas $5 \mathrm{ren} / \mathrm{h}$. Na $5^{\mathrm{a}}$ fase, os parâmetros dos dias típicos de verão e inverno passaram a ser iguais.

De forma a facilitar a visualização dos resultados comparativos nas tabelas de resultados das simulações, foram utilizadas 3 cores para destacar as células. A tabela contém os horários e temperaturas internas e externas mais críticas tanto para os dias típicos de verão quanto inverno. Os critérios de cores utilizados para análise dos resultados são apresentados na tabela 9 abaixo.

\section{Tabela de Critérios dos Resultados}

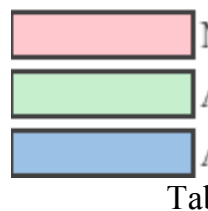

Não atende ao requisito mínimo da Norma de Desempenho Atende o requisito mínimo da Norma de Desempenho

Atende ao requisito intermediário ou acima da Norma de Desempenho

Tabela 9 - Critérios de cores utilizadas para análise comparativa dos resultados e nível de desempenho dos painéis por ambiente.

Fonte: Arquivo pessoal, 2016

Para proporcionar uma visualização da passagem do sol nos dias típicos utilizados para as simulações, de forma meramente ilustrativas, são utilizadas algumas imagens abaixo (Figuras 34 a 45). Porém, é importante ressaltar que não é possível, através das mesmas, distingui-las entre as 3 regiões Nordeste, Sudeste e Sul, uma vez que o programa somente apresenta o movimento do sol em função do fuso horário e não separadamente por cidades do mesmo fuso.

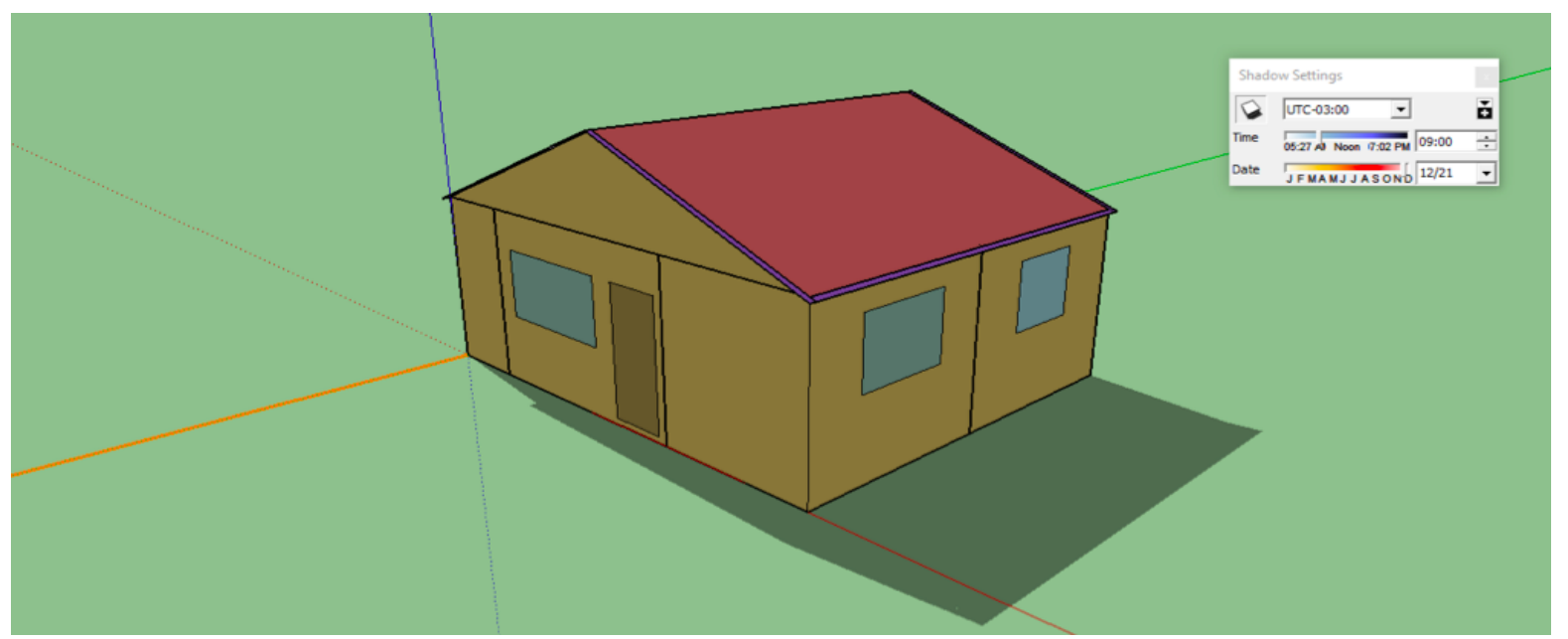

Figura 34 - Ilustração das faces norte e oeste às 9:00h no dia 21/12 utilizado como dia típico de verão em Fortaleza-CE - Fuso horário de Brasília (UTC-3)

Fonte: Arquivo pessoal, 2016 


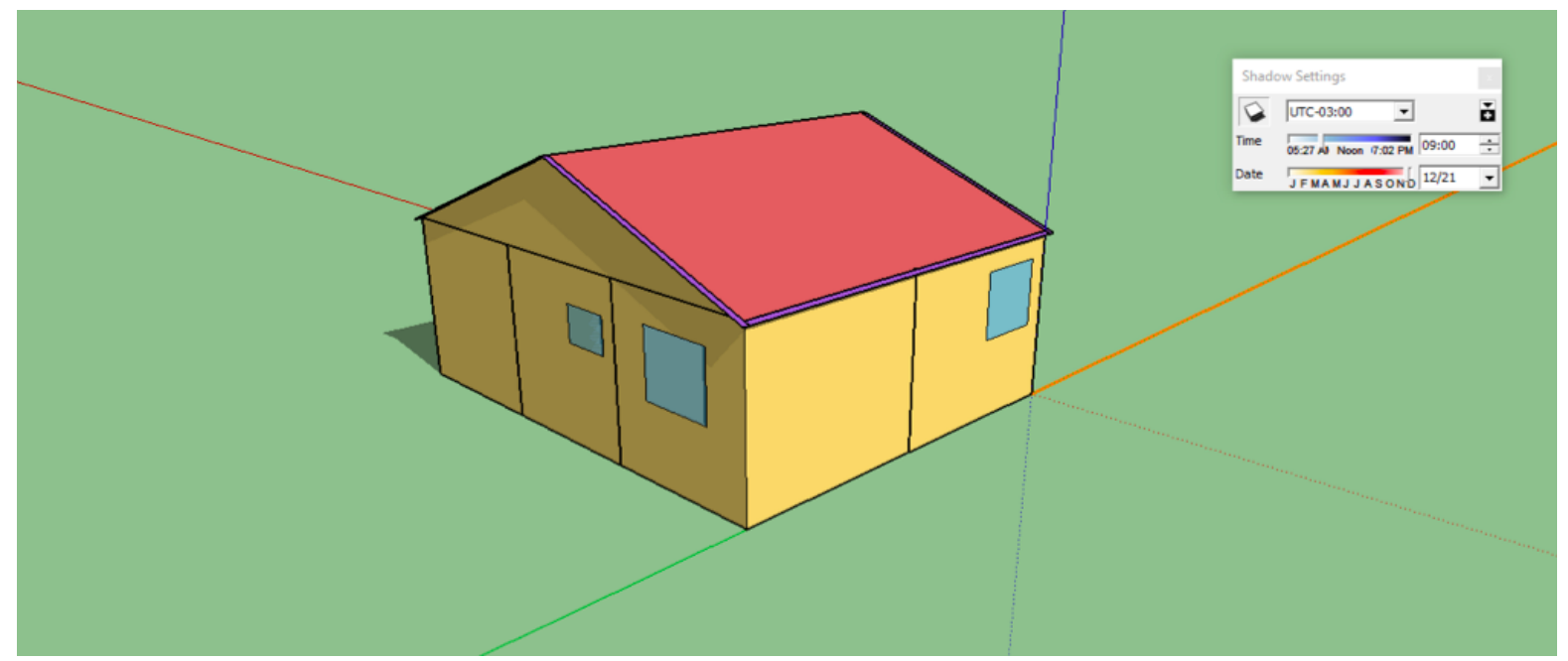

Figura 35 - Ilustração das faces sul e leste às 9:00h no dia 21/12 utilizado como dia típico de verão em Fortaleza-CE - Fuso horário de Brasília (UTC-3)

Fonte: Arquivo pessoal, 2016

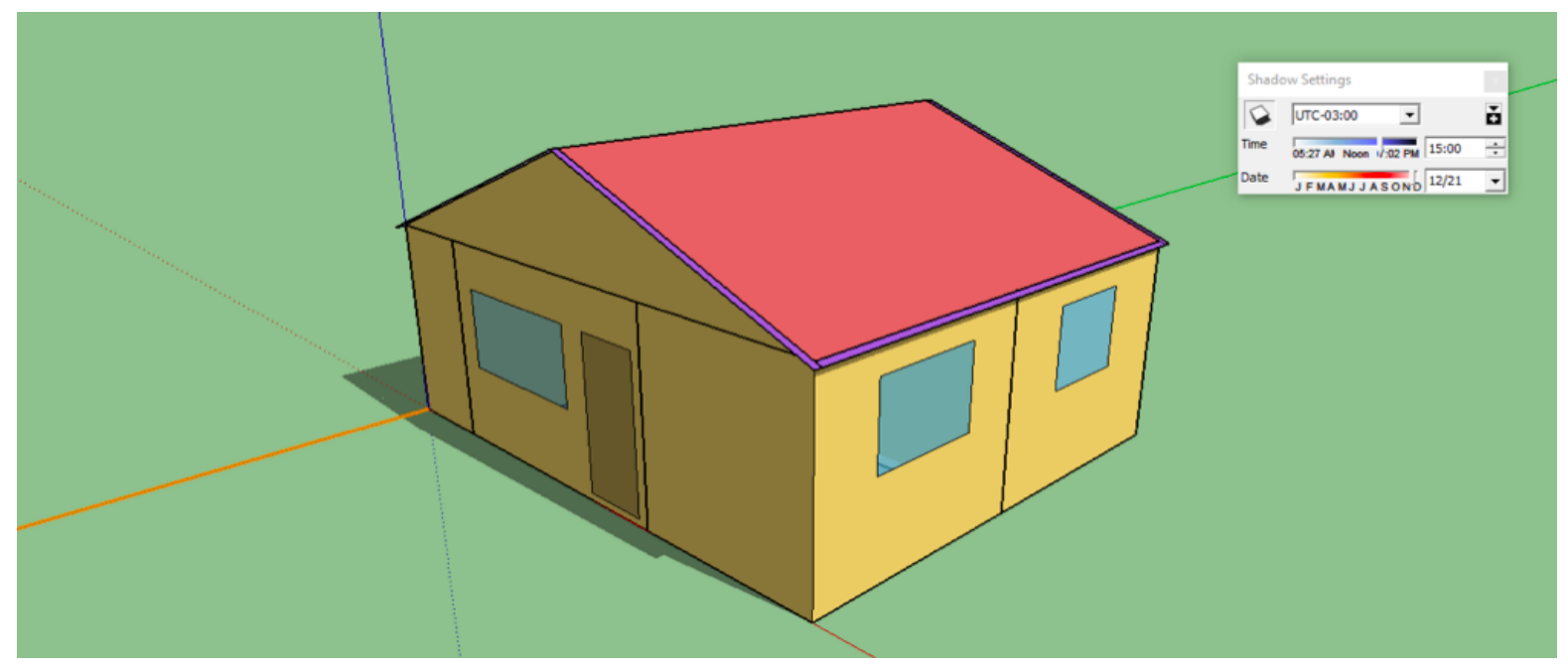

Figura 36 - Ilustração das faces norte e oeste às 15:00h no dia 21/12 utilizado como dia típico de verão em Fortaleza-CE - Fuso horário de Brasília (UTC-3)

Fonte: Arquivo pessoal, 2016

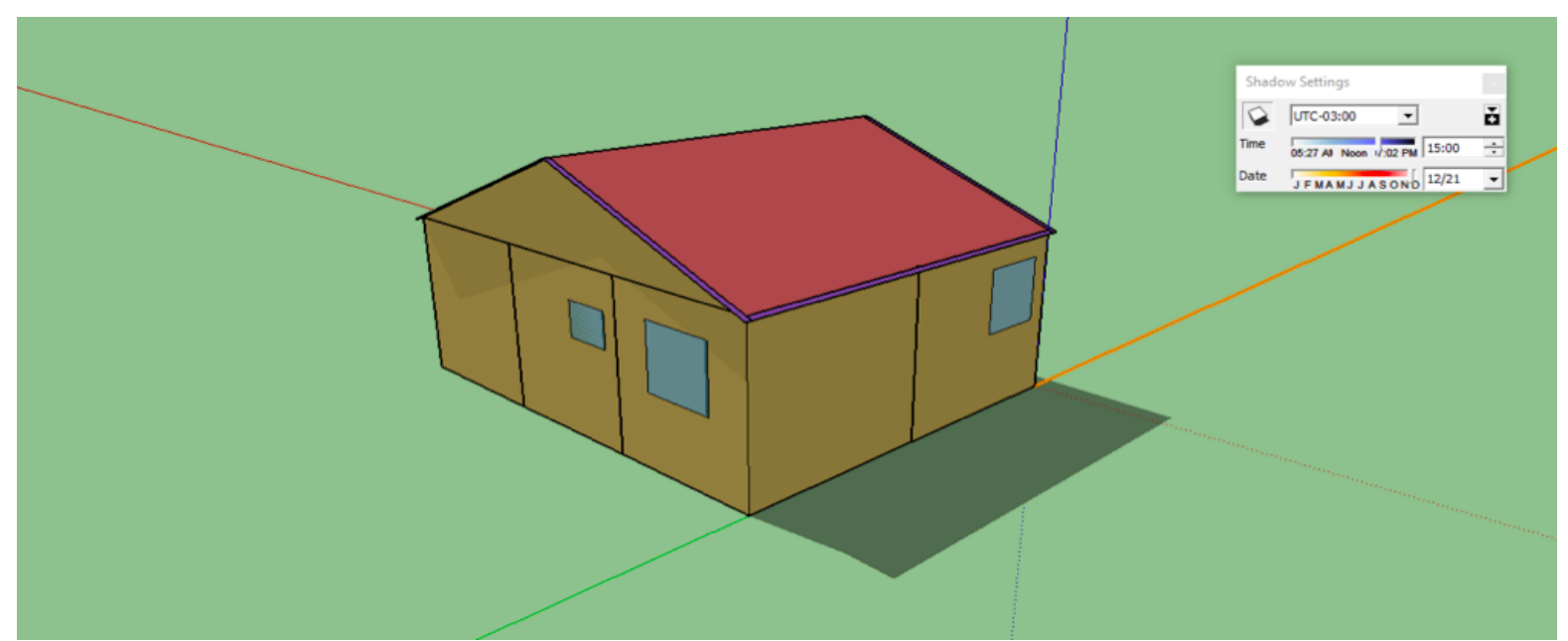

Figura 37 - Ilustração das faces sul e leste às 15:00h no dia 21/12 utilizado como dia típico de verão em Fortaleza-CE - Fuso horário de Brasília (UTC-3)

Fonte: Arquivo pessoal, 2016 


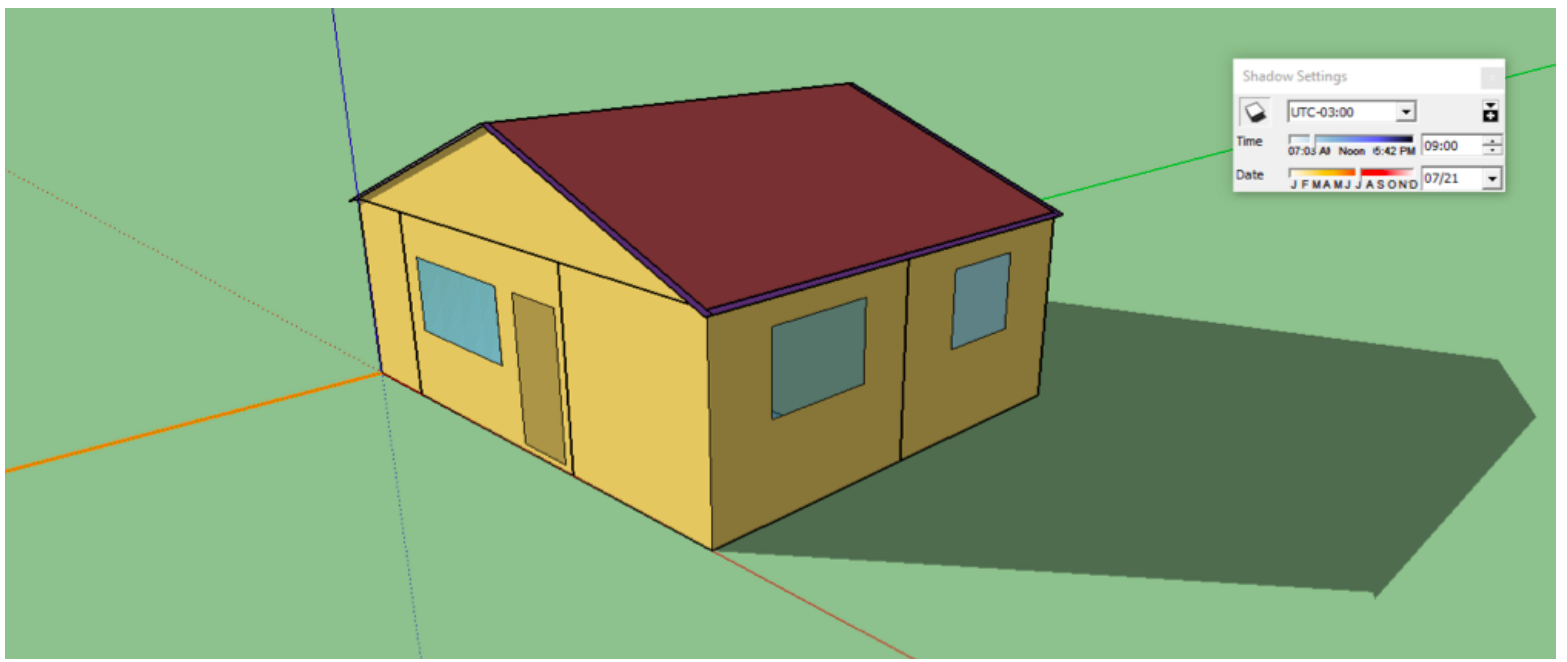

Figura 38- Ilustração das faces norte e oeste às 09:00h no dia 21/07 utilizado como dia típico de inverno para as 3 cidades - Fuso horário de Brasília (UTC-3)

Fonte: Arquivo pessoal, 2016

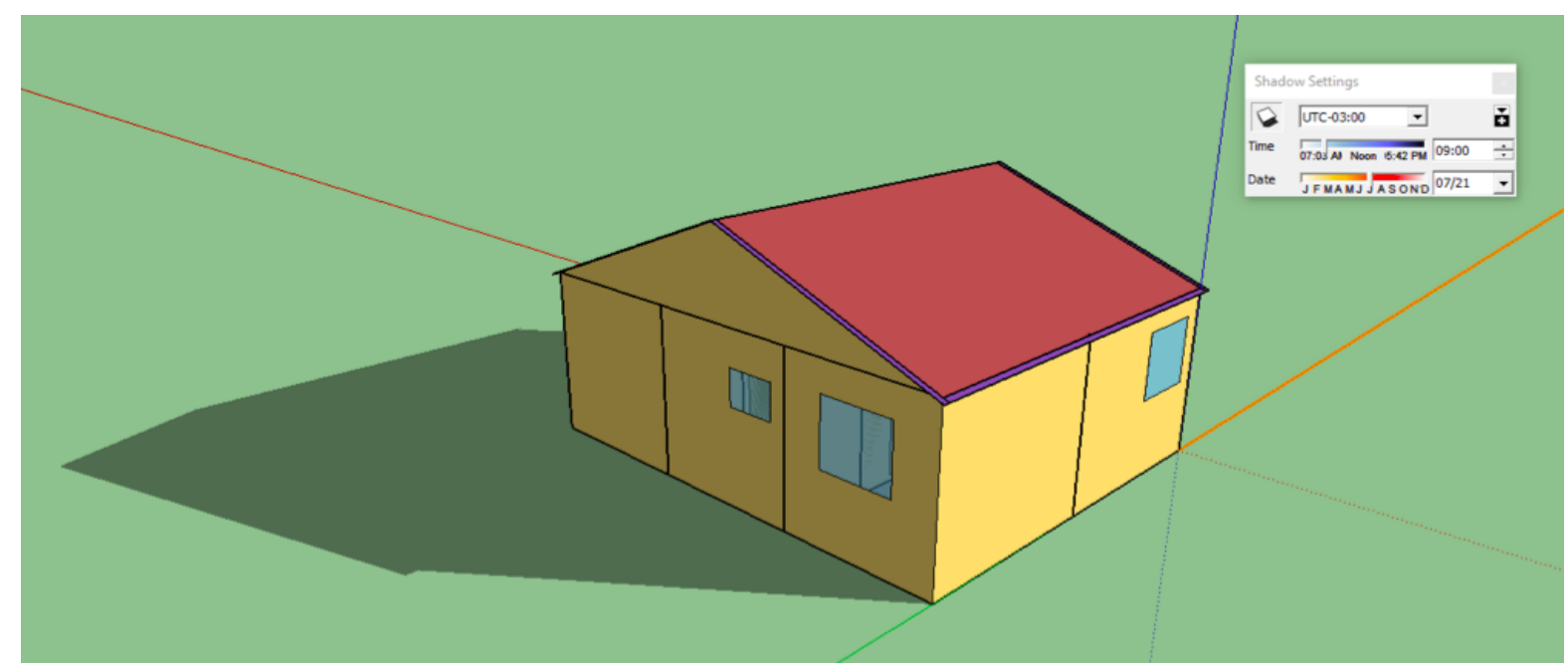

Figura 39- Ilustração das faces sul e leste às 09:00h no dia 21/07 utilizado como dia típico de inverno para as 3 cidades - Fuso horário de Brasília (UTC-3)

Fonte: Arquivo pessoal, 2016

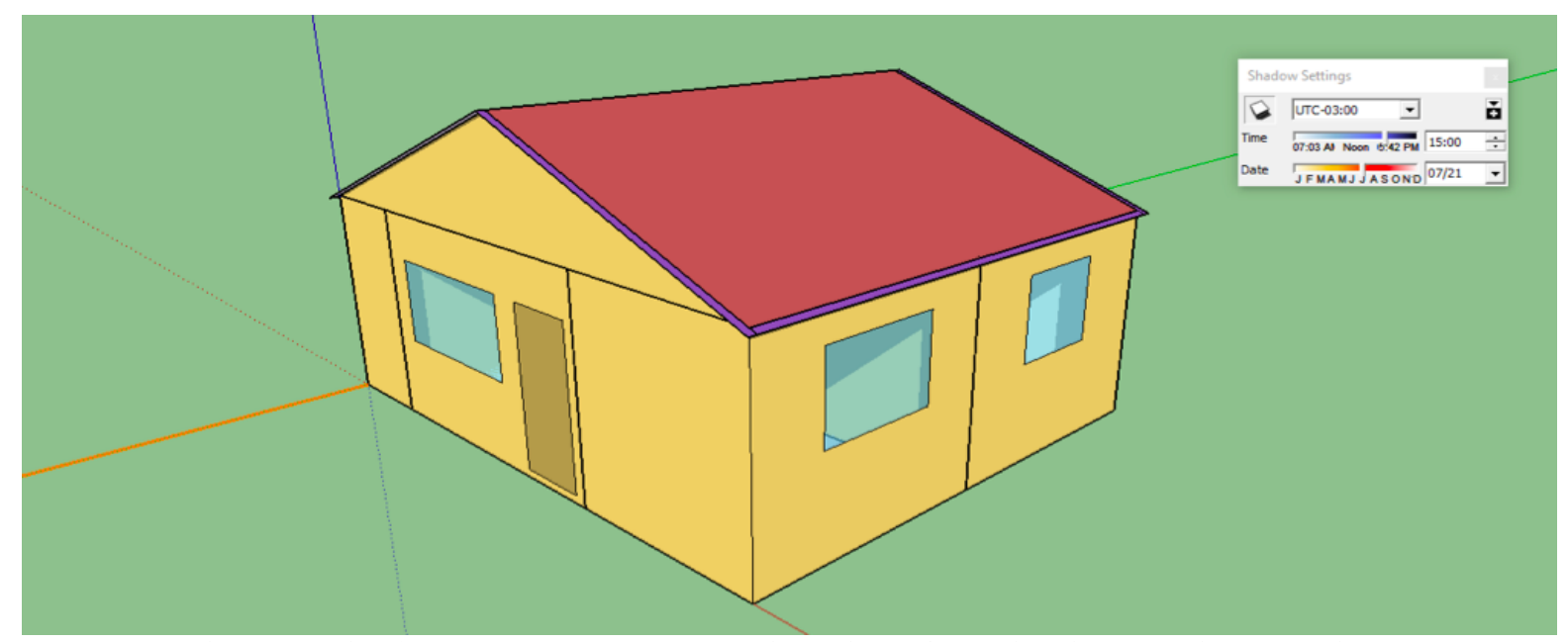

Figura 40 - Ilustração das faces norte e oeste às 15:00h no dia 21/07 utilizado como dia típico de inverno para as 3 cidades - Fuso horário de Brasília (UTC-3)

Fonte: Arquivo pessoal, 2016 


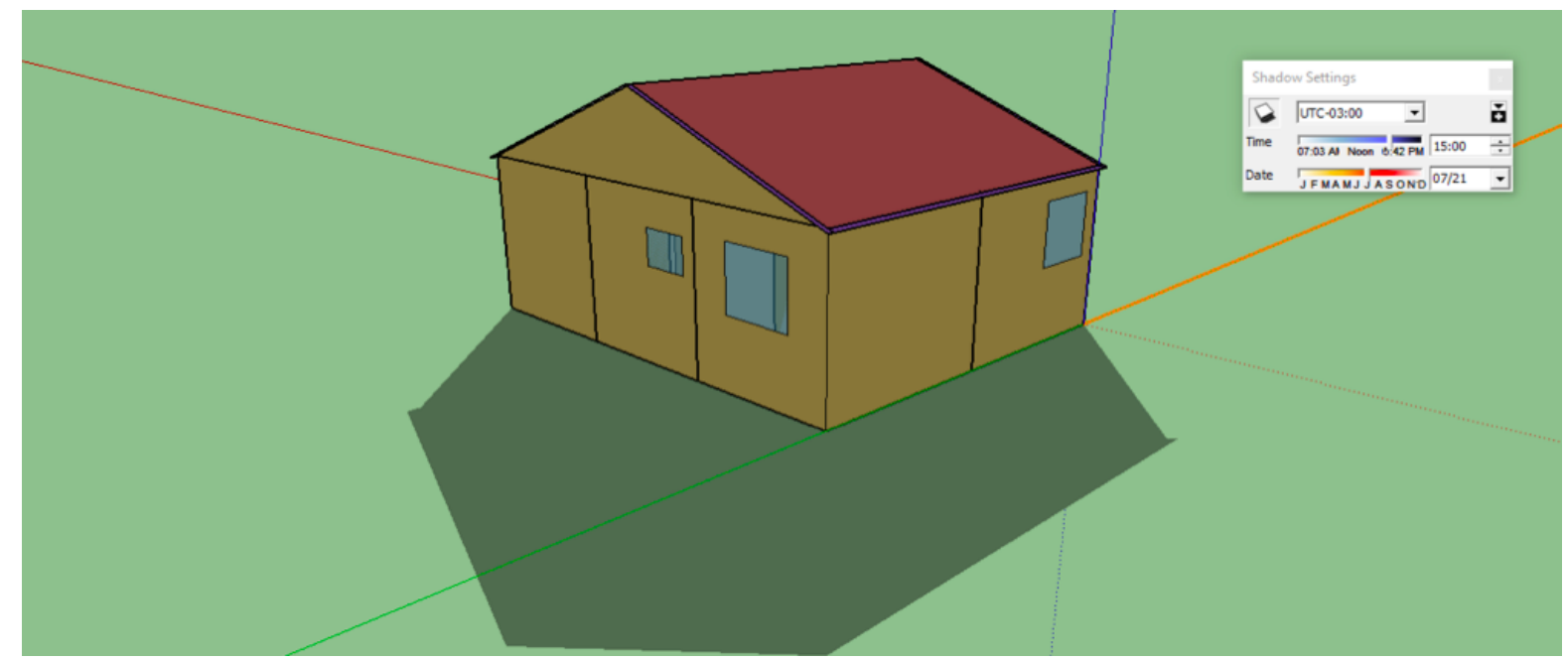

Figura 41- Ilustração das faces sul e leste às 15:00h no dia 21/07 utilizado como dia típico de inverno para as 3 cidades - Fuso horário de Brasília (UTC-3)

Fonte: Arquivo pessoal, 2016

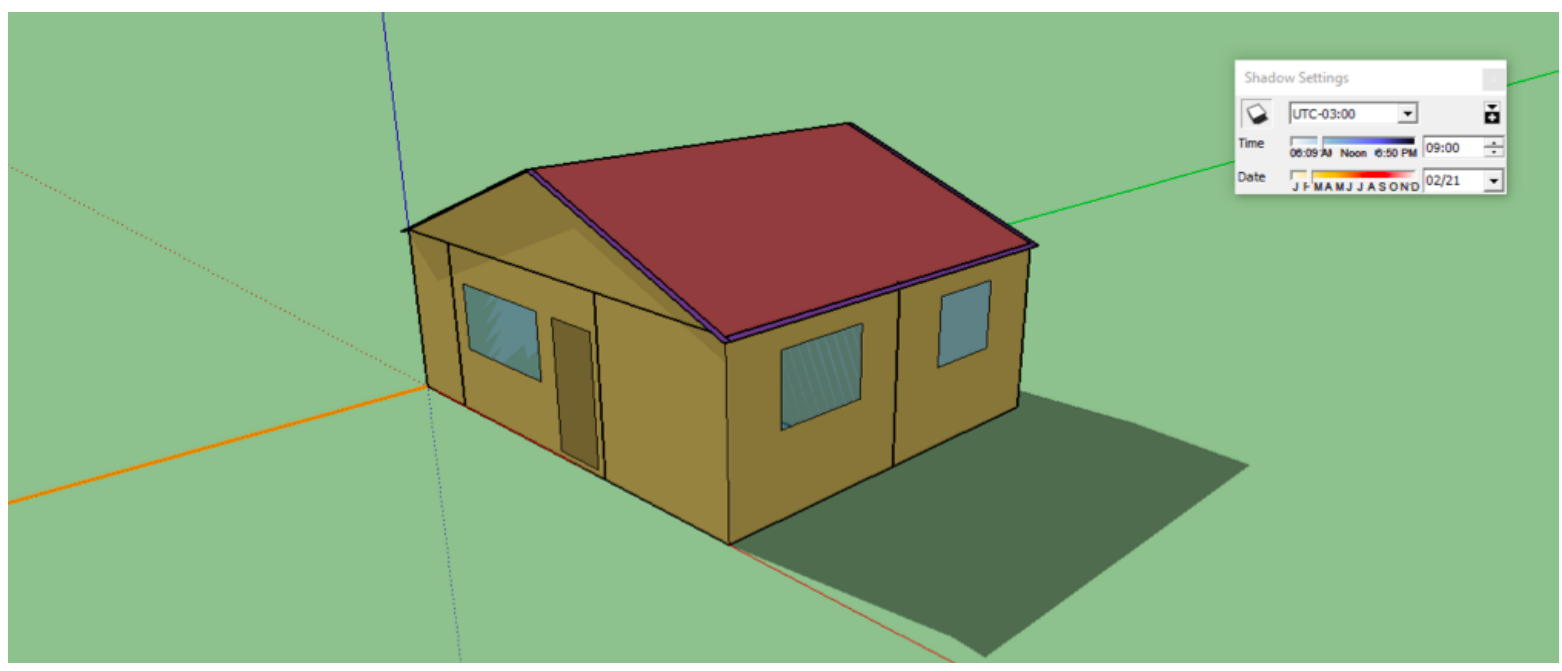

Figura 42 - Ilustração das faces norte e oeste às 09:00h no dia 21/02 utilizado como dia típico de verão para as cidades de São Paulo-SP e Curitiba-PR - Fuso horário de Brasília (UTC-3)

Fonte: Arquivo pessoal, 2016

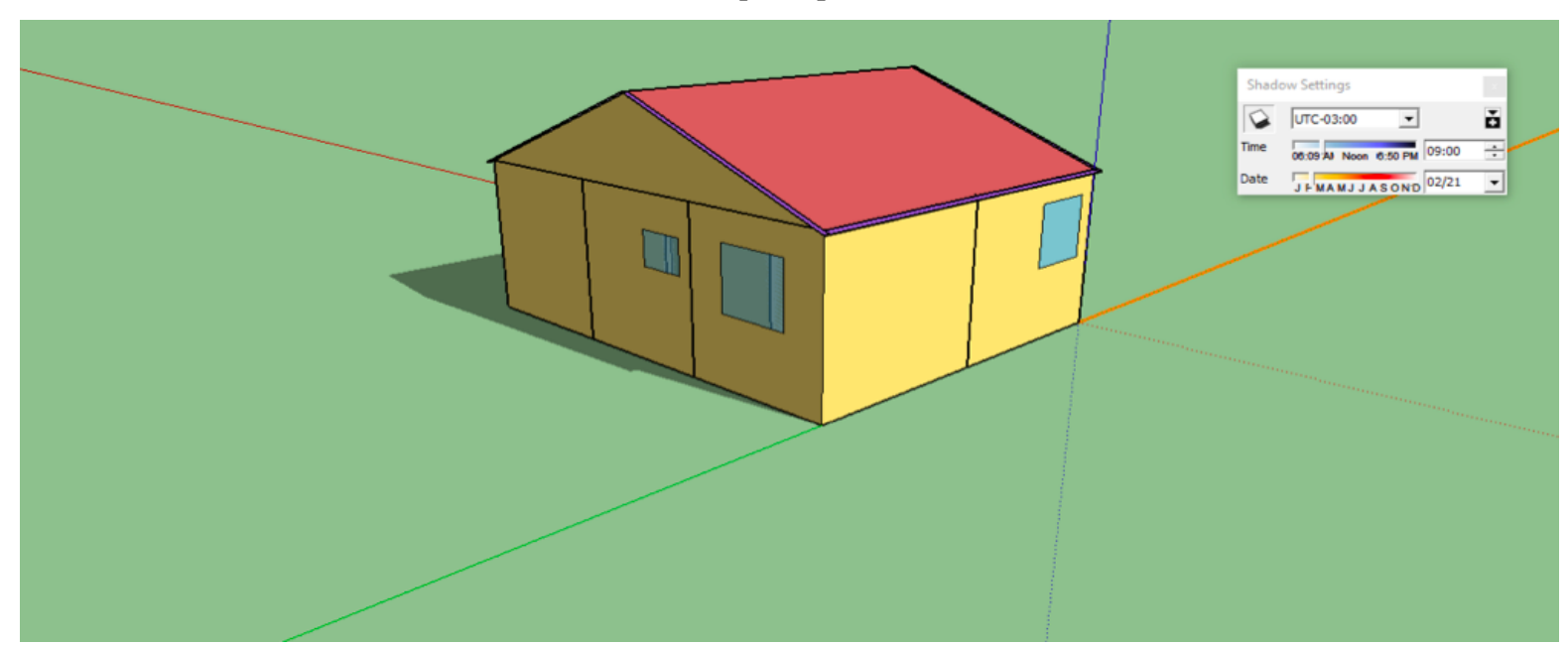

Figura 43 - Ilustração das faces sul e leste às 09:00h no dia 21/02 utilizado como dia típico de verão para as cidades de São Paulo-SP e Curitiba-PR - Fuso horário de Brasília (UTC-3)

Fonte: Arquivo pessoal, 2016 


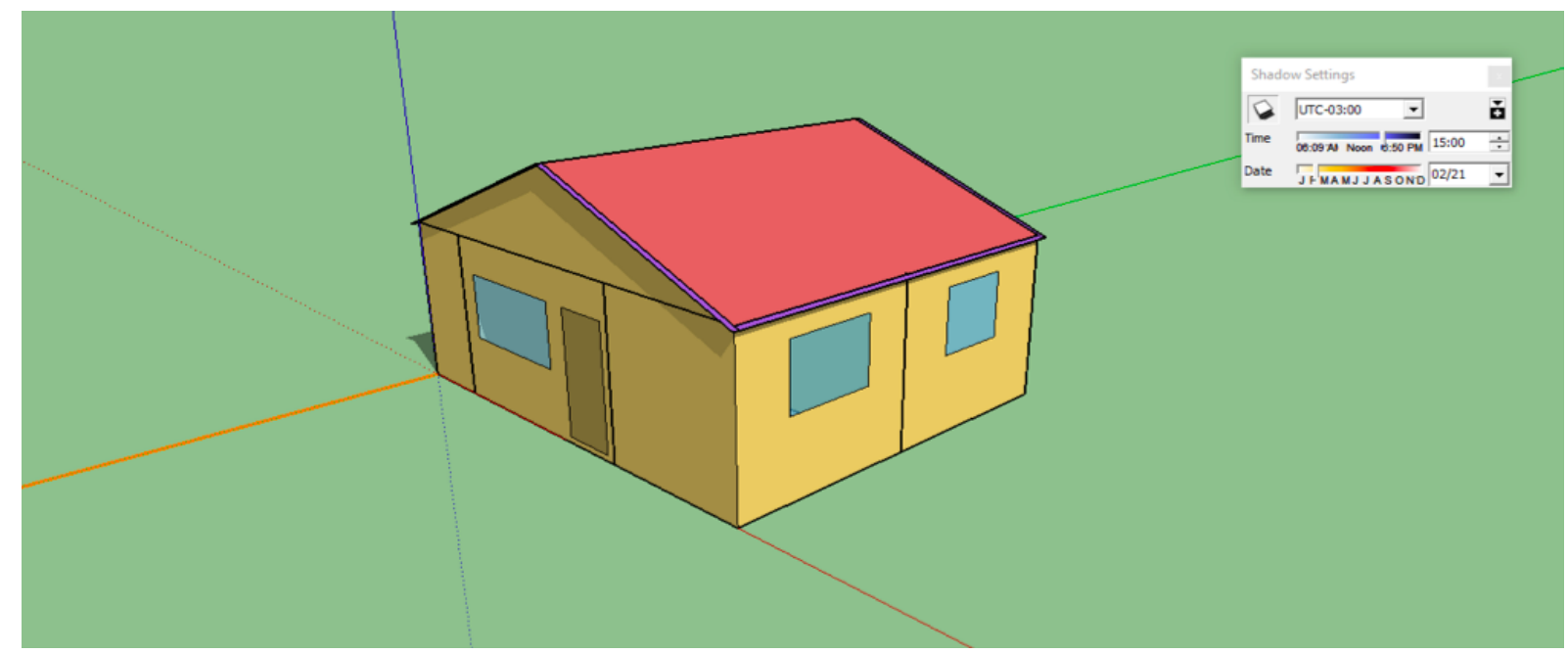

Figura 44 - Ilustração das faces norte e oeste às 15:00h no dia 21/02 utilizado como dia típico de verão para as cidades de São Paulo-SP e Curitiba-PR - Fuso horário de Brasília (UTC-3)

Fonte: Arquivo pessoal, 2016

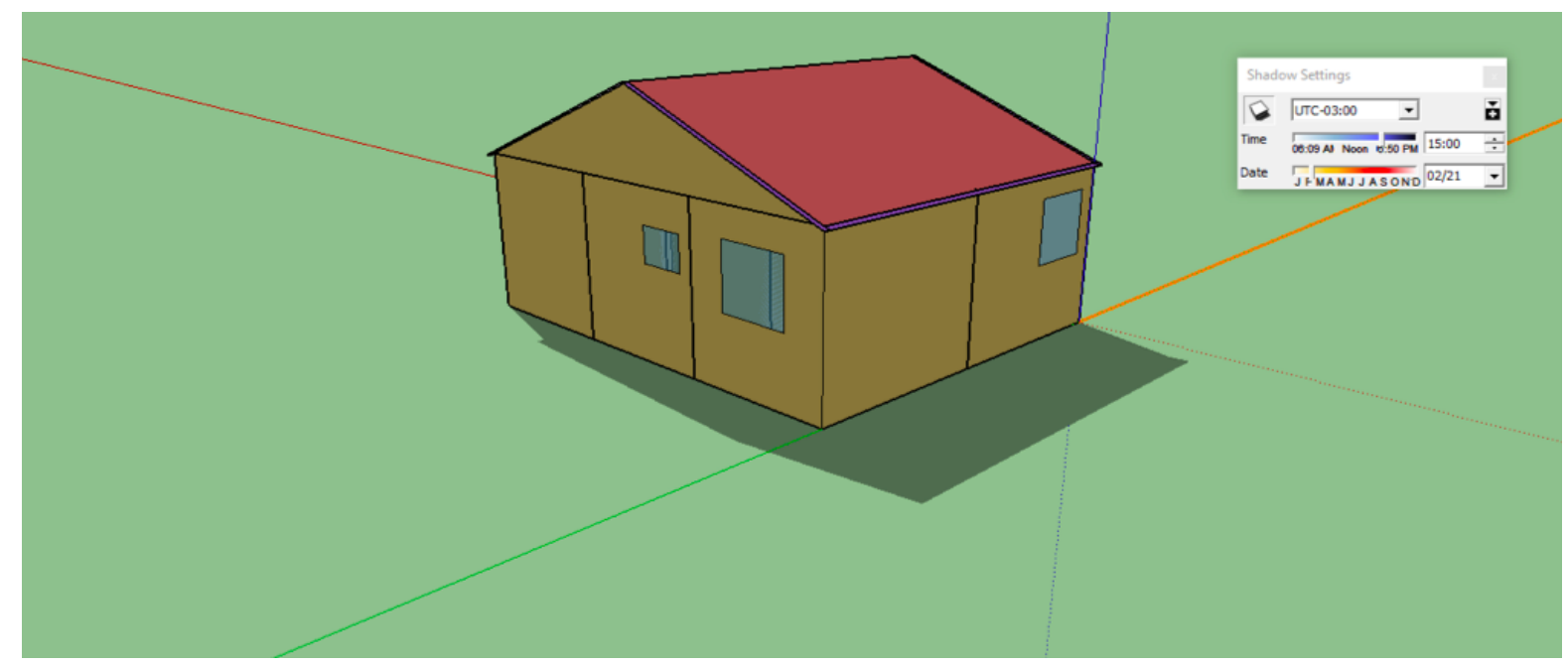

Figura 45 - Ilustração das faces sul e leste às 15:00h no dia 21/02 utilizado como dia típico de verão para as cidades de São Paulo-SP e Curitiba-PR - Fuso horário de Brasília (UTC-3)

Fonte: Arquivo pessoal, 2016 


\section{ANÁLISES DOS RESULTADOS}

\subsection{RESULTADOS DA $1^{\mathrm{a}}$ E $2^{\mathrm{a}}$ FASE}

As 12 tipologias de painéis da $1^{\mathrm{a}}$ e $2^{\mathrm{a}}$ fase foram simulados 2 vezes cada uma, para cada cidade escolhida, sendo uma para o dia típico de verão e outra para o dia típico de inverno. É importante relembrar que os parâmetros utilizados nestas fases foram os mais restritivos, sendo para o as simulações de verão, considerado uma renovação de ar por hora (ABNT NBR 15575-1/2013) e todas as portas e janelas da residência fechadas. Sendo este, o cenário mais desfavorável para um dia quente de verão. Já para os dias típicos de inverno as portas e janelas foram consideradas totalmente abertas, sendo este também, o cenário mais desfavorável para um dia frio.

Com base nas simulações realizadas pode-se avaliar comparativamente o desempenho de cada tipologia de painel em diferentes cidades e situações de exposição. Os gráficos referentes a $1^{\text {a }}$ e $2^{\mathrm{a}}$ fases são apresentados nas seções 5.1.1 a 5.1.6 a seguir. 


\subsubsection{Resultados das simulações para o dia típico de verão em Fortaleza-CE}

O gráfico da Figura 46 abaixo apresenta os resultados das simulações realizadas no ambiente da sala, com as 12 tipologias de painéis da $1^{\mathrm{a}}$ e $2^{\mathrm{a}}$ fase considerando as condições da zona bioclimática 8, Região Nordeste, cidade de Fortaleza e dia típico de verão, na data 21 de novembro.

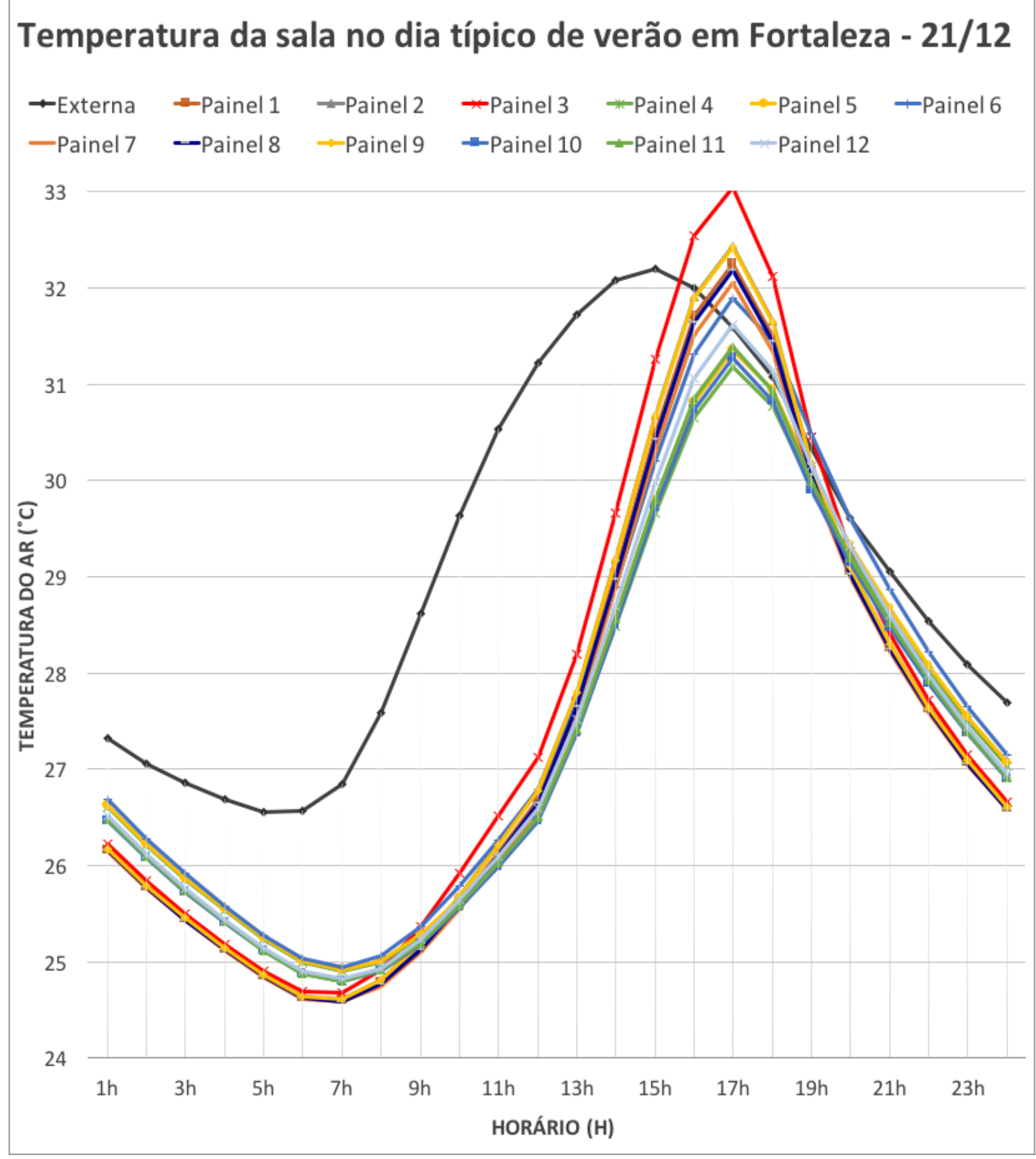

Figura 46 - Resultados das simulações dos painéis no ambiente da sala nas condições e dia típico de verão para a cidade de Fortaleza-CE

Fonte: Arquivo pessoal, 2016 
De acordo com o gráfico da Figura 46 acima, de 12 tipologias simuladas, 8 painéis apresentaram temperaturas máximas internas da sala (ambiente em posição mais crítica) inferior à máxima externa, sendo estas as tipologias 4, 5, 6, 7, 8, 10, 11 e 12 .

A temperatura externa mais elevada, de $32,20^{\circ} \mathrm{C}$ ocorre às $15: 00 \mathrm{~h}$ e os horários mais críticos da temperatura interna acontecem às 17:00h; a temperatura máxima do painel 4 foi de $31,17^{\circ} \mathrm{C}$, do painel 5 foi de $31,35^{\circ} \mathrm{C}$, do painel 6 foi de $31,89^{\circ} \mathrm{C}$, do painel $7,31,05^{\circ} \mathrm{C}$, painel $8,32,18^{\circ} \mathrm{C}$, painel $10,31,27^{\circ} \mathrm{C}$, painel $11,31,39^{\circ} \mathrm{C}$ e do painel $12,31,61^{\circ} \mathrm{C}$; portanto, resultando em desempenho mínimo de acordo com a ABNT NBR 15575-1/2013.

Apesar de não ser a tipologia de painel que apresenta o melhor resultado, dentre aquelas que obtiveram resultados favoráveis, o painel 8 é a tipologia que utiliza menor quantidade de material, com apenas uma placa cimentícia na face interna e outra na face externa.

Os painéis 1, 2 e 3 apresentaram temperaturas máximas internas acima da máxima externa, ficando o painel 1 com temperatura máxima de $32,25^{\circ} \mathrm{C}$, painel 2 com máxima de $32,40^{\circ} \mathrm{C}$ e o painel 3 com $33,04^{\circ} \mathrm{C}$; portanto, não atenderam aos requisitos mínimos conforme estipula a Norma de Desempenho. Entre os 3 painéis, o desempenho mais desfavorável apresentado foi o do painel 3 (linha em vermelho). 


\subsubsection{Resultados das simulações para o dia típico de inverno em Fortaleza-CE}

O gráfico da Figura 47 abaixo apresenta os resultados das simulações realizadas no ambiente dormitório 1, com todas as tipologias de painéis, considerando as condições da zona bioclimática 8, Região Nordeste, cidade de Fortaleza e dia típico de inverno 21 de julho.

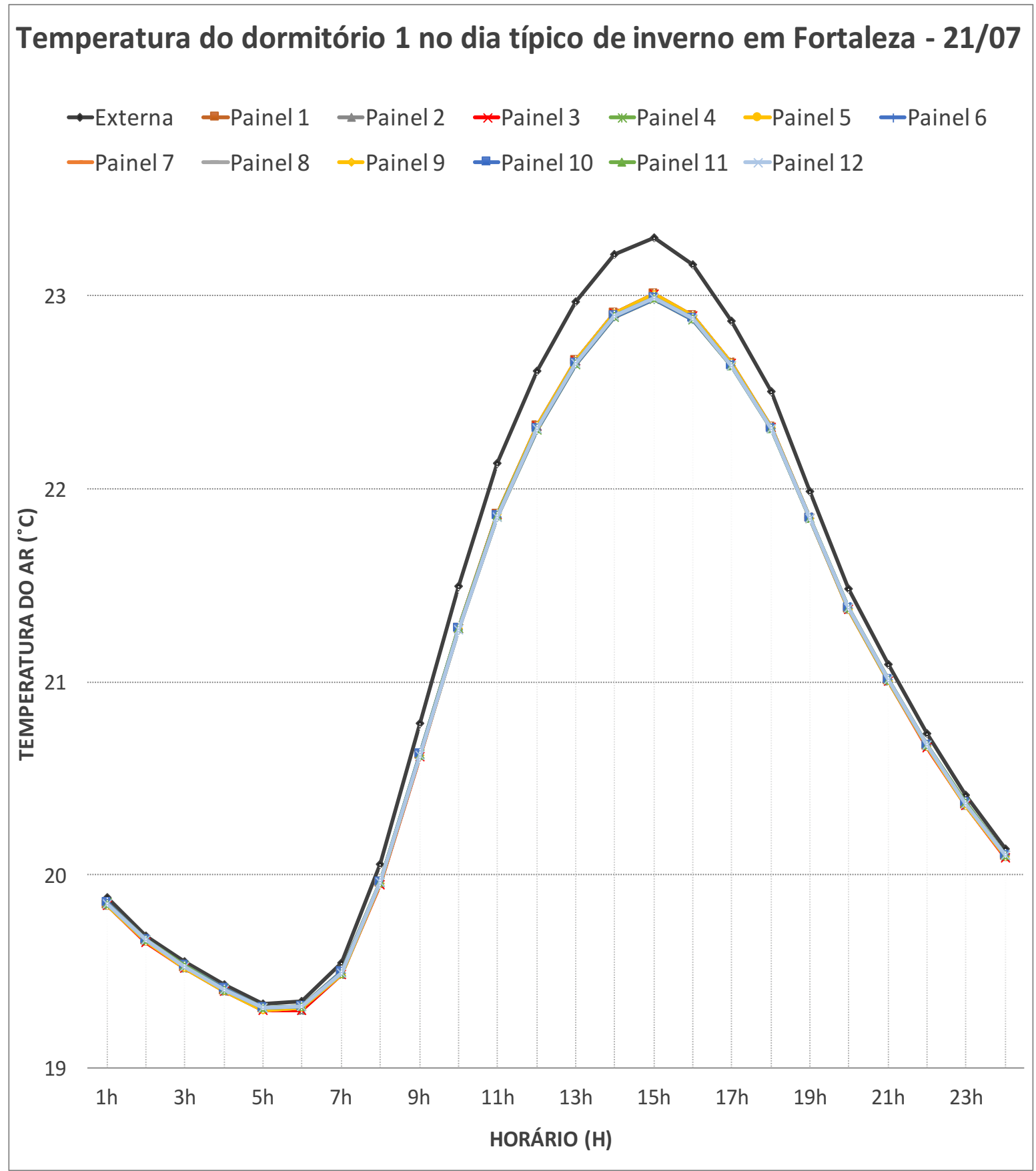

Figura 47 - Resultados das simulações dos painéis no ambiente do dormitório 1 nas condições e dia típico de inverno para a cidade de Fortaleza-CE

Fonte: Arquivo pessoal, 2016 
Apesar desta zona climática não necessitar de avaliação para o dia típico de inverno (conforme Tabela 8), optou-se por incluí-lo. O gráfico da Figura 47 acima apresenta os resultados das simulações das 12 diferentes tipologias de painéis da $1^{\mathrm{a}}$ e $2^{\mathrm{a}}$ fase, onde todas as temperaturas mínimas internas no ambiente do dormitório 1 (ambiente em posição mais desfavorável conforme Figura 32) praticamente acompanham a curva de temperatura mínima externa (linha cinza escuro).

As temperaturas mínimas ocorrem entre $5 \mathrm{~h}$ e $6 \mathrm{~h}$ da manhã. Para atendimento ao desempenho mínimo da ABNT NBR 15575-1/2013 é necessária uma diferença de na temperatura mínima interna pelo menos $+3^{\circ} \mathrm{C}$ com relação a mínima externa.

Portanto, caso fosse necessário verificar o desempenho dos painéis nos dias típicos de inverno para esta cidade, nenhuma das tipologias de painéis atenderiam aos requisitos mínimos estipulados na Norma de Desempenho. 


\subsubsection{Resultados das simulações para o dia típico de verão em São Paulo - SP}

O gráfico da Figura 48 abaixo apresenta os resultados das simulações realizadas no ambiente da sala, com todas as tipologias de painéis, considerando as condições da zona bioclimática 3, Região Sudeste, cidade de São Paulo e dia típico de verão na data de 21 de fevereiro.

\section{Temperatura da sala no dia típico de verão em São Paulo- 21/02}

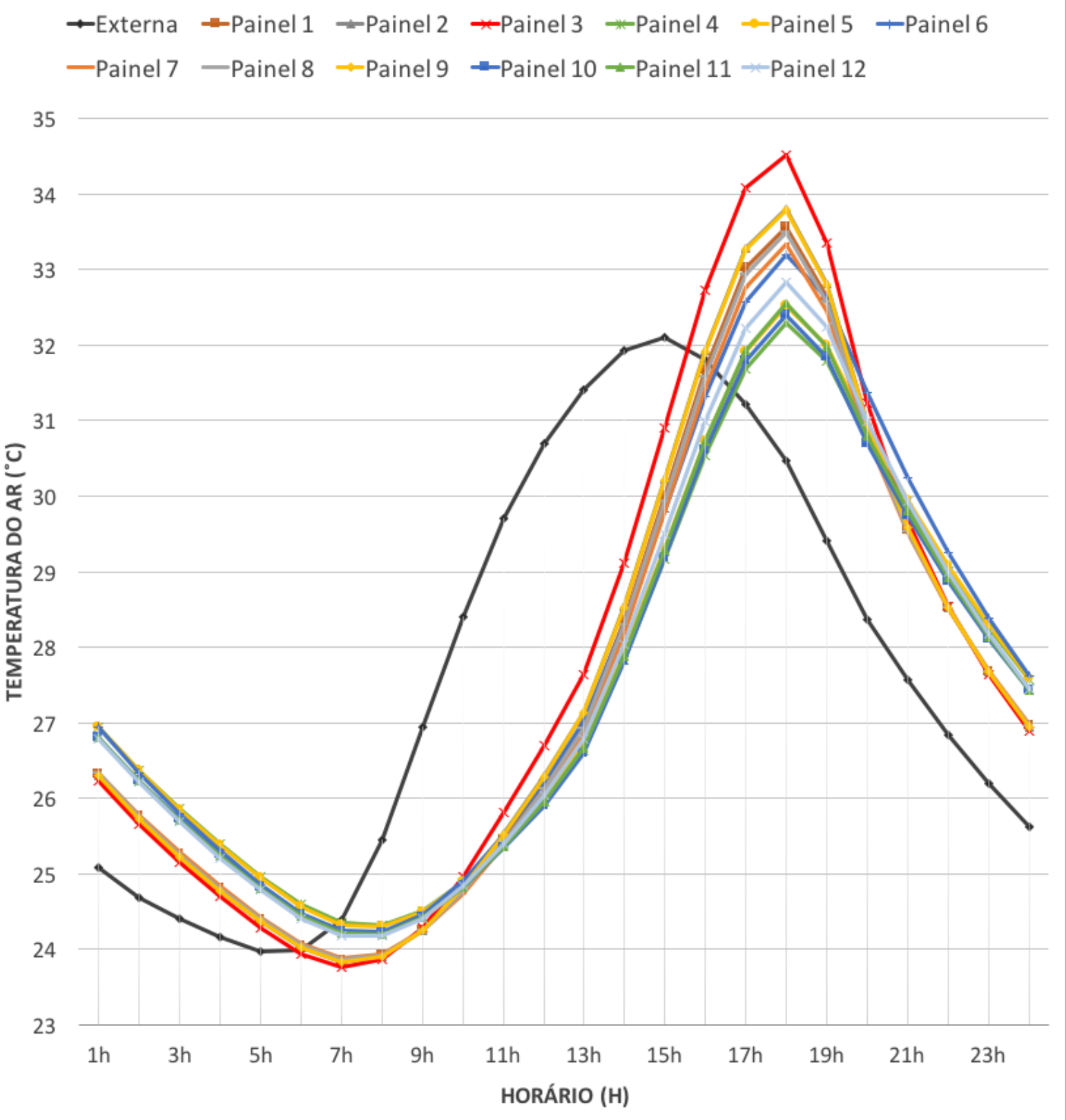

Figura 48 - Resultados das simulações dos painéis no ambiente da sala nas condições e dia típico de verão para a cidade de São Paulo-SP

Fonte: Arquivo pessoal, 2016 
De acordo com o gráfico da Figura 48 acima, os 12 painéis avaliados apresentaram temperaturas máximas internas acima da máxima externa no ambiente da sala. A temperatura máxima externa ocorre às $15: 00 \mathrm{~h}$ sendo $32,10^{\circ} \mathrm{C}$, e a interna às $18: 00 \mathrm{~h}$, sendo $34,52^{\circ} \mathrm{C}$ apresentado na tipologia de painel 3 (linha em vermelho).

$\mathrm{O}$ resultado do painel 4 apresentou temperatura interna de $32,29^{\circ} \mathrm{C}$, ficando apenas com $0,9^{\circ} \mathrm{C}$ acima da temperatura externa, sendo a mais próxima de atender ao requisito mínimo. Nenhuma das tipologias de painéis atenderam aos requisitos mínimos estipulados pela Norma de Desempenho na a cidade de São Paulo. 


\subsubsection{Resultados das simulações para o dia típico de inverno em São Paulo - SP}

O gráfico da Figura 49 abaixo apresenta os resultados das simulações realizadas no ambiente dormitório 1, com todas as tipologias de painéis, considerando as condições da zona bioclimática 3, Região Sudeste, cidade de São Paulo e dia típico de inverno 21 de julho.

\section{Temperatura do dormitório 1 no dia típico de inverno em São Paulo- 21/07 \\ -Externa -Painel 1 -Painel 2 -Painel3 *Painel4 -Painel5 -Painel6 \\ -Painel 7 -Painel $8 \rightarrow$ Painel 9 -Painel 10 -Painel 11 -Painel 12}

10

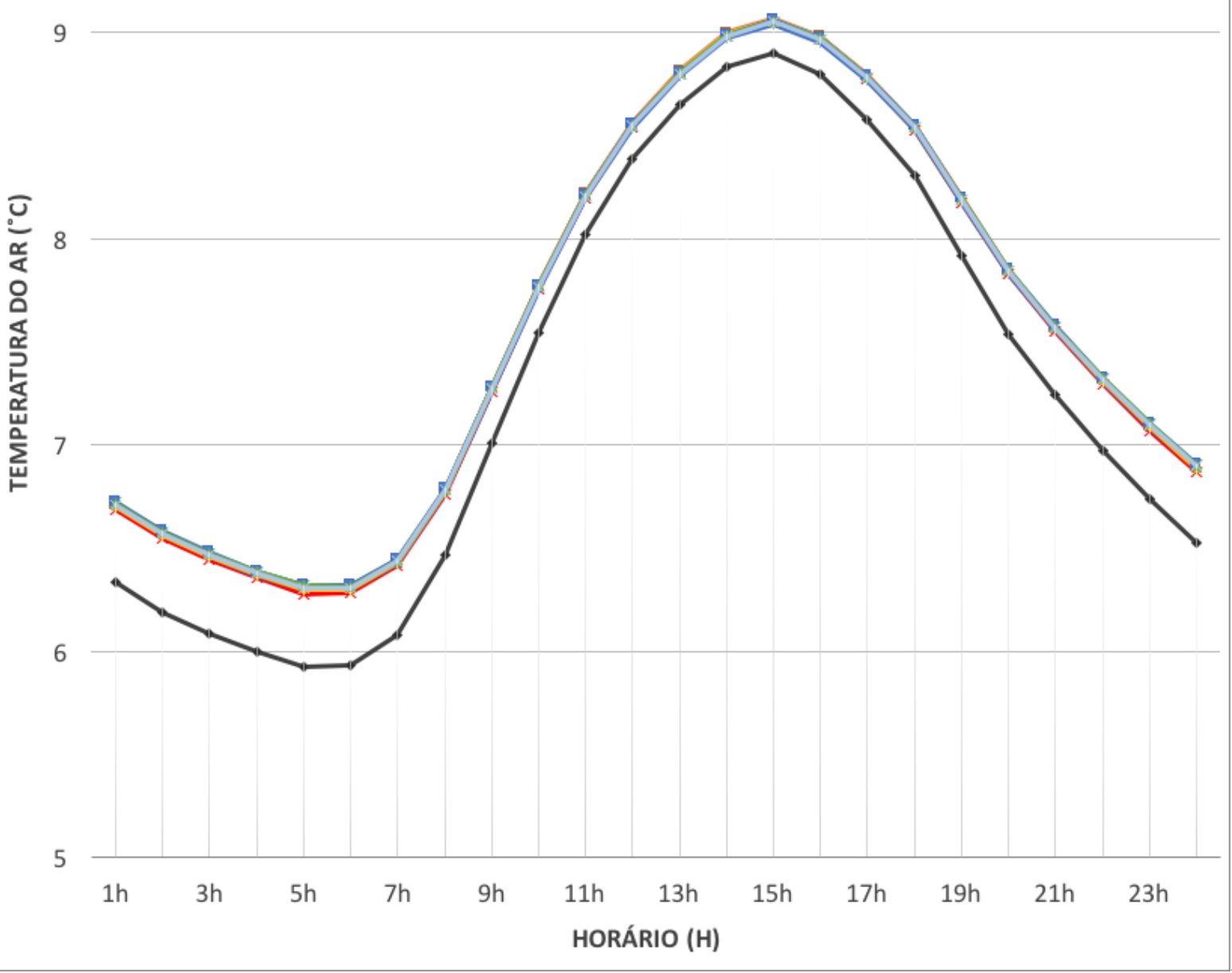

Figura 49 - Resultados das simulações dos painéis no ambiente do dormitório 1 nas condições e dia típico de inverno para a cidade de São Paulo-SP

Fonte: Arquivo pessoal, 2016 
Os resultados para o dia típico de inverno na cidade de São Paulo apresentados no gráfico da Figura 49 acima, demonstram que, a temperaturas mínimas internas dos ambientes estão acima da temperatura mínima externa (cinza escuro); ainda assim, nenhuma das composições de painéis apresentou temperaturas mínimas internas com $+3^{\circ} \mathrm{C}$ em relação à mínima externa.

Neste caso, a temperatura mínima externa de $5,93^{\circ} \mathrm{C}$ ocorreu às $5 \mathrm{~h}$, assim como as internas. As tipologias de painéis 4,10 e $11 \mathrm{com} 6.32^{\circ} \mathrm{C}$ no mesmo horário, apenas $0,01^{\circ} \mathrm{C}$ acima dos demais painéis. Os resultados de inverno na cidade de São Paulo apresentam mínimas variações. Para se ter ideia da proximidade dos resultados, a tipologia de painel minimamente mais desfavorável, foi a do painel 3 ficando com $6,28^{\circ} \mathrm{C}$ também às $6 \mathrm{~h}$. Diferença de apenas $0,04^{\circ} \mathrm{C}$ em relação aqueles que desempenharam melhores resultados. 


\subsubsection{Resultados das simulações para o dia típico de verão em Curitiba - PR}

O gráfico da Figura 50 abaixo apresenta os resultados das simulações realizadas no ambiente da sala, com todas as tipologias de painéis considerando as condições da zona bioclimática 1, Região Sul, cidade de Curitiba e dia típico de verão 21 de fevereiro.

\section{Temperatura da sala no dia típico de verão em Curitiba- 21/07}

-Externa -Painel 1 -Painel 2 -Painel3 -Painel 4 ־Painel 5 -Painel 6

-Painel 7 -Painel $8 \rightarrow$ Painel $9 \rightarrow$ Painel $10 \rightarrow$ Painel $11 \rightarrow$ Painel 12

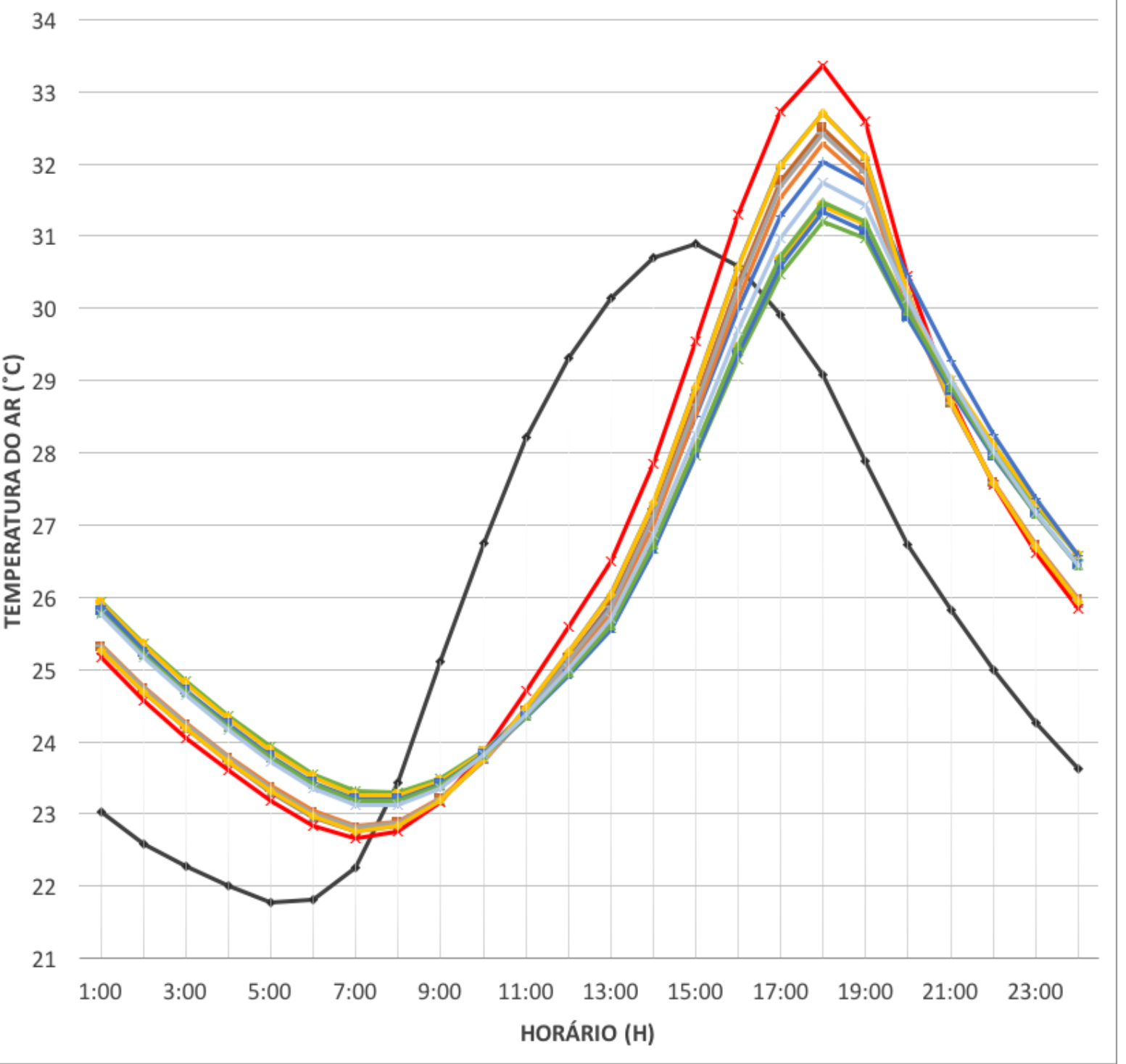

Figura 50 - Resultados das simulações dos painéis no ambiente da sala nas condições e dia típico de verão para a cidade de Curitiba-PR

Fonte: Arquivo pessoal, 2016 
O gráfico da Figura 50 acima apresenta os resultados das 12 tipologias de painéis também no ambiente da sala (ambiente em posição crítica). Inicialmente nota-se que os resultados foram similares aos apresentados no gráfico da Figura 48 da cidade de São Paulo. A temperatura máxima externa também ocorre às $15 \mathrm{~h}$ e a interna também às $18 \mathrm{~h}$.

Em Curitiba, a temperatura máxima externa é de $30,90^{\circ} \mathrm{C}$ (linha em cinza escuro) e a temperatura máxima interna, assim como na cidade de São Paulo, também foi o apresentado na simulação do painel 3 , sendo de $33,37^{\circ} \mathrm{C}$ (linha em vermelho).

Entre as tipologias de painéis estudados, o painel 4 também é o que apresenta o resultado mais próximo de atender aos requisitos mínimos da ABNT NBR 15575-1/2013, com a temperatura máxima interna de $31,21^{\circ} \mathrm{C}$, ficando com uma diferença de apenas $0.31^{\circ} \mathrm{C}$ em relação a máxima externa. Nenhuma das tipologias de painéis atenderam aos requisitos mínimos também para a cidade de Curitiba-PR no o dia típico de verão. 


\subsubsection{Resultados das simulações para o dia típico de inverno em Curitiba - PR}

O gráfico da Figura 51 abaixo apresenta os resultados das simulações realizadas no ambiente dormitório 1, com todas as tipologias de painéis, considerando as condições da zona bioclimática 1, Região Sul, cidade de Curitiba e dia típico de inverno 21 de julho.

\section{Temperatura do dormitório 1 no dia típico de Inverno em Curitiba - 21/07 \\ -Externa -Painel 1 -Painel 2 *Painel3 *Painel 4 -Painel 5 -Painel 6 \\ -Painel 7 -Painel $8 \rightarrow$ Painel $9 \rightarrow$ Painel $10 \leadsto$ Painel $11-$ Painel 12 \\ 5}

4

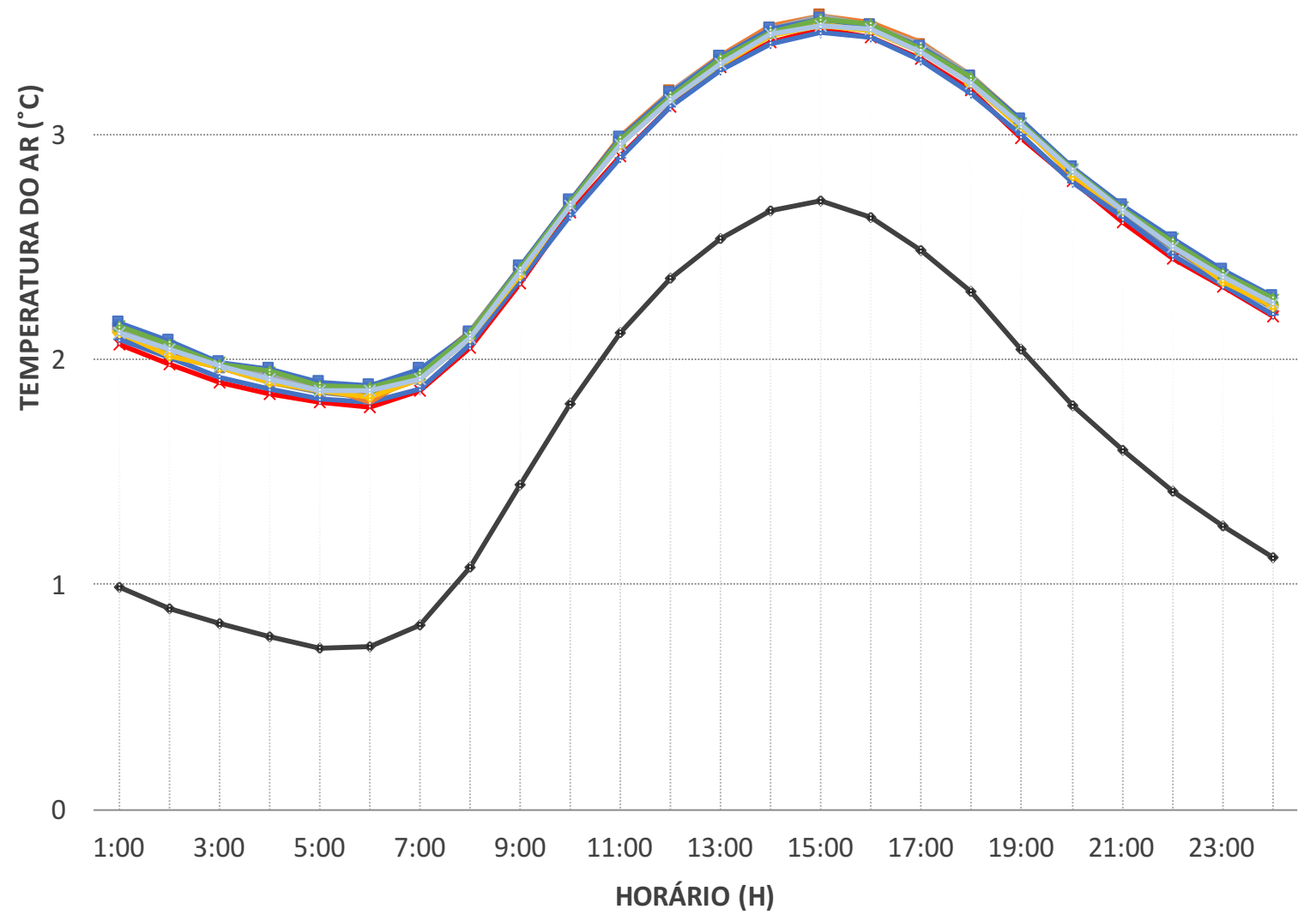

Figura 51 - Resultados das simulações dos painéis no ambiente do dormitório 1 nas condições e dia típico de inverno para a cidade de Curitiba-PR

Fonte: Arquivo pessoal, 2016 
De acordo com o gráfico da Figura 51 acima, assim como no dia típico de inverno na cidade de São Paulo (gráfico da Figura 49), a cidade de Curitiba também apresenta temperaturas mínimas internas acima da externa, porém, com uma diferença pouco acima de $1^{\circ} \mathrm{C}$, enquanto para a cidade de São Paulo esta diferença foi de no máximo $0,37^{\circ} \mathrm{C}$.

Em Curitiba, a temperatura mínima externa é de $0,7^{\circ} \mathrm{C}$ que ocorre também às $5 \mathrm{~h}$, assim como as tipologias de painéis que apresentaram resultados minimamente mais favorável foram as dos painéis 4,10 e $11, \operatorname{com} 1,88^{\circ} \mathrm{C}$ às $5 \mathrm{~h}$, ficando apenas $0,01^{\circ} \mathrm{C}$ em relação aos demais. $\mathrm{O}$ resultado mais desfavorável, mais uma vez, foi o apresentado na simulação do painel 3 ficando com $3,00^{\circ} \mathrm{C}$ às $6 \mathrm{~h}$.

Apesar de apresentarem temperaturas internas mais altas, nenhum dos resultados apresentou temperatura interna com $+3^{\circ} \mathrm{C}$ comparado a externa. Portanto, também não atendem aos requisitos mínimos da ABNT NBR 15575-1/2013. 


\subsection{RESULTADOS DA $3^{\text {a }}$ E $4^{\text {a }}$ FASE}

\subsubsection{Comparativos iniciais da $3^{\text {a }}$ fase}

Para poder avançar às fases seguintes, foi escolhida uma das tipologias analisadas anteriormente, por meio da comparação dos resultados das simulações. A tabela 10 abaixo apresenta o resumo dos resultados com as temperaturas máximas do ambiente da sala (verão) e mínimas do dormitório 1 (inverno).

\section{Análise Comparativa das Tipologias de Painéis 1 à 12}

\begin{tabular}{|c|c|c|c|c|c|c|}
\hline \multirow{3}{*}{$\begin{array}{l}\text { Tipologias } \\
\text { de painéis }\end{array}$} & \multicolumn{2}{|c|}{ Fortaleza - CE } & \multicolumn{2}{|c|}{ São Paulo - SP } & \multicolumn{2}{|c|}{ Curitiba - PR } \\
\hline & Verão & Inverno & Verão & Inverno & Verão & Inverno \\
\hline & Máxima Interna & Minima Interna & Máxima Interna & Mínima Interna & Máxima Interna & Mínima Interna \\
\hline Painel 1 & $32.25^{\circ} \mathrm{C}$ & $18.81^{\circ} \mathrm{C}$ & $33.57^{\circ} \mathrm{C}$ & $6.31^{\circ} \mathrm{C}$ & $32.50^{\circ} \mathrm{C}$ & $1.84^{\circ} \mathrm{C}$ \\
\hline Painel 2 & $32.44^{\circ} \mathrm{C}$ & $18.80^{\circ} \mathrm{C}$ & $33.81^{\circ} \mathrm{C}$ & $6.31^{\circ} \mathrm{C}$ & $32.71^{\circ} \mathrm{C}$ & $1.83^{\circ} \mathrm{C}$ \\
\hline Painel 3 & $33.04^{\circ} \mathrm{C}$ & $18.80^{\circ} \mathrm{C}$ & $34.52^{\circ} \mathrm{C}$ & $6.28^{\circ} \mathrm{C}$ & $33.37^{\circ} \mathrm{C}$ & $1.79^{\circ} \mathrm{C}$ \\
\hline Painel 4 & $31.17^{*} \mathrm{C}$ & $18.81^{\circ} \mathrm{C}$ & $32.29^{\circ} \mathrm{C}$ & $6.32^{\circ} \mathrm{C}$ & $31.21^{\circ} \mathrm{C}$ & $1.87^{\circ} \mathrm{C}$ \\
\hline Painel 5 & $31.35^{\circ} \mathrm{C}$ & $18.81^{\circ} \mathrm{C}$ & $32.51^{\circ} \mathrm{C}$ & $6.31^{\circ} \mathrm{C}$ & $31.41^{\circ} \mathrm{C}$ & $1.86^{\circ} \mathrm{C}$ \\
\hline Painel 6 & $31.89^{\circ} \mathrm{C}$ & $18.81^{\circ} \mathrm{C}$ & $33.20 \mathrm{C}$ & $6.30^{\circ} \mathrm{C}$ & $32.03^{\circ} \mathrm{C}$ & $1.81^{\circ} \mathrm{C}$ \\
\hline Painel 7 & $32.05^{\circ} \mathrm{C}$ & $18.80^{\circ} \mathrm{C}$ & $33.33^{\circ} \mathrm{C}$ & $6.31^{\circ} \mathrm{C}$ & $32.28^{\circ} \mathrm{C}$ & $1.81^{\circ} \mathrm{C}$ \\
\hline Painel 8 & $32.18^{\circ} \mathrm{C}$ & $18.80^{\circ} \mathrm{C}$ & $33.49^{\circ} \mathrm{C}$ & $6.31^{\circ} \mathrm{C}$ & $32.43^{\circ} \mathrm{C}$ & $1.87^{\circ} \mathrm{C}$ \\
\hline Painel 9 & $32.42^{\circ} \mathrm{C}$ & $18.80^{\circ} \mathrm{C}$ & $33.79^{\circ} \mathrm{C}$ & $6.30^{\circ} \mathrm{C}$ & $32.70^{\circ} \mathrm{C}$ & $1.83^{\circ} \mathrm{C}$ \\
\hline Painel 10 & $31.27^{\circ} \mathrm{C}$ & $18.81^{\circ} \mathrm{C}$ & $32.40^{\circ} \mathrm{C}$ & $6.32^{\circ} \mathrm{C}$ & $31.34^{\circ} \mathrm{C}$ & $1.87^{\circ} \mathrm{C}$ \\
\hline Painel 11 & $31.39^{\circ} \mathrm{C}$ & $18.81^{\circ} \mathrm{C}$ & $32.55^{\circ} \mathrm{C}$ & $6.32^{\circ} \mathrm{C}$ & $31.48^{\circ} \mathrm{C}$ & $1.87^{\circ} \mathrm{C}$ \\
\hline Painel 12 & $31.61 \mathrm{C}$ & $18.81^{\circ} \mathrm{C}$ & $32.84^{\circ} \mathrm{C}$ & $6.31^{\circ} \mathrm{C}$ & $31.74^{\circ} \mathrm{C}$ & $1.86^{\circ} \mathrm{C}$ \\
\hline
\end{tabular}

Tabela 10 -Resultados das temperaturas para análise comparativa e escolha de uma das tipologias de painéis de 1 a 12 a ser utilizada nas demais simulações

Fonte: Arquivo pessoal, 2016

Os resultados dos dias típicos de inverno foram extremamente próximos, quase idênticos; por este motivo não influenciaram na tomada de decisão. Já com relação aos resultados para os dias típicos de verão, estes são mais relevantes e variáveis, portanto, embasaram a escolha da tipologia de painel 4 (destacado com linha azul).

Conforme pode ser visto na tabela 10 acima, a tipologia de painel 10 é aquela que apresenta os resultados mais próximos da tipologia de painel 4, porém, é composto por perfis de $90 \mathrm{~mm}$, assim como a espessura da lã de vidro também é de $90 \mathrm{~mm}$; portanto, a tipologia de painel 10 utiliza maior quantidade de materiais, sendo, então, descartada. 


\subsubsection{Comparativos dos painéis 4.1 e 4.2 da $3^{\text {a }}$ fase}

Após a definição da tipologia de painel 4 a ser utilizada deste ponto em diante, nesta etapa foi necessário avaliar o desempenho individual da camada de placa cimentícia da face externa e da camada de placa de gesso na face interna para ser possível entender qual é a influência de cada uma delas nos resultados.

Primeiramente, foi removida uma camada de placa de gesso da face interna, resultando em uma tipologia derivada do painel 4, a qual foi denominada de painel 4.1; posteriormente, esta camada de placa de gesso retornou para face interna, e foi removida da face externa, uma camada de placa cimentícia, resultando em outra variação do painel 4, denominada painel 4.2.

A seguir na tabela 11 abaixo, são apresentados os resultados das tipologias de painel 4.1 sem a placa de gesso na face interna e a tipologia de painel 4.2 sem a placa cimentícia na face externa.

\section{Análise Comparativa de Desempenho do Painel 4.1 (sem placa de gesso) e Painel 4.2 (sem placa cimentícia)}

\begin{tabular}{l|c|c|c|c|c|c|}
\hline \multirow{2}{*}{$\begin{array}{l}\text { Tipologias } \\
\text { de painéis }\end{array}$} & \multicolumn{2}{|c|}{ Fortaleza - CE } & \multicolumn{2}{c|}{ São Paulo - SP } & \multicolumn{2}{c|}{ Curitiba - PR } \\
& $\begin{array}{c}\text { Verão } \\
\text { Máxima Interna }\end{array}$ & $\begin{array}{c}\text { Inverno } \\
\text { Mínima Interna }\end{array}$ & $\begin{array}{c}\text { Verão } \\
\text { Máxima Interna }\end{array}$ & $\begin{array}{c}\text { Inverno } \\
\text { Mínima Interna }\end{array}$ & $\begin{array}{c}\text { Verão } \\
\text { Inverno } \\
\text { Máxima Interna }\end{array}$ \\
\hline Painel 4.1 & $31.90^{\circ} \mathrm{C}$ & $18.81^{\circ} \mathrm{C}$ & $33.17^{\circ} \mathrm{C}$ & $6.31^{\circ} \mathrm{C}$ & $32.10^{\circ} \mathrm{C}$ & $1.86^{\circ} \mathrm{C}$ \\
\hline Painel 4.2 & $31.70^{\circ} \mathrm{C}$ & $18.81^{\circ} \mathrm{C}$ & $32.92^{\circ} \mathrm{C}$ & $6.31^{\circ} \mathrm{C}$ & $31.84^{\circ} \mathrm{C}$ & $1.87^{\circ} \mathrm{C}$ \\
\hline
\end{tabular}

Tabela 11 - Resultados de temperaturas para análise comparativa das tipologias de painéis 4.1 e 4.2 Fonte: Arquivo pessoal, 2016

Os resultados comparativos de desempenho entre as placas apontam pequena vantagem para a placa de gesso. Isto pode ser visto nas temperaturas máximas internas nas 3 cidades nos dias típicos de verão onde a tipologia de painel 4.1 (com placa cimentícia e sem placa de gesso) apresenta temperaturas internas mais elevadas comparadas às temperaturas apresentadas pela tipologia de painel 4.2 (com placa de gesso e sem placa cimentícia). Os resultados dos dias típicos de inverno foram quase idênticos. 


\subsubsection{Comparativos do painel 4.3 da $4^{\text {a }}$ fase}

Os resultados da etapa anterior serviram para direcionar a primeira simulação desta fase, que, com o objetivo de se aproximar mais ou atender aos requisitos mínimos da Norma de Desempenho, foi adicionada na face interna, mais uma camada de placa de gesso no painel 4 inicial. Portanto, passando a ter um total de 5 camadas de placas, resultando na tipologia de painel denominado 4.3. Os resultados estão apresentados na Tabela 12 a seguir.

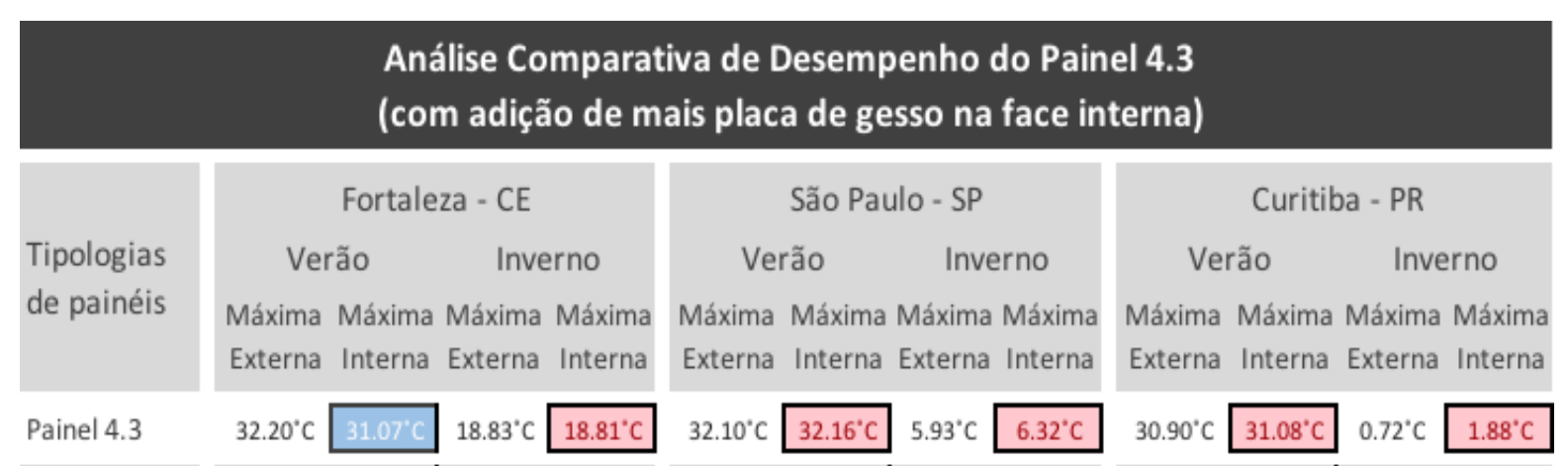

Tabela 12 - Resultados de temperaturas das 3 cidades para análise comparativa da tipologia de painel 4.3 Fonte: Arquivo pessoal, 2016

Os resultados da tabela 12 acima, demonstram obviamente que a tipologia do painel 4.3 apresentam resultados mais próximos de atender aos requisitos mínimos da ABNT NBR 155751/2013 com temperaturas máximas internas mais próximas das máximas externas nos dias típicos de verão. Porém, ainda longe de atenderem aos requisitos mínimos para o dia típico de inverno devido aos resultados não se alteraram quando comparados às temperaturas apresentadas com as tipologias de painéis anteriores. 


\subsubsection{Comparativos do painel 4.4 da $4^{\text {a }}$ fase}

Os resultados anteriores demonstraram que a premissa de adicionar material na tipologia de painel 4 até pode gerar diferentes resultados para os dias típicos de verão, porém, não altera praticamente nada, os resultados dos dias típicos de inverno nas 3 cidades. Ainda assim, optouse por prosseguir com a premissa e adicionar outra camada de placa, desta vez de placa cimentícia na face externa do painel 4.3, resultando na tipologia de painel 4.4.

As simulações com esta nova tipologia de painel, não tiveram a pretensão de atender aos requisitos mínimos dos dias de inverno, pois ficou claro que os mesmos não serão alcançados. Mas tinham como objetivo mensurar o desempenho de uma tipologia de painel composta por 3 camadas de placas cimentícias na face externa e 2 camadas de placas de gesso e mais uma de placa cimentícia na face interna (total de 6 placas). Os resultados das simulações da tipologia de painel 4.4 pode ser visto na tabela 13 a seguir.

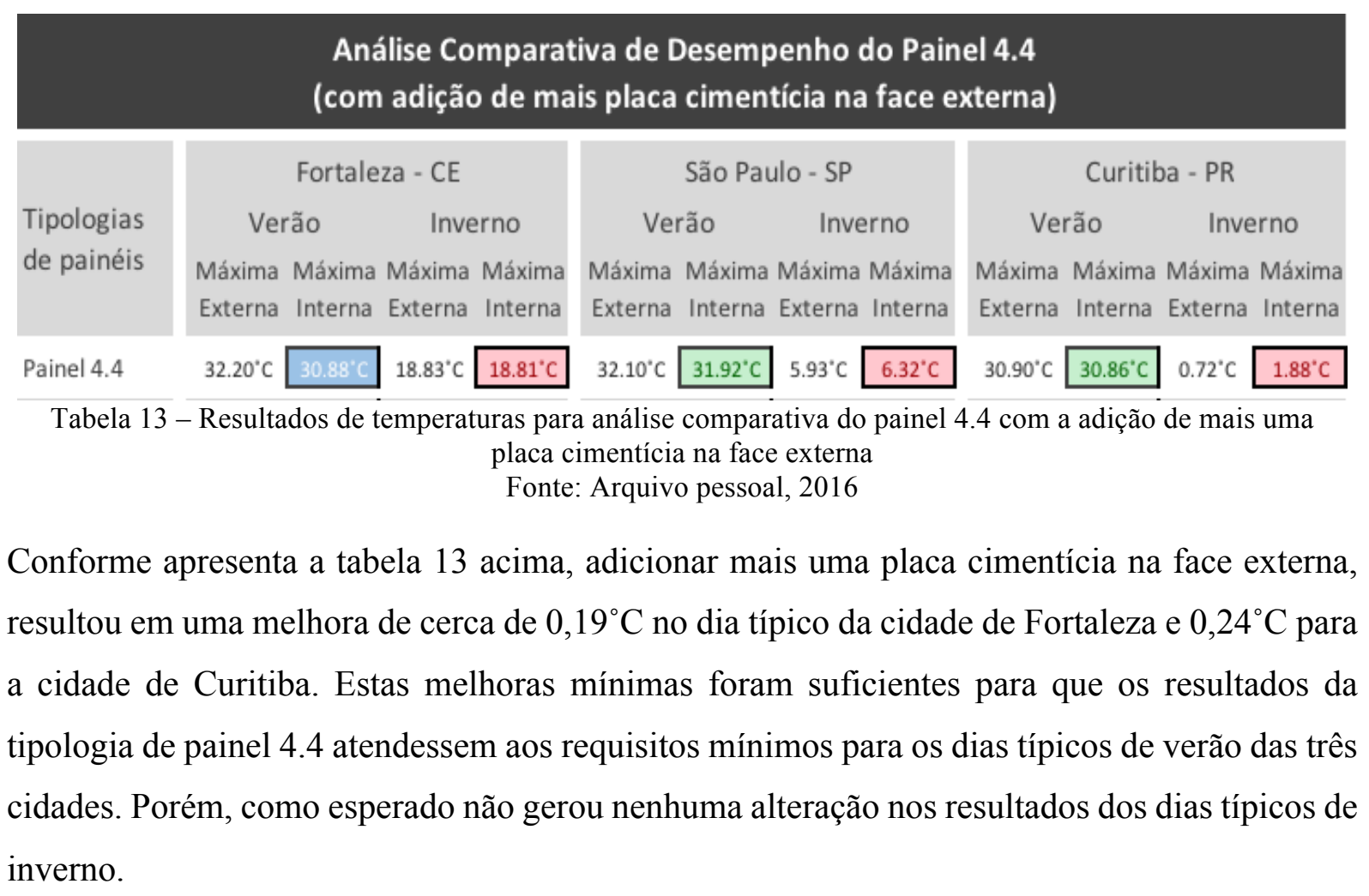




\subsection{RESULTADOS DA $5^{\mathrm{a}}$ FASE}

\subsubsection{Comparativos de verão da $5^{\mathrm{a}}$ fase}

Após ser entendido que a premissa de adição de material não resultaria no atendimento dos requisitos mínimos para os dias típicos de inverno e, ainda mesmo que atendendo para os dias típicos de verão (painel 4.4). Foi necessário modificar os parâmetros utilizados nas simulações das fases anteriores. No gráfico da Figura 52 abaixo estão apresentados os resultados da tipologia de painel 4 inicial (com 2 placas na face interna e 2 placas na face externa), que foi reutilizado na $5^{\text {a }}$ fase, porém, com os novos parâmetros com as portas e janelas sendo fechadas e a taxa de renovação de ar mudou para 5 vezes por hora ao invés de 1 vez por hora como vinha sendo utilizado.

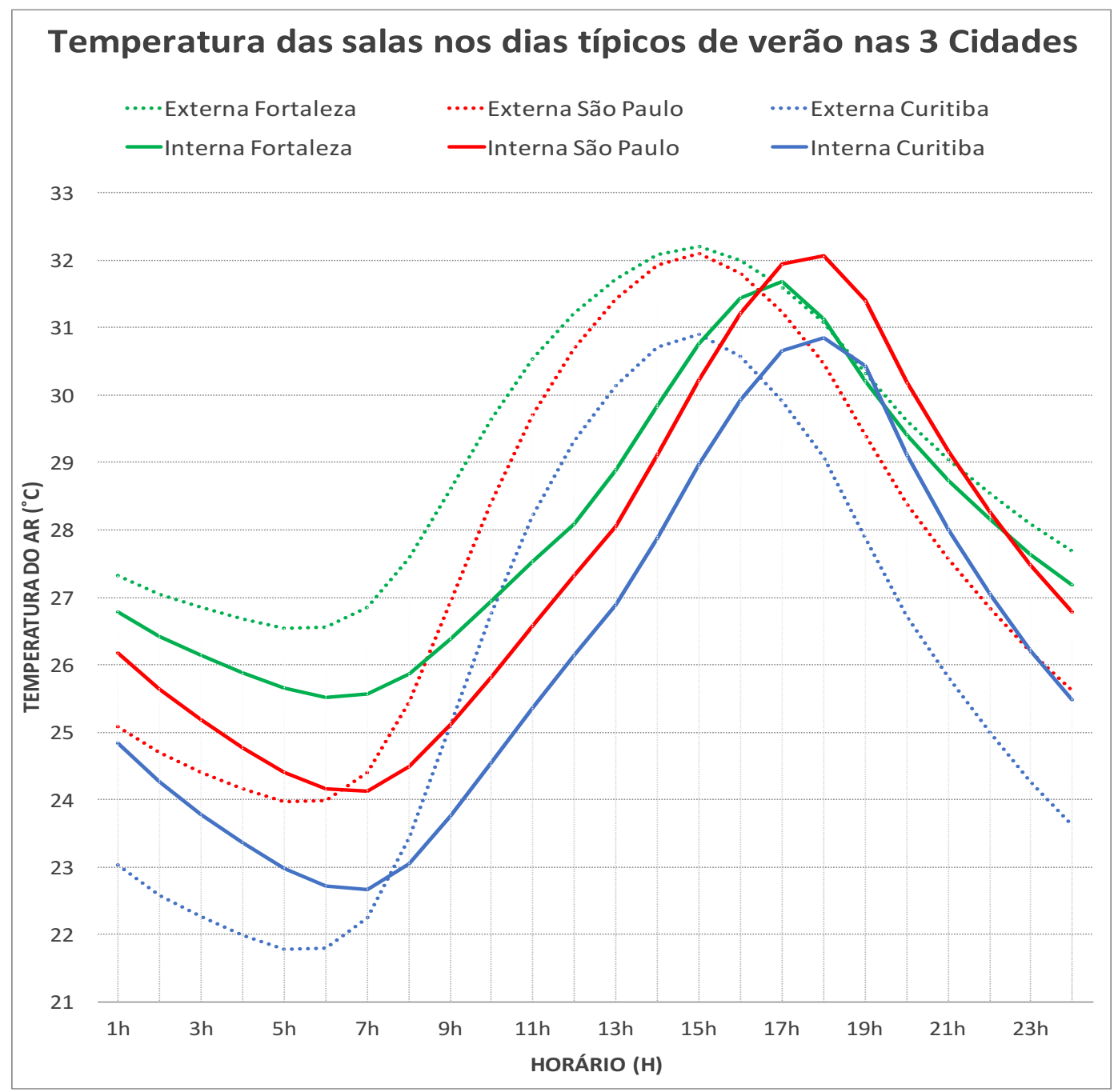

Figura 52 - Resultados das simulações com novo critério para os dias típicos de verão utilizando a tipologia de painel 4 inicial para as 3 cidades

Fonte: Arquivo pessoal, 2016 
Os resultados foram positivos para as 3 cidades com a tipologia de painel 4 inicial reutilizado considerando os novos parâmetros. Para os dias típicos de verão, os resultados passaram a atender aos requisitos mínimos exigidos pela Norma de Desempenho. Dentre as 3 cidades, Fortaleza (linhas em verde), conforme já vinha sendo notado nos resultados anteriores, continuou a ser a cidade com melhores desempenhos, estando a temperatura máxima externa em $32,20^{\circ} \mathrm{C}$ e a interna em $31,68^{\circ} \mathrm{C}$ resultando em uma diferença de $-0,52^{\circ} \mathrm{C}$.

Para a cidade de São Paulo (linhas em vermelho) os resultados foram os mais apertados entre as 3 cidades, ficando a temperatura externa $\operatorname{com} 32,10^{\circ} \mathrm{C}$ e a interna de $32,07^{\circ} \mathrm{C}$, ou seja, uma diferença mínima de $-0,03^{\circ} \mathrm{C}$.

E na cidade de Curitiba, também conforme já notado anteriormente, os resultados foram próximos aos da cidade de São Paulo. A temperatura máxima do dia típico de verão para Curitiba é de $30,90^{\circ} \mathrm{C}$ e a interna ficou em $30,85^{\circ} \mathrm{C}$ (linhas em azul), resultando em uma diferença de apenas $-0,05^{\circ} \mathrm{C}$.

Ainda assim, estas diferenças mínimas foram suficientes para atender ao critério mínimo de desempenho da ABNT NBR 15575-1/2013, a qual exige que, a temperatura máxima interna seja igual ou inferior a máxima externa. 


\subsubsection{Comparativos de inverno da $5^{\mathrm{a}}$ fase}

No gráfico da Figura 53 abaixo, estão apresentados os resultados das simulações dos dias típicos de inverno, utilizando a mesma tipologia de painel 4 inicial, porém, também com os novos parâmetros de simulação. Os parâmetros passaram a ser os mesmos que para os dias típicos de verão.



Figura 53 - Resultados das simulações com novo critério para os dias típicos de inverno utilizando a tipologia de painel 4 inicial para as 3 cidades

Fonte: Arquivo pessoal, 2016 
O gráfico da Figura 53 acima apresenta os resultados para os dias típicos de inverno nas 3 cidades, os quais são bem variados. Na cidade de Fortaleza (linhas em verde) fica na zona bioclimática 8 , que conforme dito anteriormente, não é exigido avaliação. Foi a única cidade que mesmo após as mudanças de parâmetros, continuou apresentando resultados desfavoráveis. Já para as cidades de São Paulo e Curitiba, os resultados foram positivos pela primeira vez. Sendo que, na cidade de São Paulo (linhas em vermelho) a temperatura mínima externa é de $5,93^{\circ} \mathrm{C}$ e a interna de $9,55^{\circ} \mathrm{C}$, uma diferença de $+3,62^{\circ} \mathrm{C}$, portanto, ultrapassando os $+3,00^{\circ} \mathrm{C}$ exigidos e atendendo aos requisitos mínimos de desempenho.

Para a cidade de Curitiba, a temperatura mínima externa é de $0,72^{\circ} \mathrm{C}$ e a interna de $5,97^{\circ} \mathrm{C}$ (linhas em azul), resultando em uma diferença de $+5,25^{\circ} \mathrm{C}$, ou seja, atendendo não apenas ao requisito mínimo, mas também ao intermediário conforme tabela 8 (ABNT NBR 155751/2013).

\subsubsection{Análise dos resultados com relação às condições de conforto térmico}

Considerando a tipologia de painel 4 antes e após a alteração de parâmetro no dia típico de verão as temperaturas ultrapassam a temperatura máxima considerada confortável de forma mais expressiva no período da noite, sendo este provavelmente, o período de maior uso dos ambientes. Também é possível notar que o atraso na contribuição para conforto do ambiente da sala diminui quando os parâmetros de renovação de ar são alterados de 1x por hora para 5x por hora em todas as cidades.

Já nos dias típicos de inverno, também comparando a tipologia de painel 4 antes e após a alteração de parâmetro, a cidade de Fortaleza apresenta temperaturas mais confortáveis no inverno. Já para as cidades de São Paulo e Curitiba, antes e após a alteração de parâmetro as temperaturas ficam bem abaixo da temperatura considerada confortável, sendo que a contribuição para o conforto térmico aumenta quando o parâmetro é modificado. 


\section{CONCLUSÕES}

A tabela 14 abaixo apresenta os resultados de todas as tipologias de painéis que foram simuladas neste estudo, juntamente com o status de desempenho (conforme tabela 9) de cada tipologia para cada uma das 3 cidades, tanto para os dias típicos de verão, quanto para os dias típicos de inverno.

\begin{tabular}{|c|c|c|c|c|c|c|c|c|c|c|c|c|}
\hline \multirow{4}{*}{$\begin{array}{l}\text { Tipologias } \\
\text { de painéis }\end{array}$} & 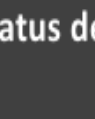 & esel & $\begin{array}{l}\text { enho } \\
\text { com }\end{array}$ & çã & req a & $\begin{array}{l}\text { aine } \\
\text { itos }\end{array}$ & $\begin{array}{l}\text { OS a } \\
\text { NBR : }\end{array}$ & $75 /$ & sal & do & rio 1 & \\
\hline & \multicolumn{4}{|c|}{ Fortaleza - CE } & \multicolumn{4}{|c|}{ São Paulo - SP } & \multicolumn{4}{|c|}{ Curitiba - PR } \\
\hline & \multicolumn{2}{|c|}{ Verão } & \multicolumn{2}{|c|}{ Inverno } & \multicolumn{2}{|c|}{ Verão } & \multicolumn{2}{|c|}{ Inverno } & \multicolumn{2}{|c|}{ Verão } & \multicolumn{2}{|c|}{ Inverno } \\
\hline & $\begin{array}{l}\text { Máxima } \\
\text { Externa }\end{array}$ & $\begin{array}{l}\text { Máxima } \\
\text { Interna }\end{array}$ & $\begin{array}{l}\text { Mínima } \\
\text { Externa }\end{array}$ & $\begin{array}{l}\text { Mínima } \\
\text { Interna }\end{array}$ & $\begin{array}{l}\text { Máxima } \\
\text { Externa }\end{array}$ & Máxima & $\begin{array}{l}\text { Mínima } \\
\text { Externa }\end{array}$ & $\begin{array}{l}\text { Mínima } \\
\text { Interna }\end{array}$ & $\begin{array}{l}\text { Máxima } \\
\text { Externa }\end{array}$ & Máxima & $\begin{array}{l}\text { Mínima } \\
\text { Externa }\end{array}$ & Minima \\
\hline Painel 1 & $32.20^{\circ} \mathrm{C}$ & $32.25^{\circ} \mathrm{C}$ & $18.83^{\circ} \mathrm{C}$ & $18.80^{\circ} \mathrm{C}$ & $32.10^{\circ} \mathrm{C}$ & $33.57^{\circ} \mathrm{C}$ & $5.93^{\circ} \mathrm{C}$ & $6.31^{\circ} \mathrm{C}$ & $30.90^{\circ} \mathrm{C}$ & $32.50^{\circ} \mathrm{C}$ & $0.72^{\circ} \mathrm{C}$ & $1.84^{\circ} \mathrm{C}$ \\
\hline Painel 2 & $32.20^{\circ} \mathrm{C}$ & $32.44^{\circ} \mathrm{C}$ & $18.83^{\circ} \mathrm{C}$ & $18.80^{\circ} \mathrm{C}$ & $32.10^{\circ} \mathrm{C}$ & $33.82^{\circ} \mathrm{C}$ & $5.93^{\circ} \mathrm{C}$ & $6.31^{\circ} \mathrm{C}$ & $30.90^{\circ} \mathrm{C}$ & $32.71^{\circ} \mathrm{C}$ & $0.72^{\circ} \mathrm{C}$ & $1.83^{\circ} \mathrm{C}$ \\
\hline Painel 3 & $32.20^{\circ} \mathrm{C}$ & $33.04^{\circ} \mathrm{C}$ & $18.83^{\circ} \mathrm{C}$ & $18.80^{\circ} \mathrm{C}$ & $32.10^{\circ} \mathrm{C}$ & $34.52^{\circ} \mathrm{C}$ & $5.93^{\circ} \mathrm{C}$ & $6.28^{\circ} \mathrm{C}$ & $30.90^{\circ} \mathrm{C}$ & $33.37^{\circ} \mathrm{C}$ & $0.72^{\circ} \mathrm{C}$ & $1,79^{\circ} \mathrm{C}$ \\
\hline Painel 4 & $32.20^{\circ} \mathrm{C}$ & $31.17^{\circ} \mathrm{C}$ & $18.83^{\circ} \mathrm{C}$ & $18.81^{\circ} \mathrm{C}$ & $32.10^{\circ} \mathrm{C}$ & $32.29^{\circ} \mathrm{C}$ & $5.93^{\circ} \mathrm{C}$ & $6.32^{\circ} \mathrm{C}$ & $30.90^{\circ} \mathrm{C}$ & $31.21^{\circ} \mathrm{C}$ & $0.72^{\circ} \mathrm{C}$ & $1.88^{\circ} \mathrm{C}$ \\
\hline Painel 5 & $32.20^{\circ} \mathrm{C}$ & $31.35^{\circ} \mathrm{C}$ & $18.83^{\circ} \mathrm{C}$ & $18.81^{\circ} \mathrm{C}$ & $32.10^{\circ} \mathrm{C}$ & $32.51^{\circ} \mathrm{C}$ & $5.93^{\circ} \mathrm{C}$ & $6.31^{\circ} \mathrm{C}$ & $30.90^{\circ} \mathrm{C}$ & $31.41^{\circ} \mathrm{C}$ & $0.72^{\circ} \mathrm{C}$ & $1.86^{\circ} \mathrm{C}$ \\
\hline Painel 6 & $32.20^{\circ} \mathrm{C}$ & $31.89^{\circ} \mathrm{C}$ & $18.83^{\circ} \mathrm{C}$ & $18.81^{\circ} \mathrm{C}$ & $32.10^{\circ} \mathrm{C}$ & $33.20^{\circ} \mathrm{C}$ & $5.93^{\circ} \mathrm{C}$ & $6.31^{\circ} \mathrm{C}$ & $30.90^{\circ} \mathrm{C}$ & $32.03^{\circ} \mathrm{C}$ & $0.72^{\circ} \mathrm{C}$ & $1.81^{\circ} \mathrm{C}$ \\
\hline Painel 7 & $32.20^{\circ} \mathrm{C}$ & $32.05^{\circ} \mathrm{C}$ & $18.83^{\circ} \mathrm{C}$ & $18.81^{\circ} \mathrm{C}$ & $32.10^{\circ} \mathrm{C}$ & $33.33^{\circ} \mathrm{C}$ & $5.93^{\circ} \mathrm{C}$ & $6.31^{\circ} \mathrm{C}$ & $30.90^{\circ} \mathrm{C}$ & $32.28^{\circ} \mathrm{C}$ & $0.72^{\circ} \mathrm{C}$ & $1.87^{\circ} \mathrm{C}$ \\
\hline Painel 8 & $32.20^{\circ} \mathrm{C}$ & $32.18^{\circ} \mathrm{C}$ & $18.83^{\circ} \mathrm{C}$ & $18.80^{\circ} \mathrm{C}$ & $32.10^{\circ} \mathrm{C}$ & $33.49^{\circ} \mathrm{C}$ & $5.93^{\circ} \mathrm{C}$ & $6.31^{\circ} \mathrm{C}$ & $30.90^{\circ} \mathrm{C}$ & $32.43^{\circ} \mathrm{C}$ & $0.72^{\circ} \mathrm{C}$ & $1.87^{\circ} \mathrm{C}$ \\
\hline Painel 9 & $32.20^{\circ} \mathrm{C}$ & $32.42^{\circ} \mathrm{C}$ & $18.83^{\circ} \mathrm{C}$ & $18.80^{\circ} \mathrm{C}$ & $32.10^{\circ} \mathrm{C}$ & $33.79^{\circ} \mathrm{C}$ & $5.93^{\circ} \mathrm{C}$ & $6.30^{\circ} \mathrm{C}$ & $30.90^{\circ} \mathrm{C}$ & $32.70^{\circ} \mathrm{C}$ & $0.72^{\circ} \mathrm{C}$ & $1.83^{\circ} \mathrm{C}$ \\
\hline Painel 10 & $32.20^{\circ} \mathrm{C}$ & $31.27^{\circ} \mathrm{C}$ & $18.83^{\circ} \mathrm{C}$ & $18.81^{\circ} \mathrm{C}$ & $32.10^{\circ} \mathrm{C}$ & $32.40^{\circ} \mathrm{C}$ & $5.93^{\circ} \mathrm{C}$ & $6.32^{\circ} \mathrm{C}$ & $30.90^{\circ} \mathrm{C}$ & $31.34^{\circ} \mathrm{C}$ & $0.72^{\circ} \mathrm{C}$ & $1.88^{\circ} \mathrm{C}$ \\
\hline Painel 11 & $32.20^{\circ} \mathrm{C}$ & $31.39^{\circ} \mathrm{C}$ & $18.83^{\circ} \mathrm{C}$ & $18.81^{\circ} \mathrm{C}$ & $32.10^{\circ} \mathrm{C}$ & $32.55^{\circ} \mathrm{C}$ & $5.93^{\circ} \mathrm{C}$ & $6.32^{\circ} \mathrm{C}$ & $30.90^{\circ} \mathrm{C}$ & $31.48^{\circ} \mathrm{C}$ & $0.72^{\circ} \mathrm{C}$ & $1.88^{\circ} \mathrm{C}$ \\
\hline Painel 12 & $32.20^{\circ} \mathrm{C}$ & $31.61^{\circ} \mathrm{C}$ & $18.83^{\circ} \mathrm{C}$ & $18.81^{\circ} \mathrm{C}$ & $32.10^{\circ} \mathrm{C}$ & $32.84^{\circ} \mathrm{C}$ & $5.93^{\circ} \mathrm{C}$ & $6.31^{\circ} \mathrm{C}$ & $30.90^{\circ} \mathrm{C}$ & $31.74^{\circ} \mathrm{C}$ & $0.72^{\circ} \mathrm{C}$ & $1.86^{\circ} \mathrm{C}$ \\
\hline Painel 4.1 & $32.20^{\circ} \mathrm{C}$ & $31.90^{\circ} \mathrm{C}$ & $18.83^{\circ} \mathrm{C}$ & $18.81^{\circ} \mathrm{C}$ & $32.10^{\circ} \mathrm{C}$ & $33.17^{\circ} \mathrm{C}$ & $5.93^{\circ} \mathrm{C}$ & $6.31^{\circ} \mathrm{C}$ & $30.90^{\circ} \mathrm{C}$ & $32.10^{\circ} \mathrm{C}$ & $0.72^{\circ} \mathrm{C}$ & $1.86^{\circ} \mathrm{C}$ \\
\hline Painel 4.2 & $32.20^{\circ} \mathrm{C}$ & $31.70^{\circ} \mathrm{C}$ & $18.83^{\circ} \mathrm{C}$ & $18.81^{\circ} \mathrm{C}$ & $32.10^{\circ} \mathrm{C}$ & $32.92^{\circ} \mathrm{C}$ & $5.93^{\circ} \mathrm{C}$ & $6.31^{\circ} \mathrm{C}$ & $30.90^{\circ} \mathrm{C}$ & $31.84^{\circ} \mathrm{C}$ & $0.72^{\circ} \mathrm{C}$ & $1.87^{\circ} \mathrm{C}$ \\
\hline Painel 4.3 & $32.20^{\circ} \mathrm{C}$ & $31.07^{\circ} \mathrm{C}$ & $18.83^{\circ} \mathrm{C}$ & $18.81^{\circ} \mathrm{C}$ & $32.10^{\circ} \mathrm{C}$ & $32.16^{\circ} \mathrm{C}$ & $5.93^{\circ} \mathrm{C}$ & $6.32^{\circ} \mathrm{C}$ & $30.90^{\circ} \mathrm{C}$ & $31.08^{\circ} \mathrm{C}$ & $0.72^{\circ} \mathrm{C}$ & $1.88^{\circ} \mathrm{C}$ \\
\hline Painel 4.4 & $32.20^{\circ} \mathrm{C}$ & $30,89^{\circ} \mathrm{C}$ & $18.83^{\circ} \mathrm{C}$ & $18.81^{\circ} \mathrm{C}$ & $32.10^{\circ} \mathrm{C}$ & $31.92^{\circ} \mathrm{C}$ & $5.93^{\circ} \mathrm{C}$ & $6.32^{\circ} \mathrm{C}$ & $30.90^{\circ} \mathrm{C}$ & $30.73^{\circ} \mathrm{C}$ & $0.72^{\circ} \mathrm{C}$ & $1.88^{\circ} \mathrm{C}$ \\
\hline \multicolumn{13}{|c|}{ Tipologia de painel 4 após mudanças de parâmetros } \\
\hline Painel 4 & $32.20^{\circ} \mathrm{C}$ & $31.68^{\circ} \mathrm{C}$ & $18.83^{\circ} \mathrm{C}$ & $18.43^{\circ} \mathrm{C}$ & $32.10^{\circ} \mathrm{C}$ & $32.07^{\circ} \mathrm{C}$ & $5.93^{\circ} \mathrm{C}$ & $9.55^{\circ} \mathrm{C}$ & $30.90^{\circ} \mathrm{C}$ & $30.85^{\circ} \mathrm{C}$ & $0.72^{\circ} \mathrm{C}$ & $6.01^{\prime} \mathrm{C}$ \\
\hline
\end{tabular}

Tabela 14 - Status de conclusão dos níveis de desempenhos de todas as tipologias de painéis estudados nos dias típicos de verão (sala - zona térmica 2) e inverno (dormitório 1 - zona térmica 5) nas 3 cidades

Fonte: Arquivo pessoal, 2016

Com o total de 72 simulações iniciais da $1^{\mathrm{a}}$ e $2^{\mathrm{a}}$ fase, somados a mais 24 simulações da $3^{\mathrm{a}}$ e $4^{\mathrm{a}}$ fase e outras 3 simulações da $5^{\text {a }}$ fase chegou-se em um total de 99 simulações. Conforme apresentado na tabela 14 acima, os resultados para o dia típico de verão para a cidade de Fortaleza foram na maioria, favoráveis; onde 13 das 17 tipologias de painéis apresentaram resultados favoráveis. Estes painéis foram os de tipologias 4, 5, 6, 7, 8, 10, 11, 12 e 4.1, 4.2, 
4.3, 4.4 com parâmetros mais restritivo (anteriores a mudança de parâmetro) e, 4 (após mudança de parâmetro).

Os resultados referentes à cidade de Fortaleza, apresentaram a menor variação para o dia típico de verão, com a tipologia de painel 4 (anterior, $31,17^{\circ} \mathrm{C}$ e após a mudança de parâmetro $31,68^{\circ} \mathrm{C}$ ), com uma diferença de $0,51^{\circ} \mathrm{C}$. Mesmo em ambas as tipologias os resultados sendo favoráveis, em Fortaleza, foi a única cidade em que os resultados para o dia típico de verão foram piores após a mudança de parâmetro.

Como a maioria dos painéis apresentaram resultados favoráveis para a cidade de Fortaleza, para o dia típico de verão e, considerando que o dia típico de inverno não é exigido, qualquer uma das tipologias descritas acima (e em verde na primeira coluna da tabela 14) poderiam ser utilizadas. Ressalta-se, no entanto, que apenas na cidade de Fortaleza a tipologia de painel 4 não é a que utiliza menor quantidade de material, e sim, os painéis 6 e 8 entre as opções que atenderam aos requisitos mínimos da ABNT NBR 15575-1/2013. Portanto, após análise comparativa final, são os painéis com melhor custo benefício para a cidade de Fortaleza.

Para as cidades de São Paulo e Curitiba os resultados foram semelhantes para todas as tipologias de painéis nos dias típicos de verão, onde 15 dos 17 painéis apresentaram resultados desfavoráveis. Apenas as tipologias de painéis 4.4 e 4 na $5^{\text {a }}$ fase, após mudança de parâmetro, resultaram em temperatura máxima interna minimamente abaixo da externa (em verde na terceira e quinta coluna da tabela 14 acima). Portanto, estas duas tipologias atenderam comparativamente aos requisitos mínimos de desempenho para as cidades de São Paulo e Curitiba.

A tabela 14 acima também apresenta os resultados das simulações de todas as tipologias de painéis para os dias típicos de inverno para as 3 cidades. Em Fortaleza, diferentemente dos dias típicos de verão, no inverno, nenhuma das tipologias de painéis resultou em temperaturas mínimas internas com $+3^{\circ} \mathrm{C}$ em relação a temperatura mínima externa. As temperaturas internas ficaram muito próximas das externas, apresentando o pior resultado para o dia típico de inverno entre as 3 cidades.

Porém, devido a Norma de Desempenho (conforme tabela 8) não exigir análise na cidade onde fica a cidade de Fortaleza (zona bioclimática 8), estes resultados não comprometem o desempenho dos painéis que apresentaram resultados positivos para o dia típico de verão desta cidade e, também não invalida os resultados positivos do painel 4 apresentados para as outras cidades. 
Inicialmente, antes das alterações de parâmetros, nas cidades de São Paulo e Curitiba, os resultados eram desfavoráveis entre todas as tipologias de painéis. Porém, após a mudança de parâmetro, os resultados foram consideravelmente favoráveis e passaram a atender nas 3 cidades com a tipologia de painel 4. A cidade de São Paulo, apresenta o nível mínimo de desempenho, e Curitiba, o nível intermediário, ficando a temperatura mínima interna $+5,00^{\circ} \mathrm{C}$ acima da externa.

Os parâmetros iniciais para os dias típicos de inverno, sendo janelas e portas abertas, inviabilizou todas as tipologias de painéis, independente da quantidade de material envolvido. Portanto, conclui-se que a premissa inicial não é viável, além de dificilmente acontecer na prática da vida real. Reduzir os níveis de exigência e modificar os parâmetros foi primordial para a conclusão do trabalho.

Após as mudanças de parâmetros, notou-se também que, a maior dificuldade passou a ser atender os requisitos nos dias típicos de verão, e não mais nos dias típicos de inverno, conforme vinham sendo apresentados os resultados até a $4^{\mathrm{a}}$ fase.

Para as tipologias de painéis 1, 4 e 4.4 foram adotados os mesmos padrões de adições de materiais. O painel 1 possui apenas uma camada de 1 placas na face interna e externa, o painel 4 possui dupla camada de placas e o painel 4.4 possui tripla camada de placas. As três tipologias possuem lã de vidro com $70 \mathrm{~mm}$ no seu interior e camadas internas e externas de acabamentos idênticas.

Este padrão de adição de materiais permite uma análise comparativa entre estas três tipologias. Ao comparar a tipologia de painel 4 (camadas duplas de placas) com a tipologia 1 (camada simples de placas), houve uma redução de temperatura mínima interna nos dias típicos de verão acima de $1,00^{\circ} \mathrm{C}$. Sendo de $1.08^{\circ} \mathrm{C}$ na cidade de Fortaleza, $1,28^{\circ} \mathrm{C}$ na cidade de São Paulo e $1,29^{\circ} \mathrm{C}$ na cidade de Curitiba.

Porém, ao comparar a tipologia 4.4 (camadas triplas de placas) com a tipologia 4 (camadas duplas de placas), os resultados foram menos significativos, ficando em $0,29^{\circ} \mathrm{C}$ na cidade de Fortaleza, $0,37^{\circ} \mathrm{C}$ na cidade de São Paulo e $0,35^{\circ} \mathrm{C}$ na cidade de Curitiba. Portanto, a adição ou a triplicação de placas não resultam exatamente, na triplicação do nível de desempenho.

Não foram necessárias outras simulações na tentativa de simplificar a tipologia de painel 4 para as cidades de São Paulo e Curitiba, sendo que após mudanças de parâmetros, apresentou resultados extremamente próximos ao desempenho mínimo exigido nos dias típicos de verão; ou seja, as temperaturas máximas internas ficaram próximas das externas. Em São Paulo 
apresentou uma diferença de apenas $0,03^{\circ} \mathrm{C}$, para Curitiba uma diferença de $0,05^{\circ} \mathrm{C}$. Portanto, qualquer alteração que fosse feita na tentativa de reduzir ou retirar alguma camada de material poderia comprometer os resultados de desempenho.

As tabelas do apêndice A (tabelas 15, 16, 17 e 18), apresentam as temperaturas mínimas e máximas dos demais ambientes da residência, bem como seus níveis de desempenho com relação à ABNT NBR 15575-1/2013. Os valores relacionados nas tabelas evidenciam que o ambiente localizado com abertura para o Norte e parede exposta para Oeste (Sala) é de fato o ambiente mais crítico no verão e que o ambiente com abertura para o Sul e parede exposta para Leste (Dormitório 1) é o que apresenta resultados mais desfavoráveis no inverno.

A cidade de São Paulo, dentre as três analisadas, é aquela que apresenta menores variações de temperatura entre todos os ambientes da residência e, a tipologia de painel 3 entre todas, é a que apresenta os níveis de desempenho mais desfavoráveis.

Conforme mencionado no item 5.3.3, ao se analisar o comportamento térmico da edificação, nota-se que os valores de temperaturas indicaram algum nível de desempenho, de acordo com os critérios ad ABNT NBR 15575/2013, mesmo quando ultrapassam os limites de faixa de temperaturas consideradas confortáveis. Ou seja, mesmo quando as temperaturas ultrapassam a faixa de conforto térmico, ainda assim podem ser consideradas como adequadas e dentro de padrões aceitáveis de desempenho.

Os resultados da pesquisa também apontam que há tendência de que para climas mais frios a utilização de painéis com materiais isolantes é mais adequada, conforme demonstram os resultados para o dia típicos de inverno que apresentam resultados consideravelmente mais satisfatórios do que para os dias típicos de verão.

Para uma análise mais precisa, seria mais adequado simular por um período de pelo menos um ano, pois, com isto, poderia ser identificado um período significativo do ano para aplicação dos painéis de tal forma a que eles contribuíssem para a melhoria do conforto e atendimento aos requisitos da norma.

Por fim, a possibilidade de poder realizar e concluir este estudo em paralelo à fase de projeto do protótipo a ser executado possibilitou na prática o uso do presente estudo em uma fase prévia à de execução, portanto, desempenhou um papel muito importante. $\mathrm{O}$ uso de simulação computacional deste estudo, pode possibilitar redução consideráveis dos riscos de negativa dos futuros testes experimentais aos quais o protótipo físico irá ser submetido, evitando retrabalhos, desperdício financeiro e de tempo. 
Não se trata simplesmente de se adicionar sucessivamente camadas de materiais ou placas no painel, caso o mesmo não apresente resultados positivos, pois os resultados de desempenho não se duplicam ou triplicam conforme duplica-se ou triplica-se a quantidade de materiais envolvidos.

A questão é saber onde se utilizar maior quantidade de materiais e onde se pode talvez utilizar menor quantidade. Conforme comentado acima, ao se analisar os demais ambientes da residência nota-se que as mesmas tipologias de painéis utilizados nos ambientes mais críticos e que apresentaram resultados extremamente próximos dos limites, atendem para os demais ambientes com folga; esta lógica ficou clara neste trabalho e será colocado na prática no protótipo.

Com relação ao presente trabalho, para os ambientes de longa permanência e considerados os mais críticos devido ao seu posicionamento podem receber a tipologia de painel 4 , já para os demais ambientes, tende-se a utilizar menor quantidade de materiais, seja na quantidade de placas na face interna e externa ou na espessura da camada isolante. Estes resultados são animadores, e vão de encontro com a necessidade do projeto da Startup, que é proporcionar uma solução com maior custo benefício dos painéis através da racionalização e utilização inteligente de materiais.

Portanto, o presente estudo já gerou impacto no projeto executivo do protótipo, servindo para guiar a definição do projeto executivo dos painéis a serem utilizados no protótipo. As simulações foram muito importantes para a definição da espessura da camada isolante e da quantidade de placas envolvidas, possibilitando prévia tomada de decisão com segurança e racionalização através da antecipação de resultados que somente seriam conhecidos após a construção do protótipo e de futuros testes físicos.

E ainda, os resultados deste estudo serão apresentados ao SENAI-PR, não apenas para justificar a composição do projeto executivo dos painéis, mas também para compartilhar os conhecimentos adquiridos. Este compartilhamento possibilita beneficiá-los em novos estudos desta tecnologia de painéis, servindo para que todos os envolvidos, inclusive outras possíveis empresas, possam se utilizar deste estudo como referência, evitando assim, resultados desfavoráveis abaixo do desempenho desejado, podendo resultar em economia financeira e de tempo para todos os envolvidos, assim como para a Startup. 


\section{SUGESTÕES DE TRABALHOS FUTUROS}

Os demais ambientes (como pode ser visto nas Tabelas do apêndice A) apresentam resultados consideravelmente mais favoráveis, tanto no inverno quanto no verão. Portanto, seria muito interessante em um novo estudo, aprofundar-se na variação de tipologias de painéis com menor quantidade de material nestes demais ambientes que não sejam aqueles com localização mais crítica (Sala e Dormitório 1). Por exemplo, seja com variações nos painéis de fachada, ou nos painéis internos, ou em ambos. Um estudo com painéis mistos, poderia determinar tipologias diferentes de painéis, mas que ainda assim mantivessem padrões de modularização e industrialização, podendo auxiliar na utilização de menor quantidade de material. 


\section{REFERÊNCIAS BIBLIOGRÁFICAS}

ASSOCIAÇÃO BRASILEIRA DE NORMAS TÉCNICAS. NB 25R: Modulação das Construções. Rio de Janeiro, 1950.

. NB 25: Coordenação Modular da Construção. Rio de Janeiro, 1970.

. NBR 5706: Coordenação Modular da Construção. Rio de Janeiro, 1977.

.NBR 15873: Coordenação Modular das Edificações. São Paulo, 2010.

.NBR 15220-2: Desempenho térmico de edificações.

.NBR 15575: Edificações habitacionais - Desempenho. Rio de Janeiro, 2013.

.NBR 15575-1: Edificações habitacionais - Desempenho Parte 1: Requisitos gerais. Rio de Janeiro, 2013.

.NBR 15575-4: Edificações habitacionais - Desempenho Parte 4: Sistemas de vedação verticais internas e externas - SVVIE. Rio de Janeiro, 2013.

.NBR 15575-5: Edificações habitacionais - Desempenho Parte 5: Requisitos para sistema de coberturas - SC. Rio de Janeiro, 2013.

ABCP, ASSOCIAÇÃO BRASILEIRA DE CIMENTO PORTLAND, São Paulo 2015. Disponível em: http:/www.abcp.org.br/cms/imprensa/banco-de-pautas/fim-do-quebraquebra-agora-tudo-se-encaixa-na-construcao/. Acesso em: 15 de dezembro de 2015.

CÂMARA BRASILEIRA DA INDÚSTRIA DA CONSTRUÇÃO. Desempenho de edificações habitacionais: guia orientativo para atendimento à norma ABNT NBR 15575/2013. $2^{a}$ ed. Brasília: Gadioli Cipolla Comunicação, 2013.

BALDAUF, Alexandra. Contribuição à implementação da coordenação modular da construção no Brasil. Porto Alegre: Universidade federal do Rio Grande do Sul, 2004.

BARBOZA, A. S. R. B. et al. Coordenação Modular e Conectividade Aplicada à Alvenaria de Blocos em Alternativas Tipológicas de Habitação de Interesse Social no Nordeste do Brasil. In: ENCONTRO NACIONAL DE TECNOLOGIA DO AMBIENTE CONSTRUÍDO, 12. 2008. Fortaleza. Anais... Fortaleza: Antac, 2008. 1 CD- ROM.

BORGES, C. A. M. O conceito de desempenho de edificações e a sua importância para o setor da construção civil no Brasil. 2008. 263 p. Dissertação (mestrado) - Escola Politécnica, Universidade de São Paulo, São Paulo, 2008.

SCI, STEEL CONSTRUCTION INSTITUTE. Building design using cold formed steel sections: an architect's guide. P. J Trebilcock. Berkshire, 1994. 
UNITED STATES. Departament of energy. Washington DC, december 11 2015. EnergyPlus Energy Simulation Software. Disponível em:

$<$ http://apps1.eere.energy.gov/buildings/energyplus/>. Acesso em: 13 de janeiro de 2017.

FGV, Resumo - Estudo de Produtividade na Construção Civil, 2012. Disponível em: http://www.cbicdados.com.br/menu/estudos-especificos-da-construcao-civil/produtividadena-construcao-civil Acesso em 22 de jul.2014.

GREVEN, H. A.; BALDAUF, A. S. F. Introdução à Coordenação Modular da Construção no Brasil: uma abordagem atualizada. Porto Alegre: ANTAC, 2007. (Coleção Habitare, 9).

GONÇALVES, O. M. et al. Normas técnicas para avaliação de sistemas construtivos inovadores para habitações. In: NORMALIZAÇÃO e certificação na construção habitacional. Porto Alegre: ANTAC, 2003. Coletânea HABITARE v. 3, Cap. 3.

HAJJAR, D.; ABOURIZK, S. M. Unified Modeling Methodology for Construction Simulation. Journal of Construction Engineering and Management, v. 128, n. 2, p. 174$185,2002$.

KAPP, Silke. Moradia e Contradição do Projeto Moderno, 2005.

LABORATÓRIO DE EFICIÊNCIA ENERGÉTICA EM EDIFICAÇÕES. Arquivos climáticos em formato EPW. Florianópolis: 2014. Disponível em:

$<$ http://www.labeee.ufsc.br/downloads/arquivos-climaticos/formato-epw $>$. Acesso em: $16 \mathrm{de}$ maio de 2014.

NATIONAL RENEWABLE ENERGY LABORATORY. Energy Design Plugin: An EnergyPus Plugin for Sketchup. Califórnia 2008. Disponível em: http://www.nrel.gov/docs/fy08osti/43569.pdf. Acesso em: 19 de janeiro de 2016.

NATIONAL RENEWABLE ENERGY LABORATORY. Open Studio Source Integrated Analysis Plataform. Austrália 2011. Disponível em:

http://www.nrel.gov/docs/fy12osti/51836.pdf. Acesso em: 19 de janeiro de 2016.

ORDONÉZ, J. A. F. (1974) Pre-fabricacion: teoría y prática. Barcelona: Editores Técnicos Associados. v.1.

PORTAL METÁLICA. Casas industrializadas: Light Steel Frame. Estrutura em Perfil Leve Metálico 2016. Disponível em: http://wwwo.metalica.com.br/casas-industrializadas-lightsteel-framing. Acesso em: 31 de janeiro de 2017.

REVEL, M. (1973). La prefabricacion em la construcion, 1.ed. Bilbao: Urmo. 457p.

SORGATO, M. J. Desempenho térmico de edificações residenciais unifamiliares ventiladas naturalmente. 2009. 216 p. Dissertação (mestrado) - Universidade Federal de Santa Catarina, Centro Tecnológico, Florianópolis, 2009.

VASCONCELOS, A. C. (2002). O Concreto no Brasil: pré-fabricação, monumentos, fundações. Volume III. Studio Nobel. São Paulo. 


\section{APÊNDICE A}

No Apêndice A serão apresentadas as temperaturas máximas internas (dias típicos de verão) e mínimas (dias típicos de inverno) de todos as outras zonas térmicas da residência não apresentadas anteriormente. Todas as tipologias de painéis estão apresentadas nas tabelas 15 a 19 abaixo e seguem os mesmos padrões de status definidos na tabela 9 e utilizados ao longo do estudo.

\begin{tabular}{|c|c|c|c|c|c|c|c|c|c|c|c|c|}
\hline \multirow{4}{*}{$\begin{array}{l}\text { Tipologias } \\
\text { de painéis }\end{array}$} & \multicolumn{12}{|c|}{ com relação aos requisitos da NBR 15575/2013 } \\
\hline & \multicolumn{4}{|c|}{ Fortaleza - CE } & \multicolumn{4}{|c|}{ São Paulo - SP } & \multicolumn{4}{|c|}{ Curitiba - PR } \\
\hline & \multicolumn{2}{|c|}{ Verão } & \multicolumn{2}{|c|}{ Inverno } & \multicolumn{2}{|c|}{ Verão } & \multicolumn{2}{|c|}{ Inverno } & \multicolumn{2}{|c|}{ Verão } & \multicolumn{2}{|c|}{ Inverno } \\
\hline & $\begin{array}{l}\text { Máxima } \\
\text { Externa }\end{array}$ & $\begin{array}{l}\text { Máxima } \\
\text { Interna }\end{array}$ & $\begin{array}{l}\text { Mínima } \\
\text { Externa }\end{array}$ & $\begin{array}{l}\text { Mínima } \\
\text { Interna }\end{array}$ & $\begin{array}{l}\text { Máxima } \\
\text { Externa }\end{array}$ & $\begin{array}{l}\text { Máxima } \\
\text { Interna }\end{array}$ & $\begin{array}{l}\text { Mínima } \\
\text { Externa }\end{array}$ & $\begin{array}{l}\text { Mínima } \\
\text { Interna }\end{array}$ & $\begin{array}{l}\text { Máxima } \\
\text { Externa }\end{array}$ & $\begin{array}{l}\text { Máxima } \\
\text { Interna }\end{array}$ & $\begin{array}{l}\text { Mínima } \\
\text { Externa }\end{array}$ & $\begin{array}{l}\text { Mínima } \\
\text { Interna }\end{array}$ \\
\hline Painel 1 & $32.20^{\circ} \mathrm{C}[$ & $28.37^{\circ} \mathrm{C}$ & $18.83^{\circ} \mathrm{C}$ & $18.78^{\circ} \mathrm{C}$ & $32.10^{\circ} \mathrm{C}$ & $28.99^{\circ} \mathrm{C}$ & $5.93^{\circ} \mathrm{C}$ & \begin{tabular}{|l} 
\\
\end{tabular} & $30.90^{\circ} \mathrm{C}$ & $28.06^{\circ} \mathrm{C}$ & $0.72^{\circ} \mathrm{C}$ & $2.36^{\circ} \mathrm{C}$ \\
\hline Painel 2 & $32.20^{\circ} \mathrm{C}$ & $28.46^{\circ} \mathrm{C}$ & $18.83^{\circ} \mathrm{C}$ & \begin{tabular}{|l|}
$18.78^{\circ} \mathrm{C}$ \\
\end{tabular} & $32.10^{\circ} \mathrm{C}$ & $29.08^{\circ} \mathrm{C}$ & $5.93^{\circ} \mathrm{C}$ & $6.62^{\circ} \mathrm{C}$ & $30.90^{\circ} \mathrm{C}$ & $28.14^{\circ} \mathrm{C}$ & $0.72^{\circ} \mathrm{C}$ & $2.34^{\circ} \mathrm{C}$ \\
\hline Painel 3 & $32.20^{\circ} \mathrm{C}$ & $28.74^{\circ} \mathrm{C}$ & $18.83^{\circ} \mathrm{C}$ & \begin{tabular}{|l|l|}
$18.77^{\circ} \mathrm{C}$ \\
\end{tabular} & $32.10^{\circ} \mathrm{C}$ & $29.36^{\circ} \mathrm{C}$ & $5.93^{\circ} \mathrm{C}$ & $6.59^{\circ} \mathrm{C}$ & $30.90^{\circ} \mathrm{c}$ [ & $28.40^{\circ} \mathrm{C}$ & $0.72^{\circ} \mathrm{C}$ & $2.30^{\circ} \mathrm{C}$ \\
\hline Painel 4 & $32.20^{\circ} \mathrm{C}$ & $28.10^{\circ} \mathrm{C}$ & $18.83^{\circ} \mathrm{C}$ & \begin{tabular}{|l|}
$18.79^{\circ} \mathrm{C}$ \\
\end{tabular} & $32.10^{\circ} \mathrm{C}$ & $28.67 \mathrm{C}$ & $5.93^{\circ} \mathrm{C}$ & $6.63^{\circ} \mathrm{C}$ & $30.90^{\circ} \mathrm{C}$ [ & $27.74^{\circ} \mathrm{C}$ & $0.72^{\circ} \mathrm{C}$ & $2.36^{\circ} \mathrm{C}$ \\
\hline Painel 5 & $32.20^{\circ} \mathrm{C}$ & $28.17^{\circ} \mathrm{C}$ & $18.83^{\circ} \mathrm{C}$ & \begin{tabular}{|l|}
$18.79^{\circ} \mathrm{C}$ \\
\end{tabular} & $32.10^{\circ} \mathrm{C}$ & 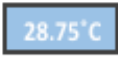 & $5.93^{\circ} \mathrm{C}$ & $6.63^{\circ} \mathrm{C}$ & $30.90^{\circ} \mathrm{C}$ [ & 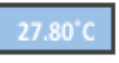 & $0.72^{\circ} \mathrm{C}$ & $2.36^{\circ} \mathrm{C}$ \\
\hline Painel 6 & $32.20^{\circ} \mathrm{C}$ & $28.41^{\circ} \mathrm{C}$ & $18.83^{\circ} \mathrm{C}$ & \begin{tabular}{|l|}
$18.79^{\circ} \mathrm{C}$ \\
\end{tabular} & $32.10^{\circ} \mathrm{C}$ & $28.99^{\circ} \mathrm{C}$ & $5.93^{\circ} \mathrm{C}$ & $6.60^{\circ} \mathrm{C}$ & $30.90^{\circ} \mathrm{C}$ & $28.02^{\circ} \mathrm{C}$ & $0.72^{\circ} \mathrm{C}$ & $2.33^{\circ} \mathrm{C}$ \\
\hline Painel 7 & $32.20^{\circ} \mathrm{C}[$ & $28.29^{\circ} \mathrm{C}$ & $18.83^{\circ} \mathrm{C}$ & \begin{tabular}{|l|}
$18.78^{\circ} \mathrm{C}$ \\
\end{tabular} & $32.10^{\circ} \mathrm{C}$ & $28.91^{\prime} \mathrm{C}$ & $5.93^{\circ} \mathrm{C}$ & $6.62^{\circ} \mathrm{C}$ & $30.90^{\circ} \mathrm{c}$ [ & $27.98^{\circ} \mathrm{C}$ & $0.72^{\circ} \mathrm{C}$ & $2.38^{\circ} \mathrm{C}$ \\
\hline Painel 8 & $32.20^{\circ} \mathrm{C}$ & $28.34^{\circ} \mathrm{C}$ & $18.83^{\circ} \mathrm{C}$ & \begin{tabular}{|l|}
$18.78^{\circ} \mathrm{C}$ \\
\end{tabular} & $32.10^{\circ} \mathrm{C}$ & $28.96^{\circ} \mathrm{C}$ & $5.93^{\circ} \mathrm{C}$ & $6.62^{\circ} \mathrm{C}$ & $30.90^{\circ} \mathrm{C}$ & $28.03^{\circ} \mathrm{C}$ & $0.72^{\circ} \mathrm{C}$ & $2.35^{\circ} \mathrm{C}$ \\
\hline Painel 9 & $32.20^{\circ} \mathrm{C}[$ & 28 & ] $18.83^{\circ} \mathrm{C}[$ & \begin{tabular}{|l|}
$18.78^{\circ} \mathrm{C}$ \\
\end{tabular} & $.10^{\circ} \mathrm{c}$ & 20078 & $5.93^{\circ} \mathrm{C}$ & $6.61^{\circ} \mathrm{C}$ & $30.90^{\circ} \mathrm{C}$ [ & \begin{tabular}{|l|l|}
$28.13^{\circ} \mathrm{C}$ \\
\end{tabular} & $0.72^{\circ} \mathrm{C}$ & $2.35^{\circ} \mathrm{C}$ \\
\hline Painel 10 & $32.20^{\circ} \mathrm{C}$ & $28.06^{\circ} \mathrm{C}$ & $18.83^{\circ} \mathrm{C}$ & \begin{tabular}{|l|}
$18.79^{\circ} \mathrm{C}$ \\
\end{tabular} & $32.10^{\circ} \mathrm{C}$ & 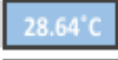 & $.93^{\circ} \mathrm{C}$ & $6.64^{\circ} \mathrm{C}$ & $30.90^{\circ} \mathrm{C}$ & $27.72^{\circ} \mathrm{C}$ & $0.72^{\circ} \mathrm{C}$ & $2.39^{\circ} \mathrm{C}$ \\
\hline Painel 11 & $32.20^{\circ} \mathrm{C}$ & $28.11^{\circ} \mathrm{C}$ & $18.83^{\circ} \mathrm{C}$ & \begin{tabular}{|l|}
$18.79^{\circ} \mathrm{C}$ \\
\end{tabular} & $32.10^{\circ} \mathrm{C}$ & $28.69^{\circ} \mathrm{C}$ & $5.93^{\circ} \mathrm{C}$ & $6.63^{\circ} \mathrm{C}$ & $30.90^{\circ} \mathrm{C}$ & $27.76^{\circ} \mathrm{C}$ & $0.72^{\circ} \mathrm{C}$ & $2.38^{\circ} \mathrm{C}$ \\
\hline Painel 12 & $32.20^{\circ} \mathrm{C}$ & $28.21^{\circ} \mathrm{C}$ & $18.83^{\circ} \mathrm{C}$ & \begin{tabular}{|l|}
$18.79^{\circ} \mathrm{C}$ \\
\end{tabular} & $32.10^{\circ} \mathrm{C}$ & $28.80^{\circ} \mathrm{C}$ & $5.93^{\circ} \mathrm{C}$ & $6.62^{\circ} \mathrm{C}$ & $30.90^{\circ} \mathrm{C}$ & $27.85^{\circ} \mathrm{C}$ & $0.72^{\circ} \mathrm{C}$ & $2.35^{\circ} \mathrm{C}$ \\
\hline Painel 4.1 & $32.20^{\circ} \mathrm{C}[$ & $28.21^{\circ} \mathrm{C}$ & ] $18.83^{\circ} \mathrm{C}[$ & $18.79^{\circ} \mathrm{C}$ & $32.10^{\circ} \mathrm{C}$ & $28.80^{\circ} \mathrm{C}$ & $5.93^{\circ} \mathrm{C}$ & $6.62^{\circ} \mathrm{C}$ & $30.90^{\circ} \mathrm{C}$ [ & $27.86^{\circ} \mathrm{C}$ & $0.72^{\circ} \mathrm{C}$ & $2.33^{\circ} \mathrm{C}$ \\
\hline Painel & $32.20^{\circ} \mathrm{C}$ & $=$ & $18.83^{\circ} \mathrm{C}$ & \begin{tabular}{|l|l}
$18.79^{\circ} \mathrm{C}$ \\
\end{tabular} & $10^{\circ} \mathrm{C}$ & 28.8 & $3^{\circ} \mathrm{C}$ & $6.62^{\circ} \mathrm{C}$ & $30.90^{\circ} \mathrm{C}$ & $27.93^{\circ} \mathrm{C}$ & $0.72^{\circ} \mathrm{C}$ & $2.36^{\circ} \mathrm{C}$ \\
\hline Painel 4.3 & $32.20^{\circ} \mathrm{C}$ & $28.08^{\circ} \mathrm{C}$ & ] $18.83^{\circ} \mathrm{C}[$ & \begin{tabular}{|l|}
$18.79^{\circ} \mathrm{C}$ \\
\end{tabular} & $32.10^{\circ} \mathrm{C}$ & $28.65^{\circ} \mathrm{C}$ & $5.93^{\circ} \mathrm{C}$ & $6.64^{\circ} \mathrm{C}$ & $30.90^{\circ} \mathrm{c}$ & $27.71^{\circ} \mathrm{C}$ & $0.72^{\circ} \mathrm{C}$ & $2.47^{\circ} \mathrm{C}$ \\
\hline Painel 4.4 & $32.20^{\circ} \mathrm{C}$ & \begin{tabular}{|l|}
$27.98^{\circ} \mathrm{C}$ \\
\end{tabular} & $18.83^{\circ} \mathrm{C}$ & $18.80^{\circ} \mathrm{C}$ & $32.10^{\circ} \mathrm{C}$ & \begin{tabular}{|l|}
$28.52^{\circ} \mathrm{C}$ \\
\end{tabular} & $5.93^{\circ} \mathrm{C}$ & $6.64^{\circ} \mathrm{C}$ & $30.90^{\circ} \mathrm{C}$ [ & $27.58^{\circ} \mathrm{C}$ & $0.72^{\circ} \mathrm{C}$ & \begin{tabular}{|l|}
$2.41^{\circ} \mathrm{C}$ \\
\end{tabular} \\
\hline \multicolumn{13}{|c|}{ Tipologia de painel 4 após mudanças de parâmetros } \\
\hline Painel 4 & $32.20^{\circ} \mathrm{C}$ & \begin{tabular}{|l|}
$29.47^{\circ} \mathrm{C}$ \\
\end{tabular} & $18.83^{\circ} \mathrm{C}$ & \begin{tabular}{|l|}
$18.44^{\circ} \mathrm{C}$ \\
\end{tabular} & $32.10^{\circ} \mathrm{C}$ & \begin{tabular}{|l|l}
$29.66^{\circ} \mathrm{C}$ \\
\end{tabular} & $5.93^{\circ} \mathrm{C}$ & $9.55^{\circ} \mathrm{C}$ & $30.90^{\circ} \mathrm{C}$ & $29.62^{\circ} \mathrm{C}$ & $0.72^{\circ} \mathrm{C}$ & $6.13^{\circ} \mathrm{C}$ \\
\hline
\end{tabular}




\section{Status de desempenho das tipologias de painéis no dormitório 2 (zona térmica 3) com relação aos requisitos da NBR 15575/2013}

\begin{tabular}{|c|c|c|c|c|c|c|c|c|c|c|c|c|}
\hline \multirow{3}{*}{$\begin{array}{l}\text { Tipologias } \\
\text { de painéis }\end{array}$} & \multicolumn{4}{|c|}{ Fortaleza - CE } & \multicolumn{4}{|c|}{ São Paulo - SP } & \multicolumn{4}{|c|}{ Curitiba - PR } \\
\hline & & \multicolumn{2}{|c|}{ Inverno } & \multicolumn{2}{|c|}{ Verão } & \multicolumn{2}{|c|}{ Inverno } & \multicolumn{2}{|c|}{ Verão } & \multicolumn{2}{|c|}{ Inverno } \\
\hline & $\begin{array}{l}\text { Máxima } \\
\text { Externa }\end{array}$ & $\begin{array}{l}\text { Máxima } \\
\text { Interna }\end{array}$ & $\begin{array}{l}\text { Mínima } \\
\text { Externa }\end{array}$ & $\begin{array}{l}\text { Mínima } \\
\text { Interna }\end{array}$ & $\begin{array}{l}\text { Máxima } \\
\text { Externa }\end{array}$ & $\begin{array}{l}\text { Máxima } \\
\text { Interna }\end{array}$ & $\begin{array}{l}\text { Mínima } \\
\text { Externa }\end{array}$ & $\begin{array}{l}\text { Mínima } \\
\text { Interna }\end{array}$ & $\begin{array}{l}\text { Máxima } \\
\text { Externa }\end{array}$ & $\begin{array}{l}\text { Máxima } \\
\text { Interna }\end{array}$ & $\begin{array}{l}\text { Mínima } \\
\text { Externa }\end{array}$ & $\begin{array}{l}\text { Mínima } \\
\text { Interna }\end{array}$ \\
\hline Painel 1 & $32.20^{\circ} \mathrm{C}$ & $31.92^{\circ} \mathrm{C}$ & $18.83^{\circ} \mathrm{C}$ & $18.71^{\circ} \mathrm{C}$ & $32.10^{\circ} \mathrm{C}$ & $32.57^{\circ} \mathrm{C}$ & $5.93^{\circ} \mathrm{C}$ & $7.02^{\circ} \mathrm{C}$ & $30.90^{\circ} \mathrm{C}$ & $31.45^{\circ} \mathrm{C}$ & $0.72^{\circ} \mathrm{C}$ & $3.06^{\circ} \mathrm{C}$ \\
\hline Painel 2 & $32.20^{\circ} \mathrm{C}$ & $32.21^{\circ} \mathrm{C}$ & $18.83^{\circ} \mathrm{C}$ & $18.71^{\circ} \mathrm{C}$ & $32.10^{\circ} \mathrm{C}$ & $32.82^{\circ} \mathrm{C}$ & $5.93^{\circ} \mathrm{C}$ & $7.02^{\circ} \mathrm{C}$ & $30.90^{\circ} \mathrm{C}$ & $31.68^{\circ} \mathrm{C}$ & $0.72^{\circ} \mathrm{C}$ & $3.03^{\circ} \mathrm{C}$ \\
\hline Painel 3 & $32.20^{\circ} \mathrm{C}$ & $33.10^{\circ} \mathrm{C}$ & $18.83^{\circ} \mathrm{C}$ & $18.70^{\circ} \mathrm{C}$ & $32.10^{\circ} \mathrm{C}$ & $33.60^{\circ} \mathrm{C}$ & $5.93^{\circ} \mathrm{C}$ & $6.97^{\circ} \mathrm{C}$ & $30.90^{\circ} \mathrm{C}$ & $32.37^{\circ} \mathrm{C}$ & $0.72^{\circ} \mathrm{C}$ & $3.00^{\circ} \mathrm{C}$ \\
\hline Painel 4 & $32.20^{\circ} \mathrm{C}$ & $30.86^{\circ} \mathrm{C}$ & $18.83^{\circ} \mathrm{C}$ & $18.74^{\circ} \mathrm{C}$ & $32.10^{\circ} \mathrm{C}$ & $31.31^{\circ} \mathrm{C}$ & $5.93^{\circ} \mathrm{C}$ & $7.05^{\circ} \mathrm{C}$ & $30.90^{\circ} \mathrm{C}$ & $30.16^{\circ} \mathrm{C}$ & $0.72^{\circ} \mathrm{C}$ & $3.12^{\circ} \mathrm{C}$ \\
\hline Painel 5 & $32.20^{\circ} \mathrm{C}$ & $31.12^{\circ} \mathrm{C}$ & $18.83^{\circ} \mathrm{C}$ & $18.74^{\circ} \mathrm{C}$ & $32.10^{\circ} \mathrm{C}$ & $31.53^{\circ} \mathrm{C}$ & $5.93^{\circ} \mathrm{C}$ & $7.04^{\circ} \mathrm{C}$ & $30.90^{\circ} \mathrm{C}$ & $30.38^{\circ} \mathrm{C}$ & $0.72^{\circ} \mathrm{C}$ & $3.10^{\circ} \mathrm{C}$ \\
\hline Painel 6 & $32.20^{\circ} \mathrm{C}$ & $31.92^{\circ} \mathrm{C}$ & $18.83^{\circ} \mathrm{C}$ & $18.73^{\circ} \mathrm{C}$ & $32.10^{\circ} \mathrm{C}$ & $32.21^{\circ} \mathrm{C}$ & $5.93^{\circ} \mathrm{C}$ & $7.00^{\circ} \mathrm{C}$ & $30.90^{\circ} \mathrm{C}$ & $30.99^{\circ} \mathrm{C}$ & $0.72^{\circ} \mathrm{C}$ & $3.03^{\circ} \mathrm{C}$ \\
\hline Painel 7 & $32.20^{\circ} \mathrm{C}$ & $31.63^{\circ} \mathrm{C}$ & $18.83^{\circ} \mathrm{C}$ & $18.72^{\circ} \mathrm{C}$ & $32.10^{\circ} \mathrm{C}$ & $32.32^{\circ} \mathrm{C}$ & $5.93^{\circ} \mathrm{C}$ & $7.04^{\circ} \mathrm{C}$ & $30.90^{\circ} \mathrm{C}$ & $31.23^{\circ} \mathrm{C}$ & $0.72^{\circ} \mathrm{C}$ & $3.12^{\circ} \mathrm{C}$ \\
\hline Painel 8 & $32.20^{\circ} \mathrm{C}$ & $31.82^{\circ} \mathrm{C}$ & $18.83^{\circ} \mathrm{C}$ & $18.71^{\circ} \mathrm{C}$ & $32.10^{\circ} \mathrm{C}$ & $32.48^{\circ} \mathrm{C}$ & $5.93^{\circ} \mathrm{C}$ & $7.02^{\circ} \mathrm{C}$ & $30.90^{\circ} \mathrm{C}$ & $31.38^{\circ} \mathrm{C}$ & $0.72^{\circ} \mathrm{C}$ & $3.10^{\circ} \mathrm{C}$ \\
\hline Painel 9 & $32.20^{\circ} \mathrm{C}$ & $32.19^{\circ} \mathrm{C}$ & $18.83^{\circ} \mathrm{C}$ & $18.71^{\circ} \mathrm{C}$ & $32.10^{\circ} \mathrm{C}$ & $32.81^{\circ} \mathrm{C}$ & $5.93^{\circ} \mathrm{C}$ & $7.01^{\circ} \mathrm{C}$ & $30.90^{\circ} \mathrm{C}$ & $31.66^{\circ} \mathrm{C}$ & $0.72^{\circ} \mathrm{C}$ & $3.03^{\circ} \mathrm{C}$ \\
\hline Painel 10 & $32.20^{\circ} \mathrm{C}$ & $30.90^{\circ} \mathrm{C}$ & $18.83^{\circ} \mathrm{C}$ & $18.73^{\circ} \mathrm{C}$ & $32.10^{\circ} \mathrm{C}$ & $31.45^{\circ} \mathrm{C}$ & $5.93^{\circ} \mathrm{C}$ & $7.06^{\circ} \mathrm{C}$ & $30.90^{\circ} \mathrm{C}$ & $30.35^{\circ} \mathrm{C}$ & $0.72^{\circ} \mathrm{C}$ & $3.14^{\circ} \mathrm{C}$ \\
\hline Painel 11 & $32.20^{\circ} \mathrm{C}$ & $31.07^{\circ} \mathrm{C}$ & $18.83^{\circ} \mathrm{C}$ & $1873^{\circ}$ & $32.10^{\circ} \mathrm{C}$ & $31.59^{\circ} \mathrm{C}$ & $5.93^{\circ} \mathrm{C}$ & $7.05^{\circ} \mathrm{C}$ & $30.90^{\circ} \mathrm{C}$ & $30.48^{\circ} \mathrm{C}$ & $0.72^{\circ} \mathrm{C}$ & $3.14^{\circ} \mathrm{C}$ \\
\hline Painel 12 & $32.20^{\circ} \mathrm{C}$ & $31.41^{\circ} \mathrm{C}$ & $18.83^{\circ} \mathrm{C}$ & $18.73^{\circ} \mathrm{C}$ & $32.10^{\circ} \mathrm{C}$ & $31.88^{\circ} \mathrm{C}$ & $5.93^{\circ} \mathrm{C}$ & $7.03^{\circ} \mathrm{C}$ & $30.90^{\circ} \mathrm{C}$ & $30.73^{\circ} \mathrm{C}$ & $0.72^{\circ} \mathrm{C}$ & $3.10^{\circ} \mathrm{C}$ \\
\hline Painel 4.1 & $32.20^{\circ} \mathrm{C}$ & $31.67^{\circ} \mathrm{C}$ & $18.83^{\circ} \mathrm{C}$ & $18.72^{\circ} \mathrm{C}$ & $32.10^{\circ} \mathrm{C}$ & $32.27^{\circ} \mathrm{C}$ & $5.93^{\circ} \mathrm{C}$ & $7.03^{\circ} \mathrm{C}$ & $30.90^{\circ} \mathrm{C}$ & $31.16^{\circ} \mathrm{C}$ & $0.72^{\circ} \mathrm{C}$ & $3.11^{\circ} \mathrm{C}$ \\
\hline Painel 4.2 & $32.20^{\circ} \mathrm{C}$ & $31.34^{\circ} \mathrm{C}$ & $18.83^{\circ} \mathrm{C}$ & $18.72^{\circ} \mathrm{C}$ & $32.10^{\circ} \mathrm{C}$ & $31.89^{\circ} \mathrm{C}$ & $5.93^{\circ} \mathrm{C}$ & $7.04^{\circ} \mathrm{C}$ & $30.90^{\circ} \mathrm{C}$ & $30.76^{\circ} \mathrm{C}$ & $0.72^{\circ} \mathrm{C}$ & $3.10^{\circ} \mathrm{C}$ \\
\hline Painel 4.3 & $32.20^{\circ} \mathrm{C}$ & $30.75^{\circ} \mathrm{C}$ & $18.83^{\circ} \mathrm{C}$ & $18.74^{\circ} \mathrm{C}$ & $32.10^{\circ} \mathrm{C}$ & $31.18^{\circ} \mathrm{C}$ & $5.93^{\circ} \mathrm{C}$ & $7.05^{\circ} \mathrm{C}$ & $30.90^{\circ} \mathrm{C}$ & $30.06^{\circ} \mathrm{C}$ & $0.72^{\circ} \mathrm{C}$ & $3.12^{\circ} \mathrm{C}$ \\
\hline Painel 4.4 & $32.20^{\circ} \mathrm{C}$ & $30.61^{\circ} \mathrm{C}$ & $18.83^{\circ} \mathrm{C}$ & $18.75^{\circ} \mathrm{C}$ & $32.10^{\circ} \mathrm{C}$ & $31.00^{\circ} \mathrm{C}$ & $5.93^{\circ} \mathrm{C}$ & $7.06^{\circ} \mathrm{C}$ & $30.90^{\circ} \mathrm{C}$ & $29.90^{\circ} \mathrm{C}$ & $0.72^{\circ} \mathrm{C}$ & $3.13^{\circ} \mathrm{C}$ \\
\hline \multicolumn{13}{|c|}{ Tipologia de painel 4 após mudanças de parâmetros } \\
\hline Painel 4 & $32.20^{\circ} \mathrm{C}[$ & $31.48^{\circ} \mathrm{C}$ & $18.83^{\circ} \mathrm{C}$ & $18.43^{\circ} \mathrm{C}$ & $32.10^{\circ} \mathrm{C}[$ & $31.48^{\circ} \mathrm{C}$ & $5.93^{\circ} \mathrm{C}$ & $9.55^{\circ} \mathrm{C}$ & $30.90^{\circ} \mathrm{C}$ & $30.27^{\circ} \mathrm{C}$ & $0.72^{\circ} \mathrm{C}$ & $6.01^{\circ} \mathrm{C}$ \\
\hline
\end{tabular}

Tabela 16 - Status dos níveis de desempenhos de todos as tipologias de painéis estudados no ambiente do dormitório 2 (zona térmica 3) nas 3 cidades

Fonte: Arquivo pessoal, 2016 


\section{Status de desempenho das tipologias de painéis no banheiro (zona térmica 4) com relação aos requisitos da NBR 15575/2013}

\begin{tabular}{|c|c|c|c|c|c|c|c|c|c|c|c|c|}
\hline \multirow{3}{*}{$\begin{array}{l}\text { Tipologias } \\
\text { de painéis }\end{array}$} & \multicolumn{4}{|c|}{ Fortaleza - CE } & \multicolumn{4}{|c|}{ São Paulo - SP } & \multicolumn{4}{|c|}{ Curitiba - PR } \\
\hline & \multicolumn{2}{|c|}{ Verão } & \multicolumn{2}{|c|}{ Inverno } & \multicolumn{2}{|c|}{ Verão } & \multicolumn{2}{|c|}{ Inverno } & \multicolumn{2}{|c|}{ Verão } & \multicolumn{2}{|c|}{ Inverno } \\
\hline & $\begin{array}{l}\text { Máxima } \\
\text { Externa }\end{array}$ & $\begin{array}{l}\text { Máxima } \\
\text { Interna }\end{array}$ & $\begin{array}{l}\text { Mínima } \\
\text { Externa }\end{array}$ & $\begin{array}{l}\text { Mínima } \\
\text { Interna }\end{array}$ & $\begin{array}{l}\text { Máxima } \\
\text { Externa }\end{array}$ & $\begin{array}{l}\text { Máxima } \\
\text { Interna }\end{array}$ & $\begin{array}{l}\text { Mínima } \\
\text { Externa }\end{array}$ & $\begin{array}{l}\text { Mínima } \\
\text { Interna }\end{array}$ & $\begin{array}{l}\text { Máxima } \\
\text { Externa }\end{array}$ & $\begin{array}{l}\text { Máxima } \\
\text { Interna }\end{array}$ & $\begin{array}{l}\text { Mínima } \\
\text { Externa }\end{array}$ & $\begin{array}{l}\text { Mínima } \\
\text { Interna }\end{array}$ \\
\hline Painel 1 & $32.20^{\circ} \mathrm{C}$ & $29.31^{\circ} \mathrm{C}$ & $18.83^{\circ} \mathrm{C}$ & $18.82^{\circ} \mathrm{C}$ & $32.10^{\circ} \mathrm{C}$ & $27.71^{\circ} \mathrm{C}$ & $5.93^{\circ} \mathrm{C}$ & $6.48^{\circ} \mathrm{C}$ & $30.90^{\circ} \mathrm{C}$ & $26.63^{\circ} \mathrm{C}$ & $0.72^{\circ} \mathrm{C}$ & $2.17^{\circ} \mathrm{C}$ \\
\hline Painel 2 & $32.20^{\circ} \mathrm{C}$ & $29.55^{\circ} \mathrm{C}$ & $18.83^{\circ} \mathrm{C}$ & $18.83^{\circ} \mathrm{C}$ & $32.10^{\circ} \mathrm{C}$ & $27.86^{\circ} \mathrm{C}$ & $5.93^{\circ} \mathrm{C}$ & $6.48^{\circ} \mathrm{C}$ & $30.90^{\circ} \mathrm{C}$ & $26.78^{\circ} \mathrm{C}$ & $0.72^{\circ} \mathrm{C}$ & $2.15^{\circ} \mathrm{C}$ \\
\hline Painel 3 & $32.20^{\circ} \mathrm{C}$ & $30.30^{\circ} \mathrm{C}$ & $18.83^{\circ} \mathrm{C}$ & $18.81^{\circ} \mathrm{C}$ & $32.10^{\circ} \mathrm{C}$ & $28.36^{\circ} \mathrm{C}$ & $5.93^{\circ} \mathrm{C}$ & $6.45^{\circ} \mathrm{C}$ & $30.90^{\circ} \mathrm{C}$ & $27.24^{\circ} \mathrm{C}$ & $0.72^{\circ} \mathrm{C}$ & $2.12^{\circ} \mathrm{C}$ \\
\hline Painel 4 & $32.20^{\circ} \mathrm{C}$ & $28.91^{\circ} \mathrm{C}$ & $18.83^{\circ} \mathrm{C}$ & $18.83^{\circ} \mathrm{C}$ & $32.10^{\circ} \mathrm{C}$ & $27.36^{\circ} \mathrm{C}$ & $5.93^{\circ} \mathrm{C}$ & $6.50^{\circ} \mathrm{C}$ & $30.90^{\circ} \mathrm{C}$ & $26.30^{\circ} \mathrm{C}$ & $0.72^{\circ} \mathrm{C}$ & $2.21^{\circ} \mathrm{C}$ \\
\hline Painel 5 & $32.20^{\circ} \mathrm{C}$ & $29.10^{\circ} \mathrm{C}$ & $18.83^{\circ} \mathrm{C}$ & $18.83^{\circ} \mathrm{C}$ & $32.10^{\circ} \mathrm{C}$ & $27.49^{\circ} \mathrm{C}$ & $5.93^{\circ} \mathrm{C}$ & $6.49^{\circ} \mathrm{C}$ & $30.90^{\circ} \mathrm{C}$ & $26.41^{\circ} \mathrm{C}$ & $0.72^{\circ} \mathrm{C}$ & $2.20^{\circ} \mathrm{C}$ \\
\hline Painel 6 & $32.20^{\circ} \mathrm{C}$ & $29.72^{\circ} \mathrm{C}$ & $18.83^{\circ} \mathrm{C}$ & $18.82^{\circ} \mathrm{C}$ & $32.10^{\circ} \mathrm{C}$ & $27.87^{\circ} \mathrm{C}$ & $5.93^{\circ} \mathrm{C}$ & $6.47^{\circ} \mathrm{C}$ & $30.90^{\circ} \mathrm{C}$ & $26.75^{\circ} \mathrm{C}$ & $0.72^{\circ} \mathrm{C}$ & $2.15^{\circ} \mathrm{C}$ \\
\hline Painel 7 & $32.20^{\circ} \mathrm{C}$ & $29.07^{\circ} \mathrm{C}$ & $18.83^{\circ} \mathrm{C}$ & $18.82^{\circ} \mathrm{C}$ & $32.10^{\circ} \mathrm{C}$ & $27.55^{\circ} \mathrm{C}$ & $5.93^{\circ} \mathrm{C}$ & $6.48^{\circ} \mathrm{C}$ & $30.90^{\circ} \mathrm{C}$ & $26.50^{\circ} \mathrm{C}$ & $0.72^{\circ} \mathrm{C}$ & $2.21^{\circ} \mathrm{C}$ \\
\hline Painel 8 & $32.20^{\circ} \mathrm{C}$ & $29.22^{\circ} \mathrm{C}$ & $18.83^{\circ} \mathrm{C}$ & $18.82^{\circ} \mathrm{C}$ & $32.10^{\circ} \mathrm{C}$ & $27.65^{\circ} \mathrm{C}$ & $5.93^{\circ} \mathrm{C}$ & $6.48^{\circ} \mathrm{C}$ & $30.90^{\circ} \mathrm{C}$ & $26.59^{\circ} \mathrm{C}$ & $0.72^{\circ} \mathrm{C}$ & $2.20^{\circ} \mathrm{C}$ \\
\hline Painel 9 & $32.20^{\circ} \mathrm{C}$ & $29.53^{\circ} \mathrm{C}$ & $18.83^{\circ} \mathrm{C}$ & $18.81^{\circ} \mathrm{C}$ & $32.10^{\circ} \mathrm{C}$ & $27.85^{\circ} \mathrm{C}$ & $5.93^{\circ} \mathrm{C}$ & $6.47^{\circ} \mathrm{C}$ & $30.90^{\circ} \mathrm{C}$ & $26.77^{\circ} \mathrm{C}$ & $0.72^{\circ} \mathrm{C}$ & $2.15^{\circ} \mathrm{C}$ \\
\hline Painel 10 & $32.20^{\circ} \mathrm{C}$ & $28.82^{\circ} \mathrm{C}$ & $18.83^{\circ} \mathrm{C}$ & $18.83^{\circ} \mathrm{C}$ & $32.10^{\circ} \mathrm{C}$ & $27.33^{\circ} \mathrm{C}$ & $5.93^{\circ} \mathrm{C}$ & $6.50^{\circ} \mathrm{C}$ & $30.90^{\circ} \mathrm{C}$ & $26.28^{\circ} \mathrm{C}$ & $0.72^{\circ} \mathrm{C}$ & $2.22^{\circ} \mathrm{C}$ \\
\hline Painel 11 & $32.20^{\circ} \mathrm{C}$ & $28.95^{\circ} \mathrm{C}$ & $18.83^{\circ} \mathrm{C}$ & $18.82^{\circ} \mathrm{C}$ & $32.10^{\circ} \mathrm{C}$ & $27.41^{\circ} \mathrm{C}$ & $5.93^{\circ} \mathrm{C}$ & $6.49^{\circ} \mathrm{C}$ & $30.90^{\circ} \mathrm{C}$ & $26.35^{\circ} \mathrm{C}$ & $0.72^{\circ} \mathrm{C}$ & $2.21^{\circ} \mathrm{C}$ \\
\hline Painel 12 & $32.20^{\circ} \mathrm{C}$ & $29.21^{\circ} \mathrm{C}$ & $18.83^{\circ} \mathrm{C}$ & $18.82^{\circ} \mathrm{C}$ & $32.10^{\circ} \mathrm{C}$ & $27.58^{\circ} \mathrm{C}$ & $5.93^{\circ} \mathrm{C}$ & $6.48^{\circ} \mathrm{C}$ & $30.90^{\circ} \mathrm{C}$ & $26.50^{\circ} \mathrm{C}$ & $0.72^{\circ} \mathrm{C}$ & $2.19^{\circ} \mathrm{C}$ \\
\hline Painel 4.1 & $32.20^{\circ} \mathrm{C}$ & $29.23^{\circ} \mathrm{C}$ & $18.83^{\circ} \mathrm{C}$ & $18.82^{\circ} \mathrm{C}$ & $32.10^{\circ} \mathrm{C}$ & $27.63^{\circ} \mathrm{C}$ & $5.93^{\circ} \mathrm{C}$ & $6.48^{\circ} \mathrm{C}$ & $30.90^{\circ} \mathrm{C}$ & $26.56^{\circ} \mathrm{C}$ & $0.72^{\circ} \mathrm{C}$ & $2.20^{\circ} \mathrm{C}$ \\
\hline Painel 4.2 & $32.20^{\circ} \mathrm{C}$ & $29.08^{\circ} \mathrm{C}$ & $18.83^{\circ} \mathrm{C}$ & $18.82^{\circ} \mathrm{C}$ & $32.10^{\circ} \mathrm{C}$ & $27.51^{\circ} \mathrm{C}$ & $5.93^{\circ} \mathrm{C}$ & $6.49^{\circ} \mathrm{C}$ & $30.90^{\circ} \mathrm{C}$ & $26.44^{\circ} \mathrm{C}$ & $0.72^{\circ} \mathrm{C}$ & $2.21^{\circ} \mathrm{C}$ \\
\hline Painel 4.3 & $32.20^{\circ} \mathrm{C}$ & $28.86^{\circ} \mathrm{C}$ & $18.83^{\circ} \mathrm{C}$ & $18.83^{\circ} \mathrm{C}$ & $32.10^{\circ} \mathrm{C}$ & $27.33^{\circ} \mathrm{C}$ & $5.93^{\circ} \mathrm{C}$ & $6.50^{\circ} \mathrm{C}$ & $30.90^{\circ} \mathrm{C}$ & $26.27^{\circ} \mathrm{C}$ & $0.72^{\circ} \mathrm{C}$ & $2.22^{\circ} \mathrm{C}$ \\
\hline Painel 4.4 & $32.20^{\circ} \mathrm{C}$ & $28.81^{\circ} \mathrm{C}$ & $18.83^{\circ} \mathrm{C}$ & $18.83^{\circ} \mathrm{C}$ & $32.10^{\circ} \mathrm{C}$ & $27.28^{\circ} \mathrm{C}$ & $5.93^{\circ} \mathrm{C}$ & $6.50^{\circ} \mathrm{C}$ & $30.90^{\circ} \mathrm{C}$ & $26.22^{\circ} \mathrm{C}$ & $0.72^{\circ} \mathrm{C}$ & $2.22^{\circ} \mathrm{C}$ \\
\hline \multicolumn{13}{|c|}{ Tipologia de painel 4 após mudanças de parâmetros } \\
\hline Painel 4 & $32.20^{\circ} \mathrm{C}$ & $29.90^{\circ} \mathrm{C}$ & $18.83^{\circ} \mathrm{C}$ & $18.50^{\circ} \mathrm{C}$ & $32.10^{\circ} \mathrm{C}$ & $28.37^{\circ} \mathrm{C}$ & $5.93^{\circ} \mathrm{C}$ & $9.79^{\circ} \mathrm{C}$ & $30.90^{\circ} \mathrm{C}$ & $27.18^{\circ}$ & $0.72^{\circ} \mathrm{C}$ & 6.27 \\
\hline
\end{tabular}

Tabela 17- Status dos níveis de desempenhos de todos as tipologias de painéis estudados no ambiente do banheiro (zona térmica 4) nas 3 cidades

Fonte: Arquivo pessoal, 2016 


\section{Status de desempenho das tipologias de painéis na lavanderia (zona térmica 6) com relação aos requisitos da NBR 15575/2013}

\begin{tabular}{|c|c|c|c|c|c|c|c|c|c|c|c|c|}
\hline \multirow{3}{*}{$\begin{array}{l}\text { Tipologias } \\
\text { de painéis }\end{array}$} & \multicolumn{4}{|c|}{ Fortaleza - CE } & \multicolumn{4}{|c|}{ São Paulo - SP } & \multicolumn{4}{|c|}{ Curitiba - PR } \\
\hline & & \multicolumn{2}{|c|}{ Inverno } & \multicolumn{2}{|c|}{ Verão } & \multicolumn{2}{|c|}{ Inverno } & \multicolumn{2}{|c|}{ Verão } & \multicolumn{2}{|c|}{ Inverno } \\
\hline & $\begin{array}{l}\text { Máxima } \\
\text { Externa }\end{array}$ & $\begin{array}{l}\text { Máxima } \\
\text { Interna }\end{array}$ & $\begin{array}{l}\text { Mínima } \\
\text { Externa }\end{array}$ & $\begin{array}{l}\text { Mínima } \\
\text { Interna }\end{array}$ & $\begin{array}{l}\text { Máxima } \\
\text { Externa }\end{array}$ & $\begin{array}{l}\text { Máxima } \\
\text { Interna }\end{array}$ & $\begin{array}{l}\text { Mínima } \\
\text { Externa }\end{array}$ & $\begin{array}{l}\text { Mínima } \\
\text { Interna }\end{array}$ & $\begin{array}{l}\text { Máxima } \\
\text { Externa }\end{array}$ & $\begin{array}{l}\text { Máxima } \\
\text { Interna }\end{array}$ & $\begin{array}{l}\text { Mínima } \\
\text { Externa }\end{array}$ & $\begin{array}{l}\text { Mínima } \\
\text { Interna }\end{array}$ \\
\hline Painel 1 & $32.20^{\circ} \mathrm{C}$ & $30.20^{\circ} \mathrm{C}$ & $18.83^{\circ} \mathrm{C}$ & $18.75^{\circ} \mathrm{C}$ & $32.10^{\circ} \mathrm{C}$ & $30.92^{\circ} \mathrm{C}$ & $5.93^{\circ} \mathrm{C}$ & $6.41^{\circ} \mathrm{C}$ & $30.90^{\circ} \mathrm{C}$ & $30.00^{\circ} \mathrm{C}$ & $0.72^{\circ} \mathrm{C}$ & $1.51^{\circ} \mathrm{C}$ \\
\hline Painel 2 & $32.20^{\circ} \mathrm{C}$ & $30.35^{\circ} \mathrm{C}$ & $18.83^{\circ} \mathrm{C}$ & $18.74^{\circ} \mathrm{C}$ & $32.10^{\circ} \mathrm{C}$ & $31.13^{\circ} \mathrm{C}$ & $5.93^{\circ} \mathrm{C}$ & $6.41^{\circ} \mathrm{C}$ & $30.90^{\circ} \mathrm{C}$ & $30.18^{\circ} \mathrm{C}$ & $0.72^{\circ} \mathrm{C}$ & $1.50^{\circ} \mathrm{C}$ \\
\hline Painel 3 & $32.20^{\circ} \mathrm{C}$ & $30.88^{\circ} \mathrm{C}$ & $18.83^{\circ} \mathrm{C}$ & $18.73^{\circ} \mathrm{C}$ & $32.10^{\circ} \mathrm{C}$ & $31.84^{\circ} \mathrm{C}$ & $5.93^{\circ} \mathrm{C}$ & $6.38^{\circ} \mathrm{C}$ & $30.90^{\circ} \mathrm{C}$ & $30.78^{\circ} \mathrm{C}$ & $0.72^{\circ} \mathrm{C}$ & $1.47^{\circ} \mathrm{C}$ \\
\hline Painel 4 & $32.20^{\circ} \mathrm{C}$ & $29.64^{\circ} \mathrm{C}$ & $18.83^{\circ} \mathrm{C}$ & $18.77^{\circ} \mathrm{C}$ & $32.10^{\circ} \mathrm{C}$ & $30.31^{\circ} \mathrm{C}$ & $5.93^{\circ} \mathrm{C}$ & $6.42^{\circ} \mathrm{C}$ & $30.90^{\circ} \mathrm{C}$ & $29.30^{\circ} \mathrm{C}$ & $0.72^{\circ} \mathrm{C}$ & $1.53^{\circ} \mathrm{C}$ \\
\hline Painel 5 & $32.20^{\circ} \mathrm{C}$ & $29.76^{\circ} \mathrm{C}$ & $18.83^{\circ} \mathrm{C}$ & $18.77^{\circ} \mathrm{C}$ & $32.10^{\circ} \mathrm{C}$ & $30.46^{\circ} \mathrm{C}$ & $5.93^{\circ} \mathrm{C}$ & $6.42^{\circ} \mathrm{C}$ & $30.90^{\circ} \mathrm{C}$ & $29.44^{\circ} \mathrm{C}$ & $0.72^{\circ} \mathrm{C}$ & $1.52^{\circ} \mathrm{C}$ \\
\hline Painel 6 & $32.20^{\circ} \mathrm{C}$ & $30.18^{\circ} \mathrm{C}$ & $18.83^{\circ} \mathrm{C}$ & $18.76^{\circ} \mathrm{C}$ & $32.10^{\circ} \mathrm{C}$ & $30.93^{\circ} \mathrm{C}$ & $5.93^{\circ} \mathrm{C}$ & $6.39^{\circ} \mathrm{C}$ & $30.90^{\circ} \mathrm{C}$ & $29.86^{\circ} \mathrm{C}$ & $0.72^{\circ} \mathrm{C}$ & $1.49^{\circ} \mathrm{C}$ \\
\hline Painel 7 & $32.20^{\circ} \mathrm{C}$ & $30.04^{\circ} \mathrm{C}$ & $18.83^{\circ} \mathrm{C}$ & $18.75^{\circ} \mathrm{C}$ & $32.10^{\circ} \mathrm{C}$ & $30.71^{\circ} \mathrm{C}$ & $5.93^{\circ} \mathrm{C}$ & $6.41^{\circ} \mathrm{C}$ & $30.90^{\circ} \mathrm{C}$ & $29.83^{\circ} \mathrm{C}$ & $0.72^{\circ} \mathrm{C}$ & $1.53^{\circ} \mathrm{C}$ \\
\hline Painel 8 & $32.20^{\circ} \mathrm{C}$ & $30.14^{\circ} \mathrm{C}$ & $\mid 18.83^{\circ} \mathrm{C}$ & $18.75^{\circ} \mathrm{C}$ & $32.10^{\circ} \mathrm{C}$ & $30.85^{\circ} \mathrm{C}$ & $5.93^{\circ} \mathrm{C}$ & $6.41^{\circ} \mathrm{C}$ & $30.90^{\circ} \mathrm{C}$ & $29.94^{\circ} \mathrm{C}$ & $0.72^{\circ} \mathrm{C}$ & $1.53^{\circ} \mathrm{C}$ \\
\hline Painel 9 & $32.20^{\circ} \mathrm{C}$ & $30.34^{\circ} \mathrm{C}$ & $18.83^{\circ} \mathrm{C}$ & $18.74^{\circ} \mathrm{C}$ & $32.10^{\circ} \mathrm{C}$ & $31.11^{\circ} \mathrm{C}$ & $5.93^{\circ} \mathrm{C}$ & $6.40^{\circ} \mathrm{C}$ & $30.90^{\circ} \mathrm{C}$ & $30.16^{\circ} \mathrm{C}$ & $0.72^{\circ} \mathrm{C}$ & $1.50^{\circ} \mathrm{C}$ \\
\hline Painel 10 & $32.20^{\circ} \mathrm{C}$ & $29.68^{\circ} \mathrm{C}$ & $18.83^{\circ} \mathrm{C}$ & $18.77^{\circ} \mathrm{C}$ & $32.10^{\circ} \mathrm{C}$ & $30.27^{\circ} \mathrm{C}$ & $5.93^{\circ} \mathrm{C}$ & $6.43^{\circ} \mathrm{C}$ & $30.90^{\circ} \mathrm{C}$ & $29.37^{\circ} \mathrm{C}$ & $0.72^{\circ} \mathrm{C}$ & $1.54^{\circ} \mathrm{C}$ \\
\hline Painel 11 & $32.20^{\circ} \mathrm{C}$ & $29.76^{\circ} \mathrm{C}$ & $18.83^{\circ} \mathrm{C}$ & $1876^{\circ}$ & $32.10^{\circ} \mathrm{C}$ & $30.37^{\circ} \mathrm{C}$ & $5.93^{\circ} \mathrm{C}$ & $6.42^{\circ} \mathrm{C}$ & $30.90^{\circ} \mathrm{C}$ & $29.46^{\circ} \mathrm{C}$ & $0.72^{\circ} \mathrm{C}$ & $1.54^{\circ} \mathrm{C}$ \\
\hline Painel 12 & $32.20^{\circ} \mathrm{C}$ & $29.21^{\circ} \mathrm{C}$ & $18.83^{\circ} \mathrm{C}$ & $18.76^{\circ} \mathrm{C}$ & $32.10^{\circ} \mathrm{C}$ & $30.58^{\circ} \mathrm{C}$ & $5.93^{\circ} \mathrm{C}$ & $6.41^{\circ} \mathrm{C}$ & $30.90^{\circ} \mathrm{C}$ & $29.93^{\circ} \mathrm{C}$ & $0.72^{\circ} \mathrm{C}$ & $1.53^{\circ} \mathrm{C}$ \\
\hline Painel 4.1 & $32.20^{\circ} \mathrm{C}$ & $30.13^{\circ} \mathrm{C}$ & $18.83^{\circ} \mathrm{C}$ & $18.75^{\circ} \mathrm{C}$ & $32.10^{\circ} \mathrm{C}$ & $30.81^{\circ} \mathrm{C}$ & $5.93^{\circ} \mathrm{C}$ & $6.41^{\circ} \mathrm{C}$ & $30.90^{\circ} \mathrm{C}$ & $29.89^{\circ} \mathrm{C}$ & $0.72^{\circ} \mathrm{C}$ & $1.53^{\circ} \mathrm{C}$ \\
\hline Painel 4.2 & $32.20^{\circ} \mathrm{C}$ & $29.86^{\circ} \mathrm{C}$ & $18.83^{\circ} \mathrm{C}$ & $18.76^{\circ} \mathrm{C}$ & $32.10^{\circ} \mathrm{C}$ & $30.50^{\circ} \mathrm{C}$ & $5.93^{\circ} \mathrm{C}$ & $6.42^{\circ} \mathrm{C}$ & $30.90^{\circ} \mathrm{C}$ & $29.59^{\circ} \mathrm{C}$ & $0.72^{\circ} \mathrm{C}$ & $1.54^{\circ} \mathrm{C}$ \\
\hline Painel 4.3 & $32.20^{\circ} \mathrm{C}$ & $29.57^{\circ} \mathrm{C}$ & $18.83^{\circ} \mathrm{C}$ & $18.77^{\circ} \mathrm{C}$ & $32.10^{\circ} \mathrm{C}$ & $30.27^{\circ} \mathrm{C}$ & $5.93^{\circ} \mathrm{C}$ & $6.43^{\circ} \mathrm{C}$ & $30.90^{\circ} \mathrm{C}$ & $29.25^{\circ} \mathrm{C}$ & $0.72^{\circ} \mathrm{C}$ & $1.55^{\circ} \mathrm{C}$ \\
\hline Painel 4.4 & $32.20^{\circ} \mathrm{C}$ & $29.59^{\circ} \mathrm{C}$ & $18.83^{\circ} \mathrm{C}$ & $18.78^{\circ} \mathrm{C}$ & $32.10^{\circ} \mathrm{C}$ & $30.24^{\circ} \mathrm{C}$ & $5.93^{\circ} \mathrm{C}$ & $6.43^{\circ} \mathrm{C}$ & $30.90^{\circ} \mathrm{C}$ & $29.22^{\circ} \mathrm{C}$ & $0.72^{\circ} \mathrm{C}$ & $1.54^{\circ} \mathrm{C}$ \\
\hline \multicolumn{13}{|c|}{ Tipologia de painel 4 após mudanças de parâmetros } \\
\hline Painel 4 & $32.20^{\circ} \mathrm{C}[$ & $30.43^{\circ} \mathrm{C}$ & $18.83^{\circ} \mathrm{C}$ & $18.45^{\circ} \mathrm{C}$ & $32.10^{\circ} \mathrm{C}[$ & $30.69^{\circ} \mathrm{C}$ & $5.93^{\circ} \mathrm{C}$ & $9.43^{\circ} \mathrm{C}$ & $30.90^{\circ} \mathrm{C}$ & $29.58^{\circ} \mathrm{C}$ & $0.72^{\circ} \mathrm{C}$ & $5.79^{\circ}$ \\
\hline
\end{tabular}

Tabela 18 - Status dos níveis de desempenhos de todos as tipologias de painéis estudados no ambiente da lavanderia (zona térmica 6) nas 3 cidades

Fonte: Arquivo pessoal, 2016 


\section{Status de desempenho das tipologias de painéis na cobertura (zona térmica 7) com relação aos requisitos da NBR 15575/2013}

\begin{tabular}{|c|c|c|c|c|c|c|c|c|c|c|c|c|}
\hline \multirow{3}{*}{$\begin{array}{l}\text { Tipologias } \\
\text { de painéis }\end{array}$} & \multicolumn{4}{|c|}{ Fortaleza - CE } & \multicolumn{4}{|c|}{ São Paulo - SP } & \multicolumn{4}{|c|}{ Curitiba - PR } \\
\hline & \multicolumn{2}{|c|}{ Verão } & \multicolumn{2}{|c|}{ Inverno } & \multicolumn{2}{|c|}{ Verão } & \multicolumn{2}{|c|}{ Inverno } & \multicolumn{2}{|c|}{ Verão } & \multicolumn{2}{|c|}{ Inverno } \\
\hline & $\begin{array}{l}\text { Máxima } \\
\text { Externa }\end{array}$ & $\begin{array}{l}\text { Máxima } \\
\text { Interna }\end{array}$ & $\begin{array}{l}\text { Mínima } \\
\text { Externa }\end{array}$ & $\begin{array}{l}\text { Mínima } \\
\text { Interna }\end{array}$ & $\begin{array}{l}\text { Máxima } \\
\text { Externa }\end{array}$ & $\begin{array}{l}\text { Máxima } \\
\text { Interna }\end{array}$ & $\begin{array}{l}\text { Mínima } \\
\text { Externa }\end{array}$ & $\begin{array}{l}\text { Mínima } \\
\text { Interna }\end{array}$ & $\begin{array}{l}\text { Máxima } \\
\text { Externa }\end{array}$ & $\begin{array}{l}\text { Máxima } \\
\text { Interna }\end{array}$ & $\begin{array}{l}\text { Mínima } \\
\text { Externa }\end{array}$ & $\begin{array}{l}\text { Mínima } \\
\text { Interna }\end{array}$ \\
\hline Painel 1 & $32.20^{\circ} \mathrm{C}$ & $44.73^{\circ} \mathrm{C}$ & $18.83^{\circ} \mathrm{C}$ & $16.18^{\circ} \mathrm{C}$ & $32.10^{\circ} \mathrm{C}$ & $48.44^{\circ} \mathrm{C}$ & $5.93^{\circ} \mathrm{C}$ & $4.31^{\circ} \mathrm{C}$ & $30.90^{\circ} \mathrm{C}$ & $45.57^{\circ} \mathrm{C}$ & $0.72^{\circ} \mathrm{C}$ & $-1.17^{\circ} \mathrm{C}$ \\
\hline Painel 2 & $32.20^{\circ} \mathrm{C}$ & $44.75^{\circ} \mathrm{C}$ & $18.83^{\circ} \mathrm{C}$ & $16.18^{\circ} \mathrm{C}$ & $32.10^{\circ} \mathrm{C}$ & $48.45^{\circ} \mathrm{C}$ & $5.93^{\circ} \mathrm{C}$ & $4.31^{\circ} \mathrm{C}$ & $30.90^{\circ} \mathrm{C}$ & $45.58^{\circ} \mathrm{C}$ & $0.72^{\circ} \mathrm{C}$ & $-1.19^{\circ} \mathrm{C}$ \\
\hline Painel 3 & $32.20^{\circ} \mathrm{C}$ & $44.81^{\circ} \mathrm{C}$ & $18.83^{\circ} \mathrm{C}$ & $16.18^{\circ} \mathrm{C}$ & $32.10^{\circ} \mathrm{C}$ & $48.46^{\circ} \mathrm{C}$ & $5.93^{\circ} \mathrm{C}$ & $4.26^{\circ} \mathrm{C}$ & $30.90^{\circ} \mathrm{C}$ & $45.58^{\circ} \mathrm{C}$ & $0.72^{\circ} \mathrm{C}$ & \begin{tabular}{|c|}
$1.26^{\circ} \mathrm{C}$ \\
\end{tabular} \\
\hline Painel 4 & $32.20^{\circ} \mathrm{C}$ & $44.61^{\circ} \mathrm{C}$ & $18.83^{\circ} \mathrm{C}$ & $16.20^{\circ} \mathrm{C}$ & $32.10^{\circ} \mathrm{C}$ & $48.30^{\circ} \mathrm{C}$ & $5.93^{\circ} \mathrm{C}$ & $4.33^{\circ} \mathrm{C}$ & $30.90^{\circ} \mathrm{C}$ & $45.44^{\circ} \mathrm{C}$ & $0.72^{\circ} \mathrm{C}$ & $-1.15^{\circ} \mathrm{C}$ \\
\hline Painel 5 & $32.20^{\circ} \mathrm{C}$ & $44.63^{\circ} \mathrm{C}$ & $18.83^{\circ} \mathrm{C}$ & $16.20^{\circ} \mathrm{C}$ & $32.10^{\circ} \mathrm{C}$ & $48.31^{\circ} \mathrm{C}$ & $5.93^{\circ} \mathrm{C}$ & $4.32^{\circ} \mathrm{C}$ & $30.90^{\circ} \mathrm{C}$ & $45.44^{\circ} \mathrm{C}$ & $0.72^{\circ} \mathrm{C}$ & $-1.17^{\circ} \mathrm{C}$ \\
\hline Painel 6 & $32.20^{\circ} \mathrm{C}$ & $44.68^{\circ} \mathrm{C}$ & $18.83^{\circ} \mathrm{C}$ & $16.21^{\circ} \mathrm{C}$ & $32.10^{\circ} \mathrm{C}$ & $48.38^{\circ} \mathrm{C}$ & $5.93^{\circ} \mathrm{C}$ & $4.28^{\circ} \mathrm{C}$ & $30.90^{\circ} \mathrm{C}$ & $45.44^{\circ} \mathrm{C}$ & $0.72^{\circ} \mathrm{C}$ & $-1.23^{\circ} \mathrm{C}$ \\
\hline Painel 7 & $32.20^{\circ} \mathrm{C}$ & $44.71^{\circ} \mathrm{C}$ & $18.83^{\circ} \mathrm{C}$ & $16.18^{\circ} \mathrm{C}$ & $32.10^{\circ} \mathrm{C}$ & $48.44^{\circ} \mathrm{C}$ & $5.93^{\circ} \mathrm{C}$ & $4.33^{\circ} \mathrm{C}$ & $30.90^{\circ} \mathrm{C}$ & $45.57^{\circ} \mathrm{C}$ & $0.72^{\circ} \mathrm{C}$ & $-1.15^{\circ} \mathrm{C}$ \\
\hline Painel 8 & $32.20^{\circ} \mathrm{C}$ & $44.72^{\circ} \mathrm{C}$ & $18.83^{\circ} \mathrm{C}$ & $16.18^{\circ} \mathrm{C}$ & $32.10^{\circ} \mathrm{C}$ & $48.44^{\circ} \mathrm{C}$ & $5.93^{\circ} \mathrm{C}$ & $4.31^{\circ} \mathrm{C}$ & $30.90^{\circ} \mathrm{C}$ & $45.57^{\circ} \mathrm{C}$ & $0.72^{\circ} \mathrm{C}$ & $-1.15^{\circ} \mathrm{C}$ \\
\hline Painel 9 & $32.20^{\circ} \mathrm{C}$ & $44.75^{\circ} \mathrm{C}$ & $18.83^{\circ} \mathrm{C}$ & $16.18^{\circ} \mathrm{C}$ & $32.10^{\circ} \mathrm{C}$ & $48.45^{\circ} \mathrm{C}$ & $5.93^{\circ} \mathrm{C}$ & $4.30^{\circ} \mathrm{C}$ & $30.90^{\circ} \mathrm{C}$ & $45.58^{\circ} \mathrm{C}$ & $0.72^{\circ} \mathrm{C}$ & $-1.19^{\circ} \mathrm{C}$ \\
\hline Painel 10 & $32.20^{\circ} \mathrm{C}$ & $44.64^{\circ} \mathrm{C}$ & $18.83^{\circ} \mathrm{C}$ & $16.20^{\circ} \mathrm{C}$ & $32.10^{\circ} \mathrm{C}$ & $48.35^{\circ} \mathrm{C}$ & $5.93^{\circ} \mathrm{C}$ & $4.34^{\circ} \mathrm{C}$ & $30.90^{\circ} \mathrm{C}$ & $45.49^{\circ} \mathrm{C}$ & $0.72^{\circ} \mathrm{C}$ & $-1.14^{\circ} \mathrm{C}$ \\
\hline Painel 11 & $32.20^{\circ} \mathrm{C}$ & $44.65^{\circ} \mathrm{C}$ & $18.83^{\circ} \mathrm{C}$ & $16.20^{\circ} \mathrm{C}$ & $32.10^{\circ} \mathrm{C}$ & $48.36^{\circ} \mathrm{C}$ & $5.93^{\circ} \mathrm{C}$ & $4.33^{\circ} \mathrm{C}$ & $30.90^{\circ} \mathrm{C}$ & $45.50^{\circ} \mathrm{C}$ & $0.72^{\circ} \mathrm{C}$ & $-1.15^{\circ} \mathrm{C}$ \\
\hline Painel 12 & $32.20^{\circ} \mathrm{C}$ & $44.68^{\circ} \mathrm{C}$ & $18.83^{\circ} \mathrm{C}$ & $16.20^{\circ} \mathrm{C}$ & $32.10^{\circ} \mathrm{C}$ & $48.36^{\circ} \mathrm{C}$ & $5.93^{\circ} \mathrm{C}$ & $4.31^{\circ} \mathrm{C}$ & $30.90^{\circ} \mathrm{C}$ & $45.50^{\circ} \mathrm{C}$ & $0.72^{\circ} \mathrm{C}$ & $-1.18^{\circ} \mathrm{C}$ \\
\hline Painel 4.1 & $32.20^{\circ} \mathrm{C}$ & $44.73^{\circ} \mathrm{C}$ & $18.83^{\circ} \mathrm{C}$ & $16.18^{\circ} \mathrm{C}$ & $32.10^{\circ} \mathrm{C}$ & $48.44^{\circ} \mathrm{C}$ & $5.93^{\circ} \mathrm{C}$ & $4.32^{\circ} \mathrm{C}$ & $30.90^{\circ} \mathrm{C}$ & $45.57^{\circ} \mathrm{C}$ & $0.72^{\circ} \mathrm{C}$ & $-1.16^{\circ} \mathrm{C}$ \\
\hline Painel 4.2 & $32.20^{\circ} \mathrm{C}$ & $44.66^{\circ} \mathrm{C}$ & $18.83^{\circ} \mathrm{C}$ & $16.19^{\circ} \mathrm{C}$ & $32.10^{\circ} \mathrm{C}$ & $48.36^{\circ} \mathrm{C}$ & $5.93^{\circ} \mathrm{C}$ & $4.32^{\circ} \mathrm{C}$ & $30.90^{\circ} \mathrm{C}$ & $45.50^{\circ} \mathrm{C}$ & $0.72^{\circ} \mathrm{C}$ & $-1.16^{\circ} \mathrm{C}$ \\
\hline Painel 4.3 & $32.20^{\circ} \mathrm{C}$ & $44.59^{\circ} \mathrm{C}$ & $18.83^{\circ} \mathrm{C}$ & $16.21^{\circ} \mathrm{C}$ & $32.10^{\circ} \mathrm{C}$ & $48.27^{\circ} \mathrm{C}$ & $5.93^{\circ} \mathrm{C}$ & $4.33^{\circ} \mathrm{C}$ & $30.90^{\circ} \mathrm{C}$ & $45.41^{\circ} \mathrm{C}$ & $0.72^{\circ} \mathrm{C}$ & $-1.15^{\circ} \mathrm{C}$ \\
\hline Painel 4.4 & $32.20^{\circ} \mathrm{C}$ & $44.59^{\circ} \mathrm{C}$ & $18.83^{\circ} \mathrm{C}$ & $16.21^{\circ} \mathrm{C}$ & $32.10^{\circ} \mathrm{C}$ & $48.27^{\circ} \mathrm{C}$ & $5.93^{\circ} \mathrm{C}$ & $4.34^{\circ} \mathrm{C}$ & $30.90^{\circ} \mathrm{C}$ & $45.41^{\circ} \mathrm{C}$ & $0.72^{\circ} \mathrm{C}$ & $-1.15^{\circ} \mathrm{C}$ \\
\hline
\end{tabular}

Tipologia de painel 4 após mudanças de parâmetros

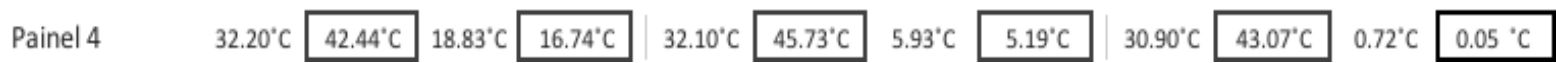

Tabela 19 - Resultados de temperaturas mínimas e máximas com todos as tipologias de painéis estudados na área da cobertura (zona térmica 7) nas 3 cidades

Fonte: Arquivo pessoal, 2016 